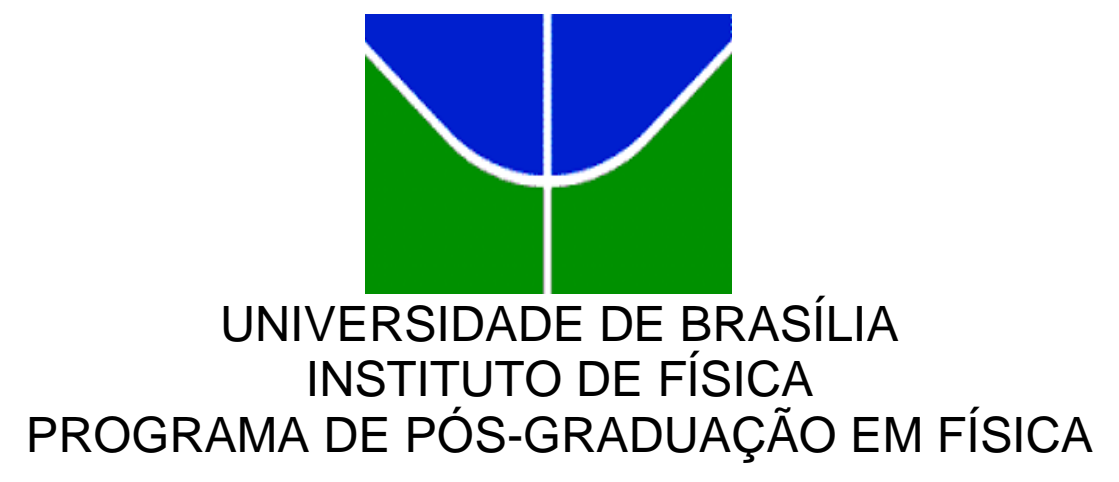

DISSERTAÇÃO DE MESTRADO

\title{
FILMES FORMADOS PELO COPOLÍMERO SEBS E NANOPARTÍCULAS DE ÓXIDOS DE FERRO: PREPARAÇÃO E CARACTERIZAÇÃO
}

ALBERTO JOSÉ MOREIRA ROCHA 
UNIVERSIDADE DE BRASÍLIA

INSTITUTO DE FÍSICA

PROGRAMA DE PÓS-GRADUAÇÃO EM FÍSICA

\title{
FILMES FORMADOS PELO COPOLÍMERO SEBS E NANOPARTÍCULAS DE ÓXIDOS DE FERRO: PREPARAÇÃO E CARACTERIZAÇÃO
}

\author{
ALBERTO JOSÉ MOREIRA ROCHA
}

Dissertação de Mestrado Apresentada ao programa de Pós-Graduação em Física da Universidade de Brasília (PPGF-UnB) Como parte dos requisitos necessários para obtenção do título de mestre em Física.

ORENTADORA: Professora MARIA APARECIDA GODOY SOLER 


\title{
"Filmes formados pelo copolímero SEBS e nanopartículas de óxidos de ferro: Preparação e Caracterização."
}

\begin{abstract}
Por
Alberto José Moreira Rocha.

Dissertação submetida ao Instituto de Física da Universidade de Brasília como parte dos requisitos para a obtenção do grau de Mestre em Física.
\end{abstract}

Aprovada por:

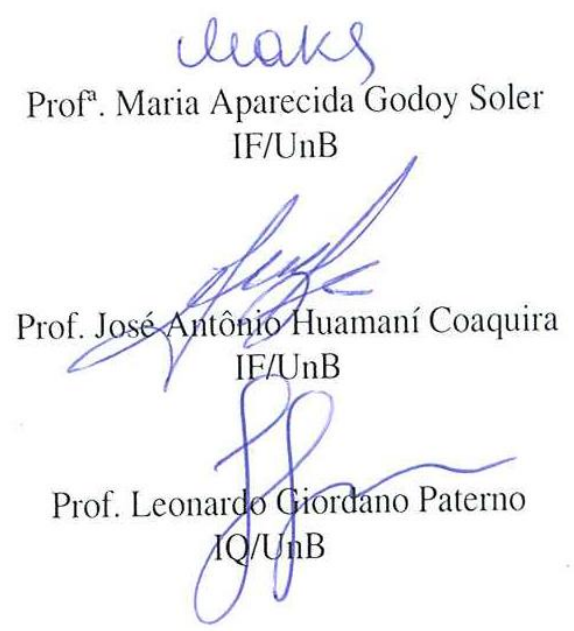

Prof. Dr. Fernando de Oliveira Albuquerque

Coordenador de Pós-Graduação

Instituto de Física 
Aos meus pais amados e queridos, Rita de Cassia e Luzeldimiro; Aos meus quatro irmãos e melhores amigos: Agberto, Adriano, Alexandre e Alex; As minhas primas e grandes amigas Meire e Leide e, à minha grande e eterna namorada e futura esposa, Talita de Nazaré Luna Fonseca, que carrega dentro de si um enorme potencial de vida, que me motiva a ser um pouco mais do que eu sou. 


\section{Agradecimentos}

Agradeço a todas as barreiras impostas propositalmente ou não pelo homem (mulher) ou pela natureza. Essas barreiras me fizeram olhar fundo, no foco, me colocando como um crente cego, para superar a adversidade.

Ao meu grande amigo Xavier, que me recebeu em Brasília e me deu apoio até eu ter condições para caminhar sozinho.

À Tatiane, ao Oscar e ao Breytner, que também me ajudaram muito nos primeiros passos em Brasília.

Agradeço aos professores que me deram suporte teórico: Magela, Aníbal, Pinzul e Fanyao.

À banca, por se dispor a avaliar este trabalho.

À minha orientadora Maria Aparecida, que teve toda a paciência do mundo, frente a um cara otimista que, se encontrara num poço profundo de pessimismo, e mesmo assim, ela disse: "Vai dar tudo certo". Eu demorei a acreditar, mas acreditei que daria.

Ao professor Ricardo Azevedo do Instituto de Biologia - IB pelos dados de microscopia eletrônica de transmissão - MET, obtidos no Instituto de Física da Universidade Federal de Goiás e a professora Maria José do laboratório de Polímeros do Instituto de química da Universidade de Brasília pelas análises Termogravimétricas.

Ao professor Leonardo Giordano Paterno do Laboratório de Polímeros do Instituto de Química da Universidade de Brasília, pelas discussões teóricas, poucas, mas de muitíssima importância.

Ao professor José Antonio Huamaní Coaquira por ceder o uso da técnica de spin coating para a eu depositar os filmes finos.

Agradeço ao Fermin pelas medidas magnéticas no VSM.

Agradeço ao professor Paulo Souza e ao estudante de pós-doutorado Leandro Figueiredo pelas medidas de Ressonância Ferromagnética.

Ao Luis Miguel, por sua precisão nas orientações transmitida. 
À Camila Letti, pela disponibilidade.

À Deizilene e a Luana pelo carinho.

Ao CNPq pelo apoio financeiro.

À todos que contribuíram direta ou indiretamente por este trabalho. 


\section{Resumo}

Neste trabalho foram produzidos filmes finos híbridos em matriz de poli(estireno)bloco-poli(etileno-ran-butileno)-bloco-poli(estireno) SEBS e nanopartículas de óxido de ferro funcionalizadas com ácido oleico, por meio da técnica de spin-coating. Em uma primeira etapa, as nanopartículas de óxidos de ferro (diâmetro de 5,8 nm) foram sintetizadas por meio do método de coprecipitação química, e caracterizadas por meio das análises de espectroscopia Raman, UV-vis e no infravermelho, microscopia eletrônica de transmissão, análise termogravimétrica TG e medidas magnéticas. O coloide magnético formado por nanopartículas de óxidos de ferro funcionalizadas com ácido oleico dispersas em hexano foi misturado com a solução do copolímero SEBS preparada previamente para posterior deposição por spin coating. O estudo foi realizado em amostras de filmes depositados variando-se a concentração de partículas de óxidos de ferro e, como controles, foram preparados um filme casting, com a maior concentração de nanopartículas empregada, e o filme obtido com o copolímero. A caracterização dos filmes produzidos foi realizada empregando-se as técnicas de perfilometria, espectroscopias Raman e UV-vis, e medidas magnéticas. Os filmes apresentaram espessuras na faixa de 45 a $104 \mathrm{~nm}$, a presença das nanopartículas no filme foi observada nos espectros Raman e de UV-vis, bem como nos resultados das medidas magnéticas. Os resultados mostraram também que os filmes apresentaram comportamento superparamagnético, indicando que as partículas de óxidos de ferro provavelmente não formam grandes agregados na arquitetura dos filmes.

Palavra Chave: Óxido de Ferro de Nanopartículas, Copolímeros, Filme Fino, Filme fino Híbrido, filmes magnéticos, SEBS Poli(estireno)-bloco-poli(etileno-ran-butileno)-blocopoli(estireno), filmes magnéticos, spin coating. 


\section{Abstract}

In this study, hybrid thin films comprising oleic acid-coated iron oxide nanoparticles embedded in the SEBS [poly(styrene)-block-poly(ethilene-ran-butylene)-block-poly(styrene)] matrix were fabricated using spin coating approach. Firstly, the iron oxides nanoparticles (diameter 5,8 $\mathrm{nm}$ ) were synthetized via chemical co-precipitation method and characterized by Raman, UV-vis and Infrared spectroscopy, transmission electron microscopy, thermogravimetry and magnetic measurements. The resulting magnetic colloid was mixed with a previously prepared solution of SEBS copolymer, and employed for the spin coating deposition. The study was performed in thin films fabricated with different concentration of iron oxides nanoparticles and, as a control film, a casting sample prepared with the highest concentration of nanoparticles employed and another comprising only the copolymer deposited by spin coating. The characterization of films was performed using perfilometry, Raman and Infrared spectroscopy, UV-vis and magnetic measurement. The prepared films present films thickness in the range from 45 to $104 \mathrm{~nm}$. The presence of the nanoparticles within the films was probed by Raman and UV-vis spectrum, as well as through magnetic measurements. The results show that films exhibit superparamagnetic behavior, indicating that particles do not form big clusters in the film structure.

Keywords: Iron Oxides nanoparticles, Copolymers, Thin Film, Hybrid thin film, SEBS ou Poly(styrene)-block-poly(ethilene-ran-butylene)-block-poly(styrene), magnetic films, spin coating. 


\section{Sumário}

Capítulo 1

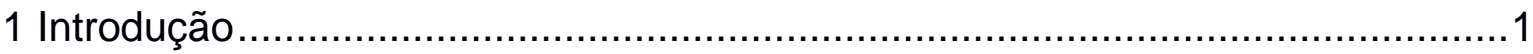

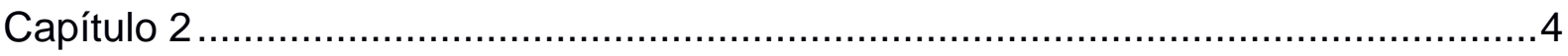

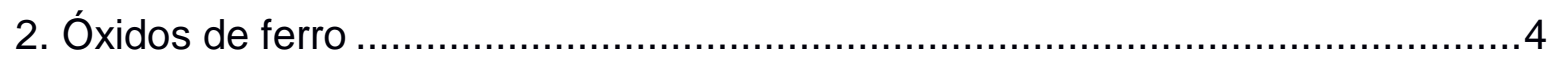

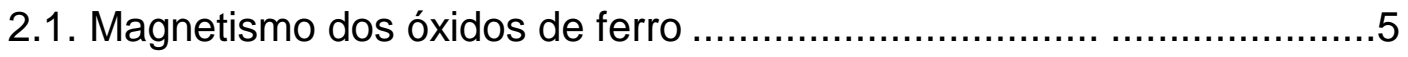

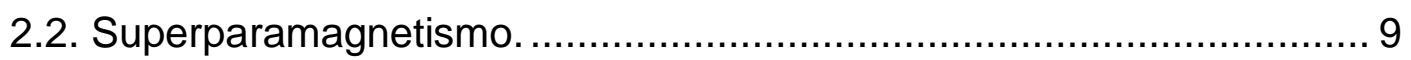

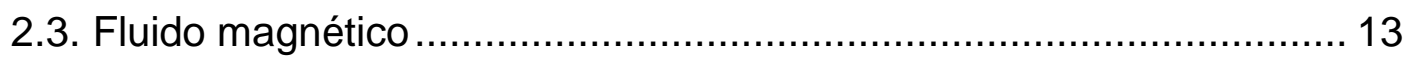

2.4. Copolímeros............................................................... 16

2.5. Técnica de deposição Spin Coating........................................ 17

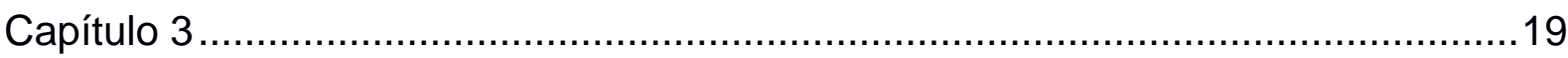

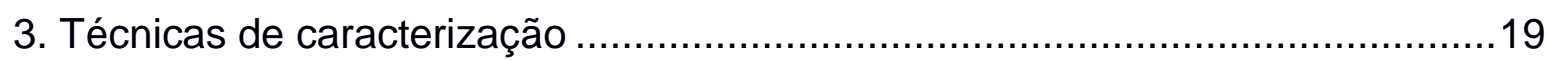

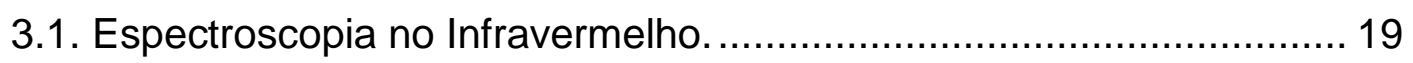

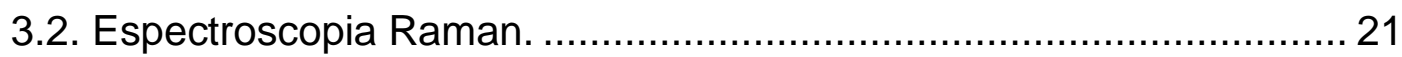

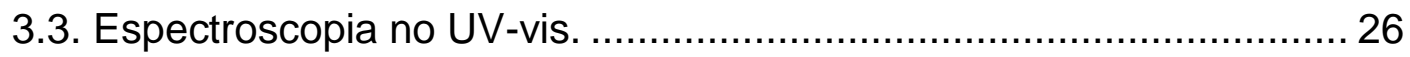

3.4. Microscopia Eletrônica de Transmissão MET .............................. 27

3.5. Espalhamento Dinâmico de Luz.............................................27

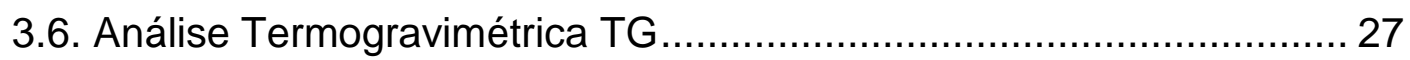

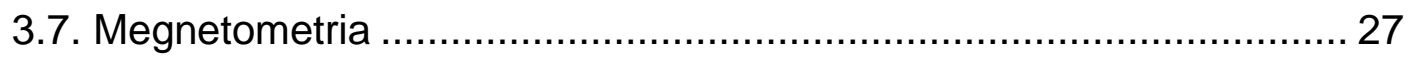

3.8. Ressonância Ferromagnética ............................................ 28

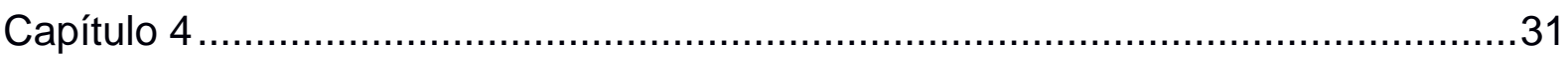

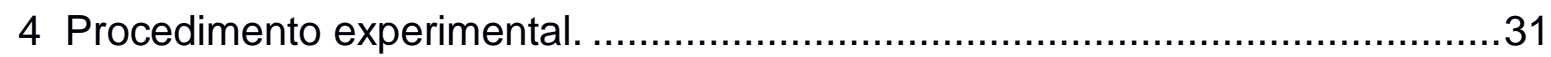


4.1. Materiais.

4.2. Preparação das partículas coloidais.............................................. 31

4.3. Caracterização das partículas coloidais ........................................ 33

4.4. Deposição do filme fino. .......................................................... 33

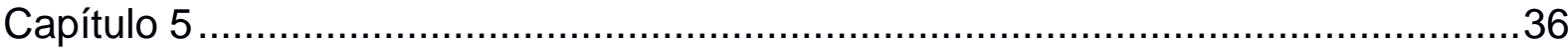

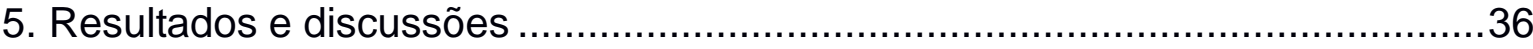

5.1. Nanopartículas coloidais ...................................................... 36

5.1.1. Caracterização das propriedades magnéticas.................................42

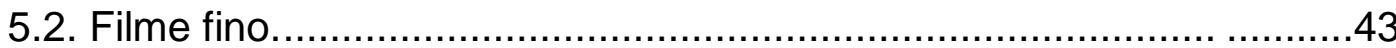

5.2.1. Caracterização das propriedades estruturais ..................................43

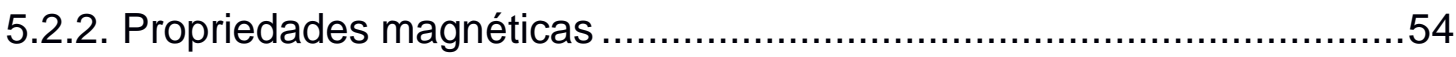

5.2.2.1. Medidas de Ressonância Ferromagnética ...............................56

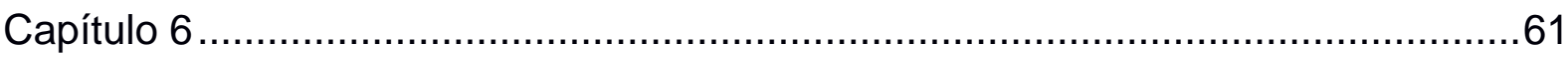

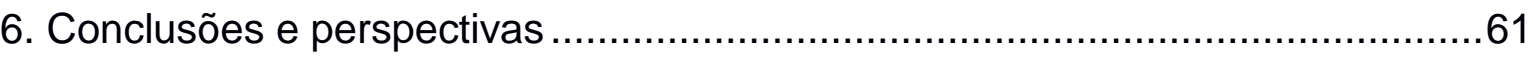

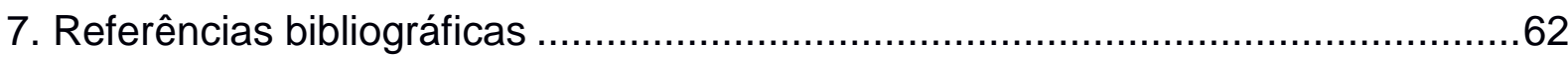




\section{Lista de Tabelas}

3.1. Número de onda atribuídos aos modos vibracionais da magnetita e maguemita (com asterístico, são relativos à maguemita).

4.1. Nomenclatura dos Filmes finos.

5.2. Espessura das amostras produzidas obtidas por perfilometria.

5.2. Números de onda atribuídos aos modos Raman obtidos do espectro do SEBS (pó), da Sigma Aldrich e do poliestireno. 


\section{Lista de Figuras}

2.1. Esquema de uma estrutura do tipo espinélio formada por uma rede cúbica de face centrada de ânions de ôxigênio (esferas maiores) com sítios preenchidos por cátions (esferas menores). Os sítios A e B são representados conforme a indicação das setas. A figura foi modificada da referência [70].

2.2. Ordenamento dos momentos magnéticos dos materiais diamagnéticos e paramagnéticos com e sem a aplicação do campo externo e dos materiais magnéticos (ferro, ferri e antiferromagnético) sem a aplicação do campo. Figura reproduzida da referência [54].

2.3. Estrutura de domínios magnéticos. As setas representam a direção do momento magnético efetivo de cada domínio. As linhas de separação representam as paredes de domínio.

2.4. Curva de histerese de um material ferromagnético.

2.5. Representação gráfica do campo coercivo em função do diâmetro da partícula.

2.6. Curva de Magnetização versus campo magnético aplicado para um sistema de partículas superparamagnéticas.

2.7. Poço de potencial duplo em uma dimensão na representação da dinâmica dos momentos de dipolos magnéticos de spin em partículas monodomínios. Modificada da referência [125].

2.8. Em (a) uma representação das partículas carregadas com cargas negativas na superfície e, dispersas num meio aquoso. Em (b), uma representação das partículas funcionalizadas com moléculas surfactantes e dispersas em meio orgânico.

2.9. Fórmula química estrutural do copolímero SEBS.

2.10. Ilustração do método de deposição spin coating.

3.1. Representação do espalhamento Raman. Em (a) o fóton $h v$ (em laranja) incide na molécula, que no estado fundamental transita para o estado virtual e decai em seguida para o estado vibracional excitado, emitindo um fóton (em amarelo) de energia $h\left(v_{0}-v_{j}\right)$. Em (b) o fóton $h v$ (em laranja) incide na molécula, que já se encontra no estado vibracional excitado e, transita para o estado virtual e decai em seguida para o estado fundamental, emitindo um fóton (em azul) de energia $h\left(v_{0}+v_{j}\right)$. Em (c), o fóton $h v$ (em laranja) incide na molécula que está no estado fundamental. A molécula sofre transição para o estado virtual e, em seguida, decai para o estado fundamental, emitindo um fóton (em azul celeste) de energia $h v$.

3.2. Processo de excitação eletrônico.

3.3. Desenho esquemático da técnica VSM. 
3.4. Antes da aplicação do campo magnético, os estados 1 e 2 estão superpostos num único estado (reparar na vertical de $H=0$ ). Na aplicação do campo magnético os estados se desdobram em dois, um com mais alta energia e outro com menor energia, com a metade do valor da diferença entre eles (reparar na vertical de $H \neq 0$ ).

3.5. Espectro típico de RFM de partículas magnéticas.

4.1. Processo de síntese das partículas de Magnetita com a cobertura de ácido oleico.

4.2. Câmara de spin coating. Em (a) a câmara cilíndrica e spin coating e o controle de programação. Em (b), o substrato onde se deposita a dispersão ou solução para a formação do filme.

5. 1. Espectro UV-VIS do coloide magnético sintetizado.

5.2. Análise TG e DTG da Nanopartícula/cobertura.

5.3. Espectro no infravermelho de sólido nanoparticulado funcionalizado com ácido oleico.

5.4. Espectro no infravermelho, restringido a região de 3600 à $2400 \mathrm{~cm}^{-1}$, de sólido nanoparticulado funcionalizado com ácido oleico.

5.5. Imagem típica de MET (microscopia eletrônica de transmissão) de nanopartículas sintetizadas.

5.6. Histograma da distribuição de tamanho das partículas (barras verticais). A linha sólida representa o melhor ajuste usando uma função distribuição log-normal.

5.7. Gráfico de distribuição de partículas no colóide com diâmetro hidrodinâmico $D_{h}=$ $28,04 \mathrm{~nm}$.

5.8. Espectro Raman da partícula coberta com ácido oleico.

5.9. Curva de histerese magnética do fluido magnético.

5.10. Espectro FMR do fluido magnético.

5.11. Ajuste linear da espessura.

5.12. Espectros UV-vis obtidos do controle (CD) e dos filmes preparados com diferentes concentrações de partículas magnéticas (amostras CD, CPD20, CPD30, CPD40 e CPD50). No interior da figura observa-se o gráfico da absorbância obtida em $480 \mathrm{~nm}$ para as diferentes amostras.

5.13. Espectro Raman típico do copolímero SEBS na forma de pó (C).

5.14. Espectro Raman disponibilizado pelo fornecedor do SEBS, Sigma.

5.15. Espectros Raman das amostras: C (SEBS na forma de pó, em preto), e do copolímero depositado na forma de filme antes do tratamento térmico (CA) em vermelho e após o tratamento térmico (CD), em azul.

5.16. Espectros Raman na região entre 170 e $964 \mathrm{~cm}^{-1}$ obtidos das amostras: C (SEBS na forma de pó), em preto, e do polímero depositado na forma de filme antes do tratamento térmico (CA), em vermelho, e após (CD), em azul. 
5.17. Espectros Raman na região entre 673 e $1413 \mathrm{~cm}^{-1}$ obtidos das amostras: C (SEBS - na forma de pó, em preto), e do polímero depositado na forma de filme (CA) antes do tratamento térmico, em vermelho, e após, em azul (CD).

5.18. Espectros Raman na região entre 1200 à $1750 \mathrm{~cm}^{-1}$ obtidos das amostras: C (SEBS na forma de pó, em preto), e do polímero depositado na forma de filme (CA) antes do tratamento térmico, em vermelho, e após, em azul (CD).

5.19. Espectros Raman obtidos dos filmes CD e CPD50.

5.20. Espectros Raman obtidos dos filmes CD e CPD50 para a região entre 2681 e $3165 \mathrm{~cm}^{-}$ 1.

5.21. Curva de magnetização em função do campo magnético aplicado do filme CPD50, depositado por meio da técnica spin coating.

5.22. Curva de magnetização em função do campo magnético aplicado do filme CPD50, depositado por casting.

5.23. Espectros de ressonância ferromagnética. Medidas da intensidade em função do ângulo para a amostra CPD40.

5.24. Espectros de ressonância ferromagnética. Intensidade em função do ângulo para a amostra CPD50.

5.25. Espectro de FMR do filme de CPD40 e 50. Comparação com a direção paralela do campo magnético aplicado.

5.26. Espectro de FMR do NC de CPD40 e CPD50. Comparação com a direção perpendicular ao campo magnético aplicado.

5.27. Comportamento do campo ressonante em função de vários ângulos para as amostras CPD40 e CPD50.

5.28. Comportamento do campo ressonante em função de vários ângulos para as amostras CPD50 depositadas por spin coating e casting.

5.29. Espectro FMR da amostra CPD50-casting com campo magnético aplicado paralelamente e perpendicularmente à superfície do filme. 


\section{Lista de Símbolos}

$\mathrm{Fe}^{+2}-$ Íon ferroso

$\mathrm{Fe}^{+3}$ - íon férrico

$T_{d}$ - grupo de coordenação tetraédrica

$O_{h}$ - grupo de coordenação octaédrica

$\mathrm{O}^{-2}$ - Ânion de Oxigênio

$e$ - carga elementar do elétron

$\varepsilon_{0}$ - permissividade no vácuo

$\pi-\mathrm{pi}$

$r$ - distância entre dois elétrons

$V\left(\overrightarrow{r_{1}}, \overrightarrow{r_{2}}\right)$ - Função representativa da interação coloumbiana.

\langle\rangle - valor médio

$J_{\text {troca }}$ - termo da interação de troca

$\left\langle\Psi\left(\overrightarrow{r_{1}}, \overrightarrow{r_{2}}\right)\right|-B r a$

$\left|\Psi\left(\overrightarrow{r_{1}}, \overrightarrow{r_{2}}\right)\right\rangle-$ Ket

$H_{t r}$ - Hamiltoniana de troca

$\overrightarrow{S_{l}}$ ou $\overrightarrow{S_{J}}$ - momento de spin i ou j.

$M$ - Magnetização do meio

$T_{C}$ - Temperatura de Curie

$\mathrm{M}_{\mathrm{S}}$ - Magnetização de saturação

MET - Microscopia eletrônica de transmissão

FRM - Ressonância Ferromagnética

$\chi$ - Susceptibilidade magnética

$m$ - Momento de dipolo magnético

$\mu$ - Momento de dipolo elétrico

$\mu^{\prime}$ - Momento de dipolo elétrico permanente

$J$ - Constante de troca

$K_{\text {ef }}$ Constante de anisotropia

$\mu_{0}$ - Permeabilidade magnética no vácuo

$V$ - volume

$H$ - Campo magnético aplicado

$h$ - Constante de Plank

$\mu_{B}$ - Magnéton de Bohr

$H_{C}$ - Campo coercivo

$K_{B}$ - Constante de Bolztmann 
$K_{e f}$ - Constante de anisotropia efetiva

$K$ - Constante de anisotropia uniaxial

$\tau_{\text {eff }}$ - Tempo de relaxação efetivo

$\tau_{\text {obs }}$ - Tempo de observação

$T_{\mathrm{b}}$ - Temperatura de bloqueio

$N$ - número de partículas contadas

$P(D)$ - Distribuição log-normal

$\sigma$ - Desvio padrão do diâmetro

$\psi_{0}$ - Potencial Zeta

I - Intensidade do laser após atravessar a amostra

$I_{0}$ - Intensidade do laser antes de atravessar a amostra

$q_{j}$ - Coordenada normal de vibração

$\alpha$ - Polarizabilidade

$P$ - Momento de dipolo elétrico

$K_{e}$ - Vetor de onda da luz espalhada

$K_{i}$ - Vetor de onda da luz incidente

$v_{i}$ - Frequência do fóton incidente

$v$ - Frequência

$v_{f}$ - Frequência do fônon

$v_{e}$ - Frequência do fóton espalhado

$\mathrm{H}_{2} \mathrm{O}$ - Fórmula química da água

$D_{M E T}$ - Diâmetro médio obtido por MET

$D_{\text {hidr }}$ - Diâmetro hidrodinâmico

$r_{\text {hidr }}$ - raio hidrodinâmico

$D_{c}$ - Diâmetro crítico

$V_{\text {hidr }}$ - Volume hidrodinâmico

$\eta$ - Viscosidade do fluido

$\tau_{\mathrm{B}}-$ Tempo de relaxação Browniano

$\tau_{N}-$ Tempo de relaxação de Néel

$N_{\mathrm{A}}$ - Constante de Avogradro

$c$ - Concentração do eletrólito

$c^{\prime}$ - Concentração molar do soluto

$\varepsilon$ - Permissividade do meio

$\in$ - Absorvidade molar

$A$ - Constante de Hameker

$z$ - íons tratados como cargas puntiformes 


\section{CAPÍTULO 1}

\section{Introdução}

A nanociência envolve o estudo dos fenômenos em nível atômico, molecular ou macromolecular em materiais que possuem pelo menos uma de suas dimensões em escala nanométrica (1 a $100 \mathrm{~nm}$ ) e apresentam propriedades diferentes daquelas dos mesmos quando em dimensão macroscópica. A nanociência é multidisciplinar englobando as áreas de física, química, engenharia de materiais, biologia, farmácia, medicina, entre outras. $\mathrm{O}$ emprego dos conceitos desenvolvidos em nanociência para a manipulação da matéria e a criação de novos materiais, dispositivos e sistemas com novas propriedades deu origem à nanotecnologia. Como resultado das pesquisas e aplicações desenvolvidas pode-se chegar a novos materiais e dispositivos para aplicações, por exemplo, em comunicação via microondas [1,2,3], armazenagem de energia em sistemas capacitivos [4], sensores químicos [5], gravação magnética [6], para colaborar com a miniaturização de componentes eletrônicos e dos dispositivos que os empregam, tais como telefones celulares, que fazem parte do cotidiano das pessoas, e são produzidos em larga escala.

Os nanomateriais que vêm sendo estudados, ou desenvolvidos se apresentam na forma de nanopartículas, bastões, nanotubos, discos, pontos quânticos, etc, obtidos de diversos materiais tais como semicondutores, óxidos de ferro, óxido de titânio, etc $[7,8,9]$. Muitos deles, tais como as nanopartículas, podem ser sintetizados e dispersos na forma coloidal facilitando sua aplicação. Em particular, aqueles formados por óxidos de ferro, tais como a magnetita, a maguemita, e a ferrita de cobalto apresentam propriedades superparamagnéticas que as credenciam para inúmeras aplicações [10,11]. Por exemplo, quando dispersas formando fluidos magnéticos à base de óleo vegetal podem ser empregadas para melhorar a eficiência de transformadores de alta potência [12,13], ou como plataformas para o transporte e entrega de marcadores ou fármacos, visando simultaneamente realizar um diagnóstico por meio da melhora do contraste da imagem de ressonância magnética, e a terapia necessária para o combate da doença, [14,15], por meio da técnica de magnetohipertermia ou da entrega de quimioterápicos localizada para tratamento de câncer [16,14]; ou da ação sobre o controle de células [17,14] seja com marcadores ou para manipulação das mesmas.

As nanopartículas magnéticas de óxidos de ferro podem ser sintetizadas in situ em matrizes não magnéticas [18], ou e dispersas como colóides e, posteriormente embebidas em matrizes não magnéticas por meio de diversas técnicas, entre elas a de automontagem camada por camada [19,20,21,22], a de casting [23], e a de spin coating [24]. Os nanocompósitos obtidos apresentam as propriedades das nanopartículas somando-se às da 
matriz. Por exemplo, no caso de polímeros que podem ser condutores, podem originar nanocompósitos com propriedades magnéticas e de condução [25]. As propriedades, dielétricas, magnéticas, óticas, de transporte, do nanocompósito obtido dependem da arquitetura do compósito, ou seja, do arranjo das NPs na matriz [4,28,29,30,31,32]. Adicionalmente, os nanocompósitos podem apresentar propriedades derivadas da interação entre as nanopartículas, e ou nanopartícula/matriz [26,5].

Estudos teóricos prevêem que quando copolímeros são empregados como matrizes para o arranjo de nanopartículas de óxidos de ferro pode ocorrer a separação de fase devido a interação partícula/copolímero [41,42,43]. Por exemplo, separação de fase por influência do solvente [24], controle de orientação de microdomínios de blocos de copolímeros pela aplicação de um campo externo [39], auto-montagem controlada pela interação da matriz copolimérica e nanopartícula [40], e influência da concentração da nanopartícula na orientação do domínio combinado à auto-montagem do copolímero [34]. Simulações computacionais também têm mostrado que o diagrama de fase de copolímero/nanopartícula exibe uma dependência com o tamanho e a concentração da nanopartícula [50,53]. Dentre as mudanças que acontecem na arquitetura interna do nanocompósito de filme fino, é bastante comum a formação de estruturas de lamelas [28,29,34,39,44], em geral, provocadas por tratamentos térmicos das amostras. Além disso, é também comum nanopartículas influenciarem a montagem da estrutura interna dos blocos de copolímeros [28,45] graças á presença de grupos funcionalizados na superfície da nanopartícula compatíveis com um seguimento, hidrofílico ou hidrofóbico presente no copolímero $[47,48,49]$. Este efeito depende do tamanho das nanopartículas $[50,51,52]$. Observou-se após o levantamento bibliográfico realizado que o estudo das interações entre nanopartículas de óxido de ferro embebidas na matriz do copolímero tri-bloco poli(estireno)bloco-poli(etileno-ran-butileno)-bloco-poli(estireno) (SEBS), bem como das propriedades dos nanocompósitos formados, não foi ainda abordado.

Neste contexto, este trabalho tem como objetivo a deposição de filmes ultrafinos compostos pelo copolímero SEBS e nanopartículas de óxido de ferro de magnetita funcionalizadas com ácido oleico, por meio da técnica spin coating. A dispersão coloidal que será empregada como fonte de nanopartículas foi sintetizada em um primeira etapa, bem como a preparação da solução polimérica. A dispersão coloidal, também chamada de fluido magnético, o sólido nanoparticulado, bem como os filmes produzidos foram caracterizados por meio das técnicas de microscopia eletrônica de transmissão MET, espectroscopia no infravermelho, Raman, no UV-vis, análise termogravimétrica TG, e medidas magnéticas.

Este trabalho está organizado de modo que o Capítulo 2 discute as propriedades dos óxidos de ferro e sua estabilização da forma de coloides, bem como apresenta o copolímero SEBS e a técnica de Spin coating; no Capítulo 3 as técnicas de caracterização empregadas 
são apresentadas; o Capítulo 4 mostra os detalhes dos procedimentos experimentais realizados; o Capítulo 5, os resultados e discussões, e o Capítulo 6 as conclusões e perspectivas. 


\section{CAPÍTULO 2}

\section{2. Óxidos de ferro}

Os óxidos de ferro são substâncias inorgânicas encontradas com abundância na natureza ou sintetizadas [57]. Por exemplo, os óxidos de ferro cúbicos tais como a, magnetita $\left(\mathrm{Fe}_{3} \mathrm{O}_{4}\right)$, maguemita $\left(\mathrm{\gamma}-\mathrm{Fe}_{2} \mathrm{O}_{3}\right)$ e a ferrita de cobalto estão sendo muito estudados na atualidade, devido às inúmeras aplicações tecnológicas. [1-9]. Aplicações estas que têm se tornado cada vez mais significativas com novas tecnologias que permitem a síntese dos óxidos de ferro em dimensões nanométricas [58-62].

Óxidos de ferro e óxidos de ferro misto apresentam estrutura do tipo espinélio e são representados pela fórmula $\mathrm{MFe}_{2} \mathrm{O}_{4}$ em que $\mathrm{M}$ é um cátion divalente de um metal de transição (Co, Ni, Mn, Cu, Zn e Cd, ou óxidos puros com M = Fe) [57,69, 54]. O nome espinélio é devido à semelhança com a estrutura do mineral, $\mathrm{MgO} \cdot \mathrm{Al}_{2} \mathrm{O}_{3}$ cujo nome é espinélio. A figura 2.1. ilustra a estrutura espinélio.

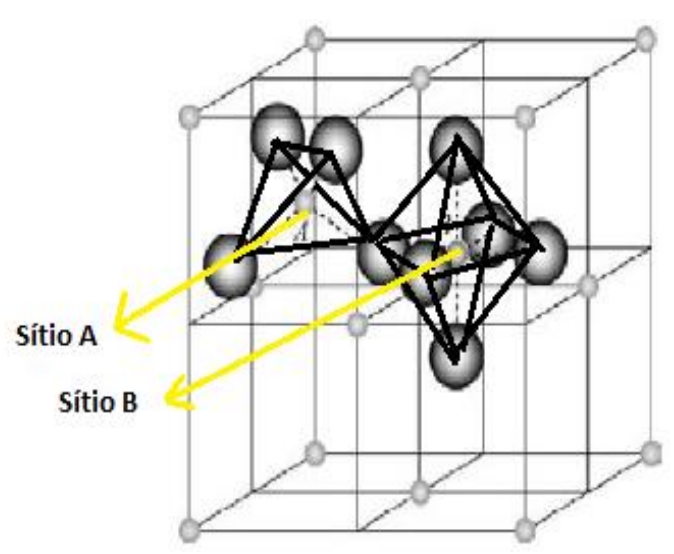

Figura 2.1: Ilustração de uma estrutura do tipo espinélio formada por uma rede cúbica de face centrada de ânions de oxigênio (esferas maiores) com sítios preenchidos por cátions de ferro (esferas menores). Os sítios A e B são representados conforme a indicação das setas. A figura foi modificada da referência [70].

O cristal de óxido de ferro pertence ao grupo espacial $O_{h}^{7}$ e o arranjo dos ânions de oxigênio é predominante na estrutura cristalográfica devido ao fato que o seu tamanho é em média, o dobro do dos cátions de ferro [57]. Os ânions de oxigênio estão dispostos em uma rede cúbica de face centrada onde os íons metálicos de $\mathrm{Fe}^{+2}$ e $\mathrm{Fe}^{+3}$ dão origem a duas subredes, que são os tipos de simetria de coordenação tetraédrica $T_{d}$ (sítio A) e octaédrica $O_{h}$ (sítio B) [57]. Existem dois tipos de estrutura espinélio definidas a partir da ocupação dos sítios pelos íons metálicos, a espinélio direta, ou normal, e a espinélio inversa. Na estrutura espinélio direta, todos os cátions metálicos divalentes ocupam os sítios $\mathrm{A}$ e todos os cátions metálicos trivalentes ocupam os sítios $\mathrm{B}$. Na estrutura espinélio inversa, todos cátions 
divalentes ocupam alguns dos sítios $B$ e os trivalentes se distribuem igualmente entre os sítios $A$ e $B$, isto é, metade dos cátions ocupam o sítio $A$ e a outra metade, o sítio $B$. Nem todos os sítios A e B da estrutura espinélio, seja normal ou inversa, são ocupados pelos íons metálicos. São 56 íons por célula unitária, desses, apenas 32 são de ânions de $\mathrm{O}^{-2}$ e 8 são cátions de $\mathrm{Fe}^{+2}$, que ocupam os sítios $\mathrm{A}$ de um total de 64 interstícios rodeados de 4 íons de $\mathrm{O}^{-2}$, e 16 cátions de $\mathrm{Fe}^{+3}$, de um total de 32 sítios $\mathrm{B}$ rodeados de 6 íons de $\mathrm{O}^{-2}$, de forma que o número de vacâncias é maior que o número de sítios ocupados. São 72 vacâncias no total, ou seja, apenas 1/8 dos sítios A são ocupados e 1/2 dos sítios B são ocupados pelos íons [57]. A estrutura de maguemita se diferencia da magnetita apenas pelo aparecimento de vacâncias no sítio $B$, e pela ausência de íons $\mathrm{Fe}^{+2}$. A fórmula que representa a maguemita pode ser escrita, por exemplo, $\mathrm{Fe}_{21.33}^{+3} \square_{2.67} \mathrm{O}_{32}^{-2}$, onde $\square$ representa a vacância. [71]. A composição química da estrutura de espinélio é representada por:

$$
M_{\delta}^{+2} \mathrm{Fe}_{1-\delta}^{+3}\left[\mathrm{M}_{1-\delta}^{+2} \mathrm{Fe}_{1+\delta}^{+3}\right] \mathrm{O}_{4}^{-2}
$$

Os colchetes representam os sítios $\mathrm{B}, \mathrm{M}$ é um cátion divalente e $\delta$ indica o grau de inversão. Para $\delta=1$ tem-se uma estrutura de espinélio normal e, para $\delta=0$, uma estrutura de espinélio inversa [72]. Para $0<\delta<1$, uma estrutura mista.

\subsection{Magnetismo dos óxidos de ferro}

Nos materiais ferromagnéticos, a magnetização espontânea tem origem na interação de troca entre spins [122], dada na equação 2.5. Em princípio, a interação de troca surge da interação coulombiana, dada de maneira simplificada, pela equação 2.2, para dois elétrons,

$$
V\left(\overrightarrow{r_{1}} \cdot \overrightarrow{r_{2}}\right)=\frac{e^{2}}{4 \pi \varepsilon_{0} r_{12}}
$$

Sendo $r_{12}=\left|\overrightarrow{r_{1}}-\overrightarrow{r_{2}}\right|$, a distância entre os dois elétrons, $V\left(\overrightarrow{r_{1}} \cdot \overrightarrow{r_{2}}\right)$ é a função que representa a interação coulombiana, $e$ é a carga do elétron e $\varepsilon_{0}$ a permissividade elétrica no vácuo. Calculando a energia média dessa interação, obtêm-se,

$$
\left\langle V\left(\overrightarrow{r_{1}} \cdot \overrightarrow{r_{2}}\right)\right\rangle=\left\langle\Psi\left(\overrightarrow{r_{1}}, \overrightarrow{r_{2}}\right)\left|V\left(\overrightarrow{r_{1}} \cdot \overrightarrow{r_{2}}\right)\right| \Psi\left(\overrightarrow{r_{1}}, \overrightarrow{r_{2}}\right)\right\rangle
$$

O valor médio da energia, dada por [122],

$$
\left\langle V\left(\overrightarrow{r_{1}} \cdot \overrightarrow{r_{2}}\right)\right\rangle=E \pm J_{\text {troca }}
$$

Onde, o sinal " \pm " será positivo ou negativo dependendo do estado de spin, se singleto ou tripleto. O segundo termo da soma, $J_{\text {troca }}$, é o termo de troca. As representações do bra, $\left\langle\Psi\left(\overrightarrow{r_{1}}, \overrightarrow{r_{2}}\right)\right|$, e ket, $\left|\Psi\left(\overrightarrow{r_{1}}, \overrightarrow{r_{2}}\right)\right\rangle$, correspondem aos orbitais, isto é, às funções relacionadas à ocupação dos elétrons (funções de onda espaciais). A interação entre os elétrons não depende explicitamente do spin (ver equação 2.2). No cálculo do valor médio de energia foi usado apenas funções de onda espaciais (orbitais). Entretanto, a energia média depende de spin porque foi levado em conta o princípio da exclusão de Pauli, e neste contexto, as funções de onda (bra ou ket) são simétrica ou antissimétrica [99]. Em função deste fato, na Hamiltoniana de Heisenberg (ver equação 2.5), oriunda do termo de troca na soma 
(equação 2.4.), vem acoplado o termo de spin para ilustrar a importância da energia de troca para explicar a ordem magnética dos materiais ferromagnéticos [123]. Originalmente, a Hamiltoniana de Heisenberg ou interação de troca foi escrita por,

$$
H_{t r}=-2 \sum_{i \neq j} J_{i j} \overrightarrow{S_{l}} \cdot \overrightarrow{S_{J}}
$$

Em que, $S_{i}$ ou $S_{j}$ representa o spin do elétron e $J_{i j}$ a constante de troca.

O magnetismo dos materiais ferromagnéticos tem origem na interação de troca. Os óxidos de ferro são materiais magnetizados naturalmente devido às interações de supertroca e dupla troca. Nestas interações, existe entre dois íons de ferro um íon intermediário à interação, em geral, um ânion. Para os óxidos de ferro, o oxigênio é o responsável por esta interação. Na estrutura cristalina das ferritas cúbicas, um cátion trivalente no sítio tetraédrico interage o spin da sua camada d com o spin da camada $p$ do ânion, que por sua vez, interage com outro cátion trivalente do sítio octaédrico [74]. Esta interação é denominado de supertroca e é uma interação antiferromagnética porque os spins interagentes estão dispostos antiparalelamente (ver figura 2.2.) [85]. Outro tipo de interação é a de dupla troca, cujos spins são paralelos entre si e, portanto, a interação é do tipo ferromagnética [83]. Esta interação ocorre na mesma estrutura da ferrita cúbica, só que entre um íon cátion trivalente do sítio tetraédrico e um íon cátion divalente do sítio octaédrico via o íon ânion. Para a descrição das interações de supertroca e dupla troca via hamiltoniana de Heisenberg, é preciso reformular a forma escrita em 2.5, acrescentando outros termos que identifique a interação de troca como supertroca e/ou dupla troca [80].

O ordenamento magnético dos materiais é explicado a partir da distinção dessas interações. Óxidos de ferro tem o ordenamento ferrimagnético (ver figura 2.2.) devido a interação de dupla troca. Embora na estrutura dos óxidos de ferro apareça o ordenamento antiferromagnético, a magnetização líquida é ferrimagnética. $O$ que diferencia 0 ordenamento magnético dos ferrimagnético ao dos ferromagnéticos são as intensidades dos momentos magnéticos. Os momentos magnéticos dos ferrimagnéticos estão alinhados de modo diferente, resultando em uma magnetização menor (Figura 2.2). Tanto os materiais ferrimagnéticos quanto os ferromagnéticos tem magnetização espontânea até uma determinada temperatura crítica, denominada de temperatura de Curie. Acima desta temperatura, o ordenamento dos momentos de spin de ambos os materiais, ferrimagnético e ferromagnético, se desfaz, apresentando uma configuração aleatória, tornando-os, portanto, paramagnéticos [124].

A resposta do material ao campo magnético externo aplicado (campo aplicado) é caracterizada pela susceptibilidade magnética, dada por:

$$
\chi=\frac{\vec{M}}{\vec{H}}
$$


Em que, $\vec{M}$ é a magnetização do material e $\vec{H}$ é o campo magnético aplicado [70]. A magnetização é dada pela relação entre os momentos de dipolo magnético $\vec{m}$ por volume $V$ do material [70]:

$$
\vec{M}=\frac{\vec{m}}{V}
$$

Os materiais podem ser classificados em diamagnéticos, paramagnéticos, e os já citados, ferromagnéticos, ferrimagnéticos e antiferromagnéticos. Os paramagnéticos têm os momentos de dipolos magnéticos alinhados paralelamente ao campo aplicado, por isso, a susceptibilidade é positiva. Sem o campo aplicado, os momentos de dipolos ficam desordenados nos materiais. Os diamagnéticos têm o alinhamento dos momentos de dipolos contrário ao campo aplicado e, portanto, tem susceptibilidade negativa [79]. Os ferromagnéticos, ferrimagnéticos e antiferromagnéticos tem alinhamento dos dipolos magnéticos independente da aplicação do campo. A figura 2.2 mostra o ordenamento magnético dos materiais com ou sem o campo aplicado.

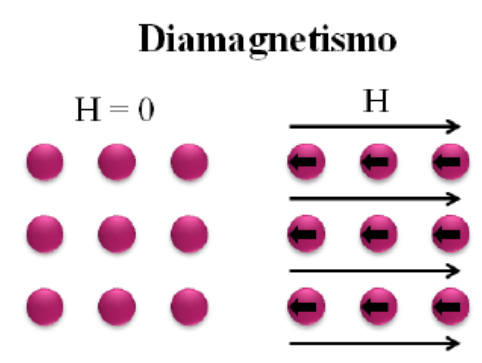

Ferromagnetismo

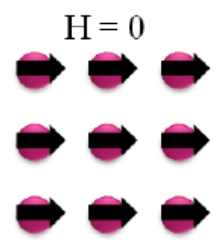

Ferrimagnetismo

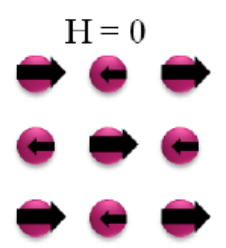

Paramagnetismo

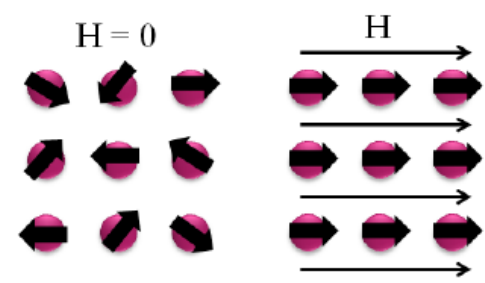

Figura 2.2: Ordenamento dos momentos magnéticos dos materiais diamagnéticos e paramagnéticos com e sem a aplicação do campo externo e dos ferromagnéticos, ferrimagnéticos e antiferromagnéticos sem a aplicação do campo. Figura reproduzida da referência [54].

Os materiais ferromagnéticos abaixo da sua temperatura de Curie é composto de pequenas regiões onde existe um alinhamento mútuo destas na direção de todos os momentos de dipolos magnéticos. Estas regiões são denominadas de domínios magnéticos. Domínios magnéticos são regiões (ver figura 2.3.) do material magnético, com valor próprio de magnetização de saturação em relação a todo material. A estrutura de domínio é organizada de modo a reduzir a energia magnetostática. $O$ tamanho, formato e orientação 
dos domínios dependem da interação entre as energias de troca, magnetostática, e de anisotropia do sistema [76]. Domínios dentro de um material são separados por contornos (ver figura 2.3.), conhecidos como paredes de domínios, através dos quais a direção de magnetização varia gradualmente. A magnetização líquida do material não magnetizado é a soma vetorial ponderada das magnetizações de todos os domínios. Se a magnetização for igual a zero, o material não apresenta magnetização líquida.

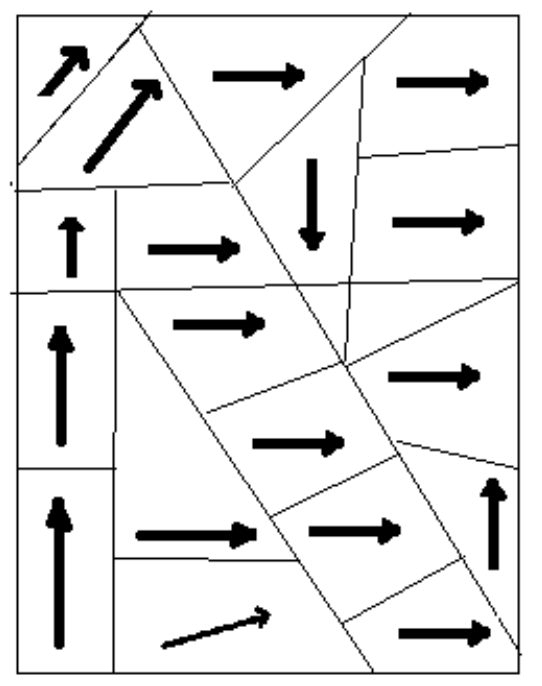

Figura 2.3. Estrutura de domínios magnéticos. As setas representam a direção do momento magnético efetivo de cada domínio. As linhas de separação representam as paredes de domínio.

A magnetização dos materiais ferro e ferrimagnéticos são caracterizadas pela curva de histerese (ver figura 2.4), dada pela magnetização em função do campo aplicado. Supondo os materiais ferro e ferrimagnéticos com uma magnetização líquida nula antes da aplicação do campo, como pode-se observar na figura 2.4, os momentos magnéticos, portanto, estão desordenados. Ao se aplicar o campo, depois de certo tempo, a curva atinge a magnetização de saturação e, neste ponto, exibe um alinhamento perfeitamente uniforme. 


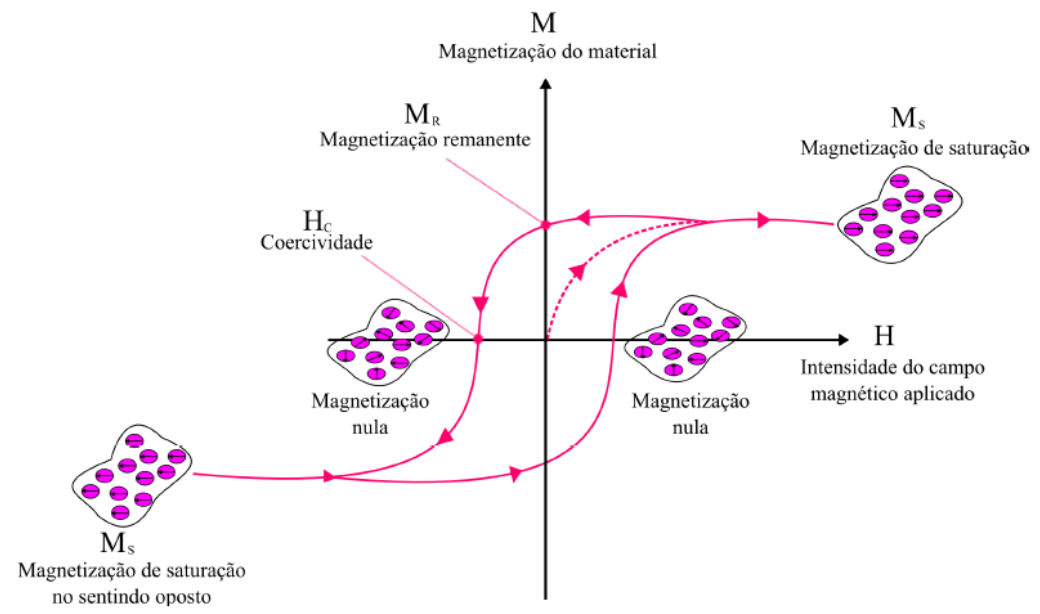

Figura 2.4: Curva de histerese de um material ferromagnético [106].

\subsection{Superparamagnetismo.}

O superparamagnetismo é um fenômeno magnético que decorre das condições de tamanho e forma das partículas magnéticas. Sua ocorrência se limita à escala nanométrica e a partir de um tamanho crítico [76]. Quando a energia associada à agitação térmica das partículas é maior do que a energia de anisotropia magnética, a magnetização das partículas flutua aleatoriamente, como se elas fossem íons paramagnéticos, mas com um alto valor de momento magnético [27]. Este fato resultou no superparamagnetismo.

Ao diminuir o volume do material magnético até a escala nanométrica, o tamanho do domínio e a largura das interfaces parede-domínio são reduzidos, modificando sua estrutura interna. A energia para criar uma interface parede-domínio nas partículas com volume abaixo de certo valor crítico é maior do que a redução correspondente na energia magnetostática [76]. Nesse limite, não há divisão em domínios menores, mas mantém-se a estrutura magnética de um único domínio [76]. Nesse regime, as partículas não interagem mais, e o tamanho crítico pode ser calculado através do diâmetro crítico expresso pela equação 2.8. [76].

$$
D_{c} \approx \frac{72 \sqrt{J K}}{\mu_{0} M_{S}^{2}}
$$

Onde, $J$ é a constante de troca; $K$ é a constante de anisotropia uniaxial; $\mu_{0}$ é a permeabilidade magnética no vácuo e $M_{S}$ é a magnetização de saturação. Para valores igual ou menor que este tamanho, as partículas se comportam como superparamagnéticas.

O diâmetro crítico, em geral, está na faixa de poucas dezenas de nanômetros e depende do material. Ele também pode ser influenciado por vários termos da energia de anisotropia. A energia de anisotropia magnética é responsável por manter o momento magnético numa certa direção e, pode ser escrita por [63],

$$
E(\theta)=K_{e f} V \sin ^{2} \theta
$$


Onde, $V$ é o volume da partícula; $K_{e f}$ é a constante de anisotropia efetiva e $\theta$ é o ângulo entre a magnetização e o eixo de fácil magnetização. A barreira de energia anisotrópica $K_{e f} V$ separa as duas regiões de fácil magnetização. Com a diminuição do tamanho da partícula, a energia térmica $K_{B} T$ excede a energia de barreira $K_{e f} V$, fazendo com que a magnetização flutue. Quando $K_{B} T>K_{e f} V$, o sistema adquire um grande (super) momento dentro de cada partícula [63]. Os momentos magnéticos das partículas comportam-se de modo análogo a um sistema paramagnético, mas com um momento total várias ordens de magnitude maior que os átomos individuais, fato este que originou o termo superparamagnetismo [76].

As paredes de domínios são responsáveis pela alta coercividade observada, mesmo em sistemas magnéticos nanoparticulado de monodomínio [64]. Nestas condições, o sistema nanoparticulado não apresenta-se no estado superparamagnético. O tamanho crítico é o limite entre as partículas monodomínio com ou sem paredes de domínio. As partículas monodomínios sem paredes de domínios não interagem entre si e, por conta desse fato, são superparamagnéticas. A figura 2.5. exemplifica esta separação da presença ou não do estado superparamagnético no regime de monodomínio.

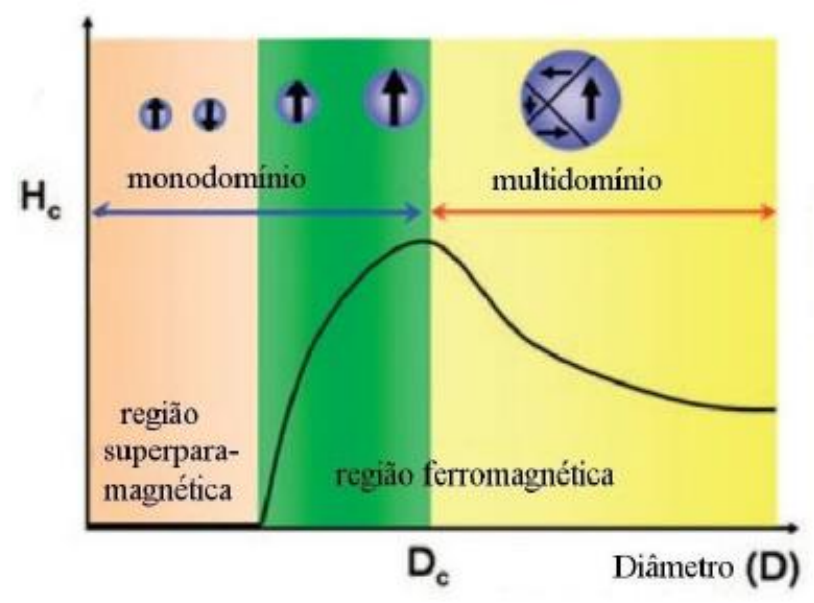

Figura 2.5: Representação gráfica do campo coercivo em função do diâmetro da partícula [125].

Associado ao estado superparamagnético da nanopartícula está o campo coercivo igual a zero. Na ausência do estado superparamagnético, o sistema de monodomínio é caracterizado pela alta coercividade, como pode ser percebido pela figura 2.5 , onde o eixo vertical representa a coercividade e o horizontal o diâmetro da partícula. A região de superparamagnetismo existe dentro da região que representa a estrutura de monodomínio (coloração berge + verde). Um diâmetro crítico separa em duas regiões, como exibido na coloração berge à esquerda da cor verde. Com o aumento do diâmetro, as partículas 
tornam-se ferromagnéticas (ferrimagnética), porém, continuam com a estrutura de monodomínio. A região em amarelo, o material se encontra no estado bulk e, portanto, a estrutura de domínios passa a ser de multidomínio. A figura 2.3 representa a curva de histerese de um sistema magnético com alto campo coercivo, enquanto que a figura 2.6 é característica de um sistema de partículas superparamagnéticas, sem o campo coercivo, à temperatura ambiente.

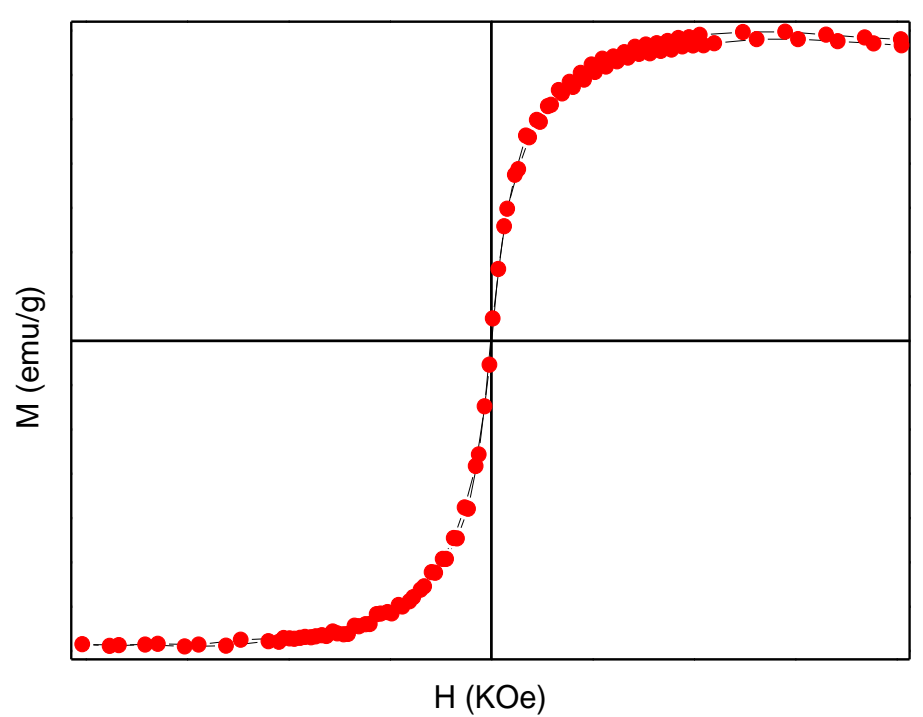

Figura 2.6. Curva de Magnetização versus campo magnético aplicado para um sistema de partículas superparamagnéticas.

O modelo mais simples de representar a dinâmica dos momentos magnéticos da partícula é o poço de potencial duplo em uma dimensão, mostrado na figura 2.7. 


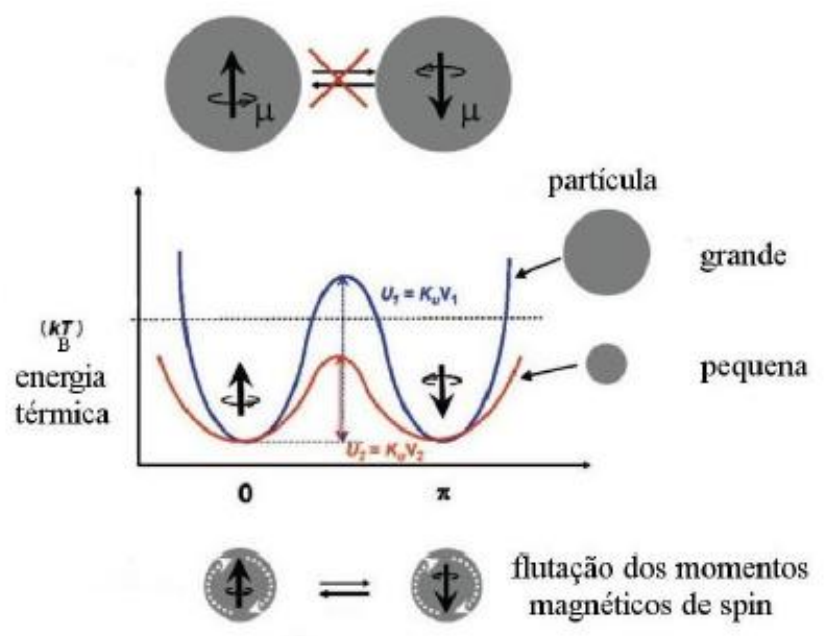

Figura 2.7. Poço de potencial duplo em uma dimensão na representação da dinâmica dos momentos de dipolos magnéticos de spin em partículas monodomínios. Modificada da referência [125].

Na posição vertical da linha tracejada, a energia de barreira é igual a energia térmica, isto é, $K_{B} T=K_{e f} V$. Acima desta linha tracejada $K_{B} T<K_{e f} V$ e abaixo $K_{B} T>K_{e f} V$. As setas na vertical dentro do circulo escuro, na parte de cima e de baixo do gráfico, indicam os momentos de dipolo magnético. As duplas setas paralelas na horizontal entre os círculos escuros representam a dinâmica de um estado para outro e a sinalização de exclusão, na parte superior da figura, nas setas paralelas, representam a não flutuação dos momentos de dipolos porque $K_{B} T<K_{e f} V$. As setas circulares tracejadas dentro dos círculos escuros na parte inferior do gráfico representam as flutuações dos momentos devido $K_{B} T>K_{e f} V$.

O tempo de relaxação típico, correspondente ao tempo médio que o momento magnético leva para reorientar-se com relação ao eixo de fácil magnetização para um sistema de partícula monodomínio que não interage é dado por [63],

$$
\tau=\tau_{0} e^{K_{e f} V / K_{B} T}
$$

$\tau_{0}$, normalmente varia de $10^{-11}$ à $10^{-9} s$.

Abaixo de certa temperatura, a temperatura de bloqueio $T_{b}$, as mudanças de direção devido a ativação térmica ocorrem em escalas de tempo mais longas do que o tempo de observação, fazendo os momentos parecerem congelados. Para um dado tempo de observação $\tau_{o b s}$, típico da técnica experimental, a temperatura de bloqueio $T_{b}$ é definida como $[86,15]$.

$$
T_{b}=\frac{K_{e f} V}{K_{B} \ln \left(\tau_{o b s} / \tau_{0}\right)}
$$

Em que, $K_{B}$ é a constante de Boltzman. 
O comportamento magnético para um sistema monodomínio em função da temperatura pode ser descrito pela função de Langevin de primeira ordem, dada por [70],

$$
M(T)=N m\left[\operatorname{coth}\left(\frac{m H}{K_{B} T}\right)-\frac{K_{B} T}{m H}\right]
$$

Em que $\mathrm{N}$ é o número de átomos por unidade de volume e $m$ é o momento magnético da partícula de monodomínio e $H$ é o campo magnético aplicado.

\subsection{Fluido magnético}

Fluido magnético é um sistema coloidal formado por um líquido dispersor e por partículas magnéticas. Adequados para uma série de aplicações desde as tecnológicas à medicina [12, 126].

Após a síntese das nanopartículas magnéticas, a tendência das mesmas é aglomerar-se devido às interações dipolo-dipolo magnéticas e atrativas de Van Der Waals. A alta energia de superfície das partículas é minimizada quando as partículas estão aglomeradas, sendo necessário tratar a superfície da partícula, inserindo forças de repulsão para contraporem às interações atrativas citadas anteriormente.

A estabilidade coloidal pode ser obtida por meio de dois mecanismos: estabilização eletrostática e a estabilização estérica. Na estabilização eletrostática a superfície das nanopartículas é eletricamente carregada (positiva ou negativamente) de modo que se estabeleça uma repulsão eletrostática entre partículas (ver figura 2.8.a). A estabilização estérica é obtida por meio da cobertura da superfície das nanopartículas com polímeros, surfactantes ou mesmo pequenas moléculas, que previnem a aproximação das partículas por impedimento estérico, conforme ilustração apresentada na figura 2.8.b. Uma combinação de ambos os mecanismos é a chamada estabilização eletrostérica $[15,87,88]$.

a)

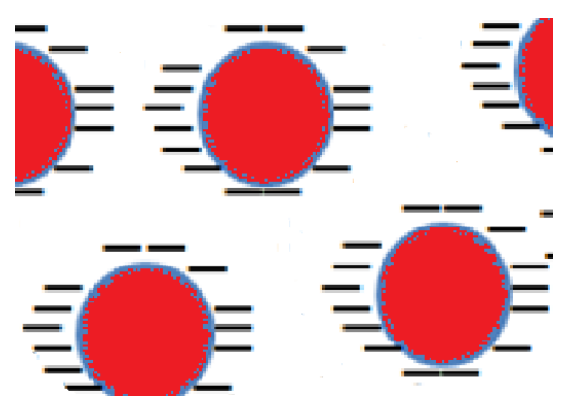

b)

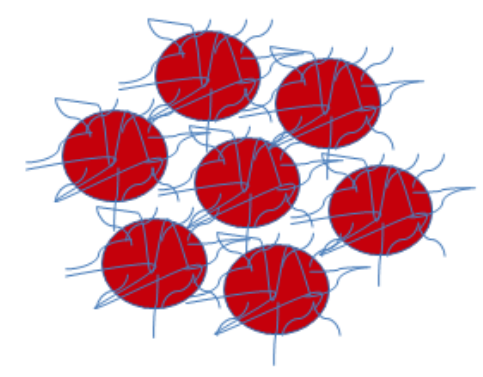

Figura 2.8: Em (a) uma representação das partículas carregada com cargas negativas na superfície e, dispersas num meio aquoso. Em (b), uma representação das partículas funcionalizadas com moléculas surfactante e dispersa em meio orgânico.

A interação de atração dipolo-dipolo pode ser modelada considerando-se os momentos magnéticos entre as partículas, separadas por uma distância $s+d$, em que $s$ é a 
distância de superfície à superfície das nanopartículas e $d$ é o diâmetro das mesmas. A energia de interação dipolo-dipolo $E_{d d}$ entre as duas partículas com momentos magnéticos $\overrightarrow{m_{1}}$ e $\overrightarrow{m_{2}}$ pode ser escrita por [87],

$$
E_{d d}=\frac{1}{4 \pi \mu_{0}}\left[\frac{\overrightarrow{m_{1}} \cdot \overrightarrow{m_{2}}}{r^{3}}-\frac{3\left(\overrightarrow{m_{1}} \cdot \overrightarrow{\mathrm{r}}\right)\left(\overrightarrow{m_{2}} \cdot \overrightarrow{\mathrm{r}}\right)}{r^{5}}\right]
$$

Quando os momentos estão alinhados, ou seja, $\overrightarrow{m_{1}}=m \hat{m}, \overrightarrow{m_{2}}=m \hat{m}$ e $\vec{r}=r \hat{r}$, a energia é escrita da seguinte maneira,

$$
E_{d d}=\frac{m^{2}}{2 \pi \mu_{0} r^{3}}
$$

Considerando $r=s+d$ e $m=\frac{\pi M \mu_{0} d^{3}}{6}$, onde $M$ é a magnetização, $\mu_{0}$ a permeabilidade magnética no vácuo, $d$ o diâmetro das partículas e substituindo na última equação da energia, obtém-se,

$$
E_{d d}=\frac{\pi \mu_{0} M^{2} d^{3}}{9(l+2)^{3}}
$$

Em que, $l=\frac{2 s}{d} . \quad l=0$, representa o contato entre as partículas.

$$
V=\frac{\pi d^{3}}{6}
$$

a energia de contato das partículas será dada por:

$$
E_{d d}=\frac{\mu_{0} M^{2} V}{12}
$$

A interação de Van der Waals ocorre devido a vários tipos de interação, por exemplo, a de dipolo induzido e dipolo permanente, pode ser dada por [87].

$$
E_{v w}=\frac{-A}{6}\left[\frac{2}{l^{2}+4 l}+\frac{2}{(l+2)^{2}}+\ln \left(\frac{l^{2}+4 l}{(l+2)^{2}}\right)\right]
$$

Onde: $A$ é a constante de Hameker, dependente das propriedades dielétrica das partículas, do meio e de $l$ do jeito que foi definido. $O$ valor da constante é calculado de acordo com o número de átomos por unidade de volume e da polarizabilidade do meio. A interação é proporcional à $l^{-1}$ para partículas próximas e a $l^{-6}$ para partículas mais afastadas.

A interação de repulsão estérica ocorre quando uma camada molecular é adsorvida na superfície da partícula. A molécula adsorvida com alta afinidade ao líquido dispersor apresenta repulsão estérica em relação a outra molécula adsorvida na superfície da partícula vizinha, impedindo a aproximação das mesmas e eventual aglomeração, provocando uma barreira estérica à aproximação. A energia de repulsão por unidade de área de superfície entre duas partículas idênticas é dada por [87], 


$$
E_{e s}=\frac{\pi d^{2} \xi k T}{2}\left[2-\left(\frac{l+2}{t}\right) \ln \left(\frac{1+t}{\left(1+\frac{l}{2}\right)}\right)-\frac{l}{t}\right]
$$

Em que, $t=2 \delta / d, k$ é a constante de Boltzmann, $T$ é a temperatura do sistema, $t$ é o comprimento da molécula adsorvida e $\xi$ é a concentração superficial das moléculas adsorvida, denominado de coeficiente grafting.

O ácido oleico é um exemplo de cobertura empregada para estabilizar as partículas em meio apolar tais como hidrocarbonetos, por exemplo, tolueno e hexano e será empregado neste trabalho.

A interação eletrostática repulsiva utiliza cargas elétricas positivas ou negativas na superfície da partícula para a obtenção da dispersão coloidal. Quando as partículas possuem cargas e potenciais de superfícies iguais e de mesmo sinal elas tendem a se repelirem, criando uma barreira de potencial que impede a agregação das mesmas [89].

Em um meio polar, as partículas adquirem cargas elétricas superficiais originárias da ionização, da adsorção de íons ou da dissolução de íons. A interação eletrostática repulsiva entre as partículas é dada pela expressão [72],

$$
E_{e l}=\frac{B \varepsilon k^{2} T^{2} a \gamma^{2}}{z^{2}} e^{-k x}
$$

Em que, $x$ é a menor distância entre duas esferas idênticas de raio $a=d / 2, z$ são cargas puntiformes distribuídas sobre uma região da superfície da partícula considerada plana. $B=4,36.10^{20} \frac{1}{A^{2} S^{2}}$, e $\gamma$ é escrito por [90],

$$
\gamma=\frac{e^{\frac{z e \psi_{0}}{2 K_{B} T}}-1}{e^{\frac{z e \psi_{0}}{2 K_{B} T}+1}}
$$

$\psi_{0}$ é o potencial de Stern ou potencial Zeta e $k$, o parâmetro de aproximação Debye-Huckel é definido por [90],

$$
k=\left(\frac{2 e^{2} N_{A} c z^{2}}{\varepsilon K_{B} T}\right)^{\frac{1}{2}}
$$

Este parâmetro é a constante de difusão da equação da difusão, sendo $N_{A}, c$ e $\varepsilon$ é a constante de avogrado, a concentração do eletrólito e a permissividade do meio, respectivamente.

As nanopartículas magnéticas dispersas formando um fluido, podem apresentar dois mecanismos de relaxação dos momentos magnéticos: o mecanismo de Néel-Arrhenius e o Browniano. Na relaxação tipo browniano, as nanopartículas mudam a orientação de seus momentos magnéticos intrínsecos por rotação da própria partícula dentro do líquido carreador devido à ativação térmica. Assim, na ausência de um campo magnético, as partículas são orientadas aleatoriamente no colóide e a magnetização líquida é nula. $O$ tempo de decaimento da magnetização de um colóide devido à sua difusão rotacional é descrito como o tempo de relaxação Browniano $\tau_{B}[15]$. 


$$
\tau_{B}=\frac{3 \eta V_{h i d r}}{K_{B} T}
$$

Onde, $V_{\text {hidr }}$ é o volume hidrodinâmico da partícula e $\eta$ é viscosidade do fluido carreador. Se ambos os mecanismos de relaxação, browniano e de Néel, estiverem presentes, o mecanismo com menor tempo de relaxação dominará o comportamento do sistema, e o tempo de relaxação efetivo $\tau_{\text {eff }}$ será dado por [15],

$$
\tau_{\text {eff }}=\frac{\tau_{N} \tau_{B}}{\tau_{N}+\tau_{B}}
$$

\subsection{Copolímeros.}

Polímeros são macromoléculas formadas pela junção de um grande número de moléculas pequenas, denominadas de monômero, numa cadeia. Esses monômeros reagem quimicamente para formar longas moléculas. As repetições dessas unidades podem ser linearmente ramificadas, ou interconectadas para formar redes tridimensionais. Compostos de uma única repetição dos monômeros são os homopolímeros, enquanto que, heteropolímeros são compostos de vários repetições dos monômeros. Copolímeros são os mais comuns entre os heteropolímeros e são formados por uma sequência de dois tipos de monômeros. A alternância entre os monômeros dos copolímeros pode ser simples como AB-A-B ou aleatoria como A-A-B-A-A-A-B-B-A-A-A-A-B [127], em que A e B representam monômeros. $O$ modo pelo qual os polímeros estão dispostos na cadeia copolimérica é classificado em quatro grupos, sendo eles: bloco, alternado, estatístico e enxertados [128]. Em especial, os copolímeros em bloco podem ser: dibloco, tribloco, multibloco e estrela [129]. Existem várias formas de copolímero bloco, inclusos nestas, estão: AB, ABA [127]. Neste último exemplo, A e B representam a cadeia de polímero e não mais monômeros como no primeiro exemplo.

Dentre os muitos tipos de copolímeros, o SEBS ou PS-PEB-PS, abreviações para poli(estireno)-bloco-poli(etileno-ran-butileno)-bloco-poli(estireno), é um copolímero tribloco do tipo ABA. É um copolímero tribloco porque é composto de três regiões formadas por dois blocos de poliestireno que têm entre eles uma cadeia de poli(etileno-ran-butileno) ligados por meio de ligações covalentes. Neste último, as cadeias de butileno estão distribuídas aleatoriamente em relação ao etileno.

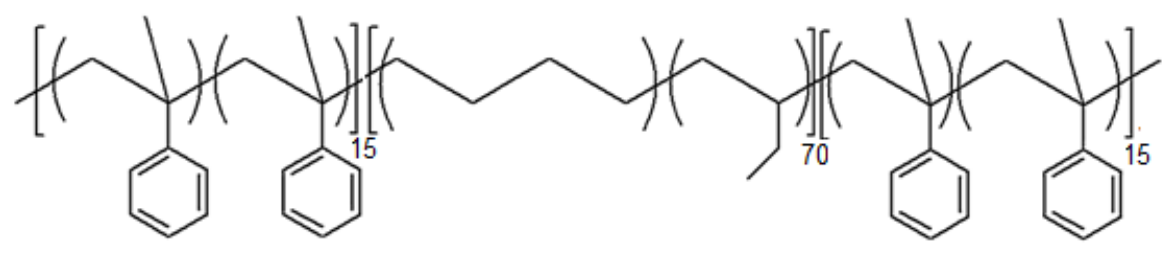

Figura 2.9. Fórmula química estrutural do copolímero SEBS. 
A figura 2.9 mostra a fórmula estrutural da cadeia do copolímero tri-bloco do SEBS. A numeração após cada colchete representa a porcentagem dos polímeros em relação ao copolímero. 15 representa 15\% para o polímero de poli(estireno) e 70 representa $70 \%$ do poli(etileno-ran-butileno).

\subsection{Técnica de deposição Spin Coating.}

Dentre as técnicas empregadas para a deposição de filmes finos destaca-se a de spin coating, por ser uma técnica relativamente simples. No caso da deposição de sistemas nanoparticulados embebidos em uma matriz de polímero, este método torna-se de grande relevância, uma vez que utiliza a rotação para formar filme fino que pode levar a diferentes arquiteturas, interna e de superfície.

Em princípio, uma solução líquida relativamente viscosa é depositada num substrato que posteriormente, executa um movimento rotatório. Após iniciar a rotação, a solução se espalha radialmente devido à força centrífuga. A figura 2.10. mostra em sequência na vertical, as etapas do processo de produção do filme fino: (a) a solução líquida é depositada; (b) o susbstrato inicia a rotação e; (c), a rotação ajuda na evaporação de parte do solvente da solução; A rotação pára e a amostra de filme está pronta.

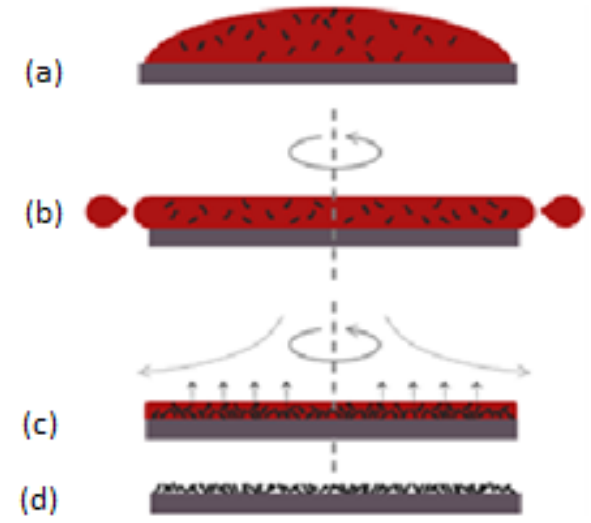

Figura 2.10. Ilustração do método de deposição Spin coating.

O solvente volátil, rapidamente evapora durante o processo de rotação do substrato, mas não completamente. Para a evaporação completa do solvente, deixa-se o filme, depois de terminado o processo de rotação, em ambiente com temperatura controlável, para ebulição do solvente.

O método de spin coating pode produzir filmes com baixa rugosidade numa superfície de área da ordem de milímetros quadrados, e o parâmetro de controle é a taxa de evaporação do solvente [130]. Adicionalmente, a espessura é outro parâmetro que também pode ser controlada. Por exemplo, a adição de nanopartícula na solução de copolímero permite aumentar a espessura do filme fino. Através de um controle programado, pode-se 
fixar os valores desejados de velocidade de rotação e tempo de rotação. Esses parâmetros também alteram a espessura do filme . 


\section{CAPÍTULO 3}

\section{Técnicas de caracterização}

As técnicas de caracterização utilizadas para o estudo das amostras produzidas, serão apresentadas a seguir. Os nanofilmes foram produzidos por meio da técnica de "spin coating" a partir de suspensão de nanopartículas de magnetita e soluções do copolímero tribloco poli(estireno)-bloco-poli(etileno-ran-butileno)-bloco-poliestireno (SEBS). Como controle, foi depositado um filme "casting". As técnicas de espectroscopia UV-vis, Infravermelho, e Raman, microscopia eletrônica de transmissão, termogravimétrica, foram empregadas para caracterização dos fluidos magnéticos. As técnicas de espectroscopia UVvis, e Raman, também foram empregadas para caracterizar os filmes produzidos, enquanto a caracterização magnética, empregando as técnicas de VSM, Ressonância ferromagnética, foi realizada em fluidos magnéticos, bem como para os filmes.

\subsection{Espectroscopia no Infravermelho.}

A técnica de espectroscopia no infravermelho é uma técnica poderosa para análise de diversos tipos de materiais ou espécies moleculares, sendo empregada para a identificação de grupos funcionais. Espectrômetros modernos quase sempre utilizam a técnica de transformada de Fourier para detecção e análise [101], que foi o caso do equipamento utilizado neste trabalho.

Nos compostos orgânicos os grupos funcionais possuem átomos ligados por arranjos específicos. A absorção de energia no infravermelho por uma molécula orgânica ocorrerá de modo característico dos grupos funcionais daquela molécula, por exemplo, a modificação de óxidos de ferro por meio de ácidos carboxílicos pode resultar numa variedade de interações entre as espécies carboxilícos/carboxilatos e o metal da superfície dos óxidos [12]. Os carboxilatos podem se ligar covalentemente aos cátions de metais de transição por meio de três tipos de coordenação: monodentada, bidentada e bidentada em ponte. Os ácidos carboxílicos também podem interagir com a superfície do metal por meio de ligações de hidrogênio [100].

Fundamentalmente, o efeito da absorção acontece quando o momento de dipolo elétrico $\mu$ da molécula sofre uma transição de estado, de $\Psi_{m}$ para $\Psi_{n}$ [99]:

$$
\left\langle\Psi_{n}|\mu| \Psi_{m}\right\rangle
$$

Esses estados representam o estado vibracional (autoestado) da molécula com um valor de energia (autovalor) associado e uma determinada frequência característica para cada um deles [95]. Pode-se também interpretar a absorção como a criação de um fônon porque este é equivalente ao modo de vibração da molécula neste caso [79]. O momento de dipolo sofre variação com a vibração molecular, podendo ser expandido em série de Taylor com relação à coordenada da vibração $q_{j}$ [95], 


$$
\mu=\mu^{\prime}+\frac{\partial \mu}{\partial q_{j}} q_{j}+\cdots
$$

Em que $\mu^{\prime}$ é o momento de dipolo permanente e, a derivada representa a variação do momento de dipolo elétrico. Os outros termos da expansão representam deslocamentos muito pequenos em torno da posição de equilíbrio, e podem ser desprezados. Como $\mu^{\prime}$ é o momento de dipolo permanente, a derivada do momento de dipolo ou qualquer uma das suas componentes deverá ser diferente de zero para que ocorra a absorção no infravermelho.

$$
\frac{\partial \mu}{\partial q_{j}} \neq 0
$$

A descrição da transição entre os estados pode ser feita por meio do momento de transição de dipolo, ou valor médio do momento de dipolo elétrico descrito na equação (3.1) e representado abaixo na forma de integral,

$$
\left\langle\Psi_{n}|\mu| \Psi_{m}\right\rangle=\mu_{m n}=\int \Psi_{m} \mu \Psi_{n} d \tau
$$

Ou explicitamente pelas componentes,

$$
\left(\mu_{i}\right)_{m n}=\int \Psi_{m} \mu_{i} \Psi_{n} d \tau
$$

Onde i representa uma das componentes x, y e z. Usando a expansão em Taylor (3.2) para o momento de dipolo, tem-se:

$$
\mu_{m n}=\mu_{0} \int \Psi_{m} \Psi_{n} d \tau+\frac{\partial \mu}{\partial q_{j}} \int \Psi_{m} q_{j} \Psi_{n} d \tau
$$

Pode-se interpretar a absorção a partir desta equação. Pela ortogonalidade das funções, a primeira integral da soma é zero, já que não haveria transição do dipolo se $m=n$, uma vez que corresponderia ao mesmo estado vibracional. Da segunda integral é que obtém-se as duas condições obrigatórias para que ocorra absorção proveniente da radiação no infravermelho que incidiu na molécula [95].

As duas condições são:

1) $\frac{\partial \mu}{\partial q_{j}} \neq 0$, ou seja, tem que haver a variação do momento de dipolo;

2) $\int \Psi_{m} q_{j} \Psi_{n} d \tau \neq 0$, o integrando $\Psi_{m} q_{j} \Psi_{n}$ deve ser par. Esta condição só é possível se $\Psi_{m}$ for ímpar (par) e $\Psi_{n}$ for par (ímpar) já que a coordenada de vibração $q_{j}$ é ímpar.

Neste trabalho, a espectroscopia no infravermelho foi empregada para caracterizar as nanopartículas presentes no fluido magnético, confirmando os modos vibracionais característico da partícula de óxido de ferro presente nas bandas 438,583 e $636 \mathrm{~cm}^{-1}$ e da molécula complexante, o ácido oleico, das bandas 2855, 2924 e $1717 \mathrm{~cm}^{-1}$ e entre a região $1360-1650 \mathrm{~cm}^{-1}$ [12], bem como, identificar a interação entre a partícula de óxido de ferro e o ácido oleico. 


\subsection{Espectroscopia Raman.}

A técnica de espectroscopia Raman está entre as mais potentes para o estudo e identificação de materiais, sendo de interesse nos mais variado ramos da pesquisa e da indústria. Tem sido aplicada com sucesso para investigar sistemas biológicos [17], análise de antigas pinturas [104], sensores químicos [5], entre outros, sendo de especial interesse para materiais nanoparticulados. Em particular, permite identificar as diferentes fases dos óxidos de ferro cúbicos, mesmo em dimensões nanométricas, especialmente a magnetita e a maghemita, que são difíceis de diferenciar por meio de outras técnicas, tais como, difração de raios-X. É uma técnica não destrutiva, não requer preparação de amostra e pode ser realizada à temperatura ambiente. $A$ análise dos resultados pode ser realizada de forma qualitativa e/ou quantitativa, e pode dar informações sobre as características dos materiais como, a simetria cristalina, o arranjo atômico, a interação molecular e a identificação de espécies orgânicas e inorgânicas [64,98,95]. As técnicas Raman e infravermelho são complementares.

O Efeito Raman é proveniente da interação da radiação com a matéria, especificamente o espalhamento inelástico de luz monocromática. A incidência da radiação, isto é, o campo elétrico $E$ da onda eletromagnética, pode ser dado por [118]:

$$
E=E_{0} \cos \left(2 \pi v_{0} t\right)
$$

Em que, $E_{0}$ é a amplitude máxima do campo elétrico, $v_{0}$ a frequência da radiação e $t$ o tempo, induz um momento de dipolo $P$ sobre as moléculas do meio, dado por [118],

$$
P=\alpha E
$$

Onde $\alpha$ representa a polarizabilidade do meio e pode ser representada pela matriz,

$$
\alpha=\left(\begin{array}{lll}
\alpha_{x x} & \alpha_{x y} & \alpha_{x z} \\
\alpha_{y x} & \alpha_{y y} & \alpha_{y z} \\
\alpha_{z x} & \alpha_{z y} & \alpha_{z z}
\end{array}\right)
$$

As vibrações das moléculas do meio são normalmente denominadas de modos normais de vibração $q_{j}$, dada por [118],

$$
q_{j}=q_{0} \cos \left(2 \pi v_{j} t\right) .
$$

Em que, $q_{0}$ é a amplitude máxima da coordenada do modo normal de vibração e $v_{j}$ é a frequência característica do j-ésimo modo normal. O termo "modo normal de vibração" mais adiante nesse texto será trocado por "fônons", que é usado comumente em física do estado sólido para estudos da rede cristalina. As duas formas são completamente equivalentes. 0 fônon é análogo ao fóton, mas representa a quantização da vibração [79]. Por enquanto, o texto ainda utilizará o termo "modos normais de vibração".

Para pequenos deslocamentos, a polarizabilidade dos elétrons na molécula pode ser expandida por uma série de Taylor, tal como [118],

$$
\alpha=\alpha_{0}+\frac{\partial \alpha}{\partial q_{j}} q_{j}+\cdots
$$


Sendo que $\alpha_{0}$ é a polarizabilidade no equilíbrio.

Com a inserção da polarizabilidade expandida, na equação (3.8), que descreve inicialmente o momento de dipolo induzido do meio, obtém-se,

$$
P=\alpha_{0} E_{0} \cos \left(2 \pi v_{0} t\right)+\frac{\partial \alpha}{\partial q_{j}} q_{0} E_{0} \cos \left(2 \pi v_{0} t\right) \cos \left(2 \pi v_{j} t\right)
$$

Os termos de ordem superior da derivada não foram incluídos por não contribuírem significativamente para a polarizabilidade. Por meio da manipulação algébrica do produto dos cossenos, obtém-se:

$$
\cos \left(2 \pi v_{0} t\right) \cos \left(2 \pi v_{j} t\right)=\frac{1}{2}\left\{\cos \left[2 \pi\left(v_{0}+v_{j}\right) t\right]+\cos \left[2 \pi\left(v_{0}-v_{j}\right) t\right]\right\}
$$

Com a inserção da equação (3.13) no segundo termo da equação (3.12) O momento de dipolo induzido passa a ser descrito da seguinte forma:

$P=\alpha_{0} E_{0} \cos \left(2 \pi v_{0} t\right)+\frac{1}{2} \frac{\partial \alpha}{\partial q_{j}} q_{0} E_{0} \cos \left[2 \pi\left(v_{0}+v_{j}\right) t\right]+\frac{1}{2} \frac{\partial \alpha}{\partial q_{j}} q_{0} E_{0} \cos \left[2 \pi\left(v_{0}-v_{j}\right) t\right]$

Sendo que no primeiro termo da expressão aparece o campo elétrico da onda incidente, de frequência $v_{0}$, referente ao espalhamento Rayleigh, ou seja, a onda espalhada com a mesma energia da onda incidente. Os dois termos seguintes, o campo elétrico está modulado nas frequência $v_{0}+v_{j}$ e $v_{0}-v_{j}$, correspondente ao espalhamento Anti-Stokes e Stokes, respectivamente, considerando, na mesma sequência, o espalhamento de radiações com maior e menor energia, quando se compara com a onda incidente. No entanto, o segundo e o terceiro termo só contribuirão para o valor do momento de dipolo se,

$$
\frac{\partial \alpha}{\partial q_{j}} \neq 0
$$

Ou seja, para ocorrer o efeito Raman é necessário que a polarizabilidade varie com o deslocamento da coordenada $q_{j}$ (modo vibracional) em relação à posição de equilíbrio [115].

Quanticamente, uma das componentes da polarizabilidade é escrita por,

$$
\alpha_{m n}=\int \Psi_{m} \alpha \Psi_{n} d \tau
$$

Onde $m$ e $n$ simbolizam os diferentes estados. Considerando $\alpha_{m n}$ uma matriz no espaço tridimensional, neste caso, o momento de dipolo induzido é dado por:

$$
\left(\begin{array}{l}
P_{x} \\
P_{y} \\
P_{z}
\end{array}\right)=\left(\begin{array}{lll}
\alpha_{x x} & \alpha_{x y} & \alpha_{x z} \\
\alpha_{y x} & \alpha_{y y} & \alpha_{y z} \\
\alpha_{z x} & \alpha_{z y} & \alpha_{z z}
\end{array}\right) \cdot\left(\begin{array}{c}
E_{x} \\
E_{y} \\
E_{z}
\end{array}\right) .
$$

Para que ocorra o efeito Raman, uma das componentes do tensor de polarizabilidade tem que ser diferente de zero,

$$
\left(\alpha_{i j}\right)_{m n}=\int \Psi_{m} \alpha_{i j} \Psi_{n} d \tau \neq 0
$$

A expansão em Taylor de $\alpha_{i j}$ permite reescrever a polarizabilidade da seguinte forma:

$$
\left(\alpha_{i j}\right)_{m n}=\alpha_{0} \int \Psi_{m} \Psi_{n} d \tau+\frac{\partial \alpha}{\partial q_{j}} \int \Psi_{m} q_{j} \Psi_{n} d \tau
$$


O primeiro termo da soma pode se anular devido à relação de ortogonalidade entre os estados $\Psi_{m}$ e $\Psi_{n}$, isto é, obrigatoriamente $m$ tem que ser diferente de $n$ para indicar que os estados são diferentes e com isso, permitir a transição. Assim, têm-se duas condições que devem ser satisfeitas para ocorrer o efeito Raman:

1) $\frac{\partial \alpha}{\partial q_{j}} \neq 0$, ou seja, tem que haver a variação da polarizabilidade;

2) $\int \Psi_{m} \alpha_{i j} \Psi_{n} d \tau \neq 0$, isto é, o integrando deve ser par. Para isso, uma das funções de onda deve ser par (ou ímpar) e a outra deve ser ímpar (ou par) já que $\alpha_{i j}$ é ímpar.

A regra de seleção deve ser a mesma do oscilador harmônico, isto é, $\Delta v= \pm 1$. Onde o sinal "+" corresponde ao espalhamento Stokes enquanto o "-" corresponde ao espalhamento Anti-Stokes. Isto significa que, respectivamente, a molécula absorve ou perde energia na transição de um estado vibracional à outro. Conforme observado na figura 3.3, a luz incide numa molécula que se encontra no estado fundamental. Com a incidência de um fóton de energia $h v$, a molécula sofre transição para um estado virtual e depois decai para um estado vibracional excitado, emitindo um outro fóton de menor energia $h\left(v_{0}-v_{j}\right)$, denominado de espalhamento Stokes. Em (b), no caso do espalhamento Anti-Stokes, a molécula se encontra num estado excitado, e ao sofrer incidência de um fóton de energia $h v$, sofre uma transição para o estado virtual e, em seguida, decai para o estado fundamental, emitindo, um fóton de energia $h\left(v_{0}+v_{j}\right)$. A molécula também pode receber energia $h v$ do fóton incidente quando no estado fundamental, sofrer transição para o estado virtual e decair para o estado fundamental, sendo chamado de espalhamento Rayleigh. 


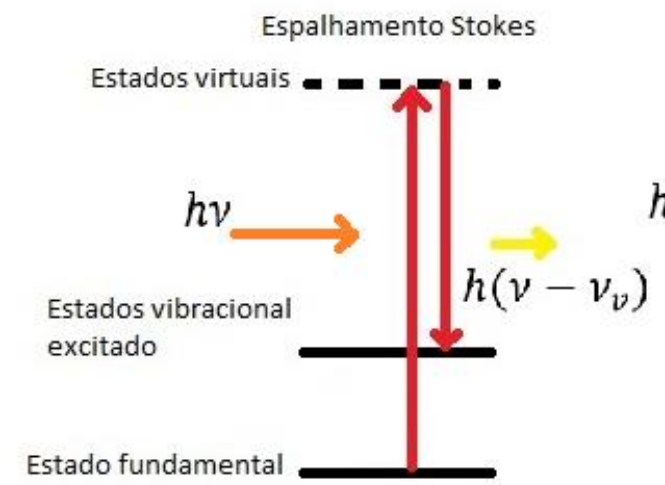

(a)

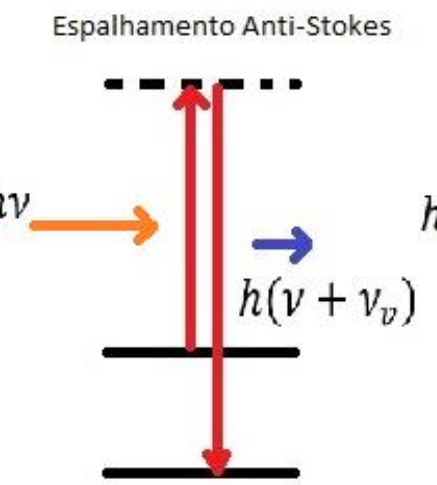

(b)

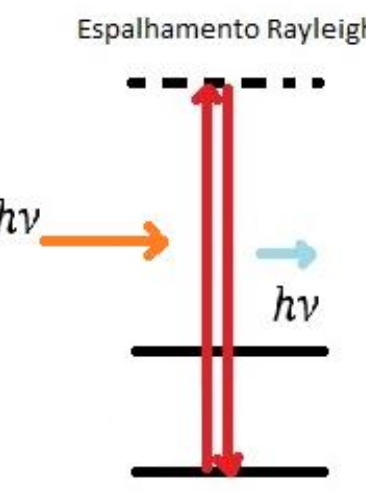

(c)

Figura 3.1. Representação do espalhamento Raman. Em (a) o fóton $h v$ (em laranja) incide na molécula, que no estado fundamental transita para o estado virtual e decai em seguida para o estado vibracional excitado, emitindo um fóton (em amarelo) de energia $h\left(v_{0}-v_{j}\right)$. Em (b) o fóton $h v$ (em laranja) incide na molécula, que já se encontra no estado vibracional excitado e, transita para o estado virtual e decai em seguida para o estado fundamental, emitindo um fóton (em azul) de energia $h\left(v_{0}+v_{j}\right)$. Em (c), o fóton $h v$ (em laranja) incide na molécula que está no estado fundamental. A molécula sofre transição para o estado virtual e, em seguida, decai para o estado fundamental, emitindo um fóton (em azul celeste) de energia $h v$.

Quando se considera a interação da radiação com materiais cristalinos, a regra de seleção de primeira ordem para o efeito Raman é dada por,

$$
\begin{aligned}
& v_{i}=v_{e} \pm v_{f} \\
& K_{i}=K_{e} \pm K_{f}
\end{aligned}
$$

Onde, $v_{i}$ e $K_{i}$ se referem à frequência e o número de onda do fóton incidente, respectivamente, enquanto, $v_{e}$ e $K_{e}$, correspondem à frequência e ao número de onda do fóton espalhado, respectivamente. Enquanto que a frequência e o número de onda do fônon são, respectivamente, $v_{f}$ e $K_{f}$. Os sinais “+” e “-“ se referem, respectivamente, ao espalhamento Anti-Stokes e Stokes. Assim, os fótons de frequências $v_{e}+v_{f}$ e $v_{e}-v_{f}$ podem ser emitidos acompanhados de uma absorção ou emissão do fônon de frequência $v_{f}$. Esses fônons envolvidos são os próximos do centro da zona de Brillouin. A regra de seleção imposta é uma consequência direta da periodicidade da rede e da simetria dos elementos constituintes devido à conservação do momento.

Estudos teóricos que empregam a teoria de grupo indicam que podem ocorrer cinco bandas ativas Raman $\left(A_{1 g}+E_{g}+3 T_{2 g}\right)$ e quatro do infravermelho $4 T_{1 u}$ para o caso da magnetita [96]. Os cincos modos Raman podem ser descritos como: $A_{1 g}$ representa 0 estiramento simétrico da ligação dos átomos de oxigênio em relação ao átomo de ferro no 
sítio tetraédrico; $E_{g}$, a flexão simétrica das ligações desses átomos de oxigênio; e os três modos $T_{2 g}$ representam respectivamente, movimento de translação dos átomos, estiramento assimétrico das ligações de oxigênio e flexão assimétrica dos átomos de oxigênio em relação aos átomos de ferro [97,94]. A presença de um centro de inversão no espaço centrossimétrico do grupo $\mathrm{Fd} 3 \mathrm{~m}$ implica em mútua exclusão das atividades Raman e no infravermelho para o mesmo modo de vibração. Somente os sítios $T_{d}$, e $C_{3 v}$ ocupados por

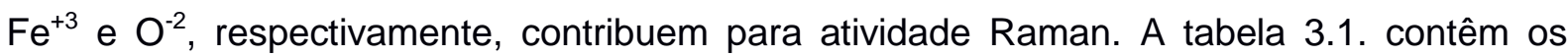
números de onda correspondente aos modos de vibração da magnetita e da maguemita.

Tabela 3.1. Número de onda atribuídos aos modos vibracionais da magnetita e maguemita (com asterístico, os números de onda são relativos a maguemita).

\section{Referência Número de onda atribuídos aos modos vibracionais $\left(\mathrm{cm}^{-1}\right)$}

\begin{tabular}{|c|c|c|c|c|c|c|c|}
\hline Gasparov[133] & 193 & & 308 & & 540 & 670 & \\
\hline De Faria[66] & 193 & 302 & & 513 & 534 & 663 & \\
\hline Shebanova[94] & 193 & 306 & & & 538 & 668 & \\
\hline Chourpa[134] & 194 & 303 & & 508 & 528 & 662 & \\
\hline Hanesch*[135] & & & 350 & $500-515$ & & 665 & 730 \\
\hline Soler ${ }^{\star}[136]$ & & & 358 & 510 & & 678 & 723 \\
\hline
\end{tabular}

A interpretação física da intensidade Raman é bem descrita pela teoria de perturbação [102,103]. A intensidade Raman depende da probabilidade de transição, ou seja, do quadrado do momento de transição e da quarta potência da frequência da radiação espalhada [95].

$$
I_{m n}=\left(\frac{16 \pi^{2}}{9 c^{4}}\right) I_{0} v^{4} \sum_{i} \sum_{j}\left|\left(\alpha_{i j}\right)_{m n}\right|^{2}
$$

Em que, $I_{0}$ é a intensidade da radiação incidente e $v$ é a frequência da radiação espalhada, $c$ é a velocidade da luz, $\alpha_{i j}$ representa o momento de transição, $I_{m n}$ a intensidade da radiação espalhada.

Embora a energia dos fótons seja maior para o espalhamento Anti-Stokes do que o espalhamento stokes, a intensidade das bandas Anti-Stokes são menores que as bandas Stokes. A explicação para este fato está na distribuição populacional do estado vibracional excitado, que obedece a estatística de Maxwell-Boltzman. A razão das intensidades AntiStokes e Stokes pode ser dada por [95],

$$
\left(\frac{I_{A}}{I_{S}}\right)=\left(\frac{v_{0}+v_{j}}{v_{0}-v_{j}}\right)^{4} e^{\frac{-e_{j}}{K_{B} T}}
$$


$I_{A}$ é a intensidade Anti-Stokes e $I_{S}$ a intensidade Stokes. $K$ é a constante de Bolztman e $T$ é a temperatura.

\subsection{Espectroscopia no UV-vis.}

A espectroscopia no UV-vis tem origem nas transições eletrônicas. Quando a radiação eletromagnética na faixa do visível incide sobre um material, o elétron vai de um estado menor de energia para outro de maior energia. Neste caso, a radiação foi absorvida pelo material e configura-se pela diferença de energia entre os níveis [108]. A figura 3.2 exemplifica o fenômeno de transição eletrônica.

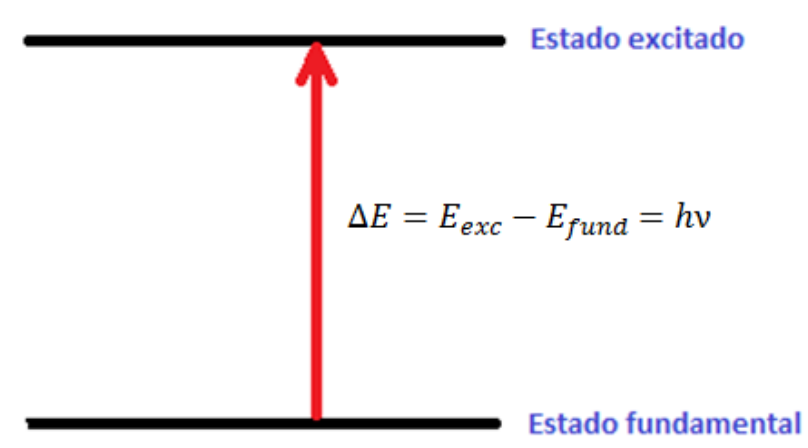

Figura 3.2: Processo de excitação eletrônico.

O espectro no UV-vis vem da absorção da luz pela molécula. Esta absorção é definida por [108],

$$
A=\log \left(\frac{I_{0}}{I}\right)
$$

Esta relação indica que a absorção da luz pela molécula é dependente do logaritmo natural da razão entre a intensidade da luz que chega $I_{0}$ na amostra pela intensidade da luz que é transmitida $I$ pela amostra. A absorção está também relacionada à absorvidade molar $\in$, a concentração molar $c^{\prime}$ do soluto e o comprimento da amostra $L$, dado pela equação 3.25 [108],

$$
A=\in c^{\prime} L
$$

A espectroscopia de UV-vis pode ser útil para identificar a presença de um material em outro, através da concentração [54,109,110]. A presença do material é reconhecida por sua banda caracterísitca, relacionada à transição eletrônica de alguns dos elementos constituintes da amostra. Esta banda poderá ser encoberta por uma banda maior e na mesma região do material matriz. Neste caso, é preciso recorrer à outra técnica de análise da presença do material naquela matriz. Neste trabalho, foi possível identificar a presença do colóide magnético na matriz copolimérica utilizando a espectroscopia UV-vis. No geral, a presença do material em outro só é possível na espectroscopia UV-vis graças a relação de proporcionalidade entre a concentração e a transição eletrônica. 


\subsection{Microscopia Eletrônica de Transmissão MET}

A técnica de Microscopia Eletrônica de Transmissão MET sonda a estrutura interna de sólidos e dá acesso aos detalhes microestrutural ou nanoestrutural [111]. O poder do MET em fornecer informações da morfologia e do tamanho de objetos da ordem de nanômetro será empregado para a análise do formato, tamanho e dispersão de tamanho das partículas coloidais sintetizadas.

\subsection{Espalhamento Dinâmico de Luz EDL}

O Espalhamento dinâmico de luz (EDL) é aplicado na caracterização de partículas, emulsões e moléculas, as quais, foram dispersas ou dissolvidas em um líquido, formando um colóide. O EDL permite obter o diâmetro hidrodinâmico dos agregados em um colóide. Este tamanho leva em conta a interação das partículas com o meio e a cobertura presente na superfície. O EDL funciona basicamente com um feixe de luz monocromático incidindo na amostra e sendo espalhado em várias direções e, um detector coleta a luz espalhada em um qângulo $\theta$ com relação a um feixe incidente. O espalhamento de ondas eletromagnéticas por qualquer sistema está relacionado a heterogeneidade destes, tanto para uma molécula quanto para agregados moleculares. Como às moléculas têm movimentos de translação, rotação e vibração, a luz espalhada no detector encontra-se em constante mudanças, variando com o tempo. Com isso, o movimento browniano das partículas ou moléculas em suspensão faz com que a luz do laser seja espalhada com intensidades diferentes. A análise dessas flutuações de intensidade resulta na velocidade do movimento browniano e assim, o tamanho de partícula pode ser descrita pela relação Stokes-Einstein [132].

$$
D=\frac{K_{B} T}{6 \pi \eta r_{h i d r}}
$$

Em que, $K_{B}$ é a constante de Boltzman, $T$ é a temperatura absoluta, $\eta$ é a viscosidade do meio, $r_{H}$ é o raio hidrodinâmico e, $D$ é o coeficiente de difusão.

\subsection{Análise Termogravimétrica TG}

A análise termogravimétrica, fornece informações sobre a perda de massa do material analisado em função da temperatura. A técnica de termogravimetria demanda um controle rigoroso nas condições de temperatura, balança de precisão e pressão. Esta técnica pode dar informações sobre fenômenos físico-químicos como vaporização, sublimação, absorção, adsorção, dessorção, quimiossorção, dessolvação, decomposição, oxidação oxidativa, reação gás-sólido (por exemplo, oxidação ou redução) [112]. Neste trabalho, a análise termogravimétrica foi utilizada para estimar a massa de ácido oleico empregado como cobertura das partículas de óxidos de ferro.

\subsection{Megnetometria}

A técnica de VSM é basicamente um instrumento de medida de propriedades magnética de uma amostra em movimento vibracional ao longo do eixo perpendicular à 
aplicação de um campo magnético uniforme. Esta técnica permite a precisão da medida de magnetização da amostra [117]. Atualmente, as técnicas de VSM utilizam supercondutores, o que aumenta bastante a precisão, mesmo em quantidade muito pequena da amostra [106].

A medida de magnetização da amostra acontece da seguinte maneira: A amostra é colocada dentro de um campo magnético uniforme proveniente de duas bobinas, que tem uma tensão induzida proporcional ao momento magnético da amostra. Este campo magnético uniforme magnetiza a amostra.

\subsection{Ressonância Ferromagnética}

A técnica de Ressonância Ferromagnética RFM se assemelha a técnica de Ressonância Paramagnética de Elétron RPE quando a frequência de precessão dos spins (ou precessão de Larmor) for dependente da forma esférica do material. Neste trabalho, é levada em conta a forma esférica das partículas embebida pela matriz copolimérica. Neste caso, a RFM se baseia na absorção ressonante da radiação pelos elétrons expostos a um campo magnético $H$. O momento magnético total dos elétrons precessa em torno da direção do campo magnético estático aplicado e o sistema absorve energia do campo alternado quando a frequência é igual à frequência de precessão.

Quando um campo magnético $\vec{H}$ é aplicado sobre uma amostra, ocorre separação de nível energético $\Delta E=E_{2}-E_{1}$ de dois estados de spins 2 e 1 . A separação em níveis de energia, provocado pela exposição ao campo magnético, é conhecido como efeito Zeeman [116]. A figura 3.4. mostra esta separação dos níveis de energia provocado pelo campo aplicado.

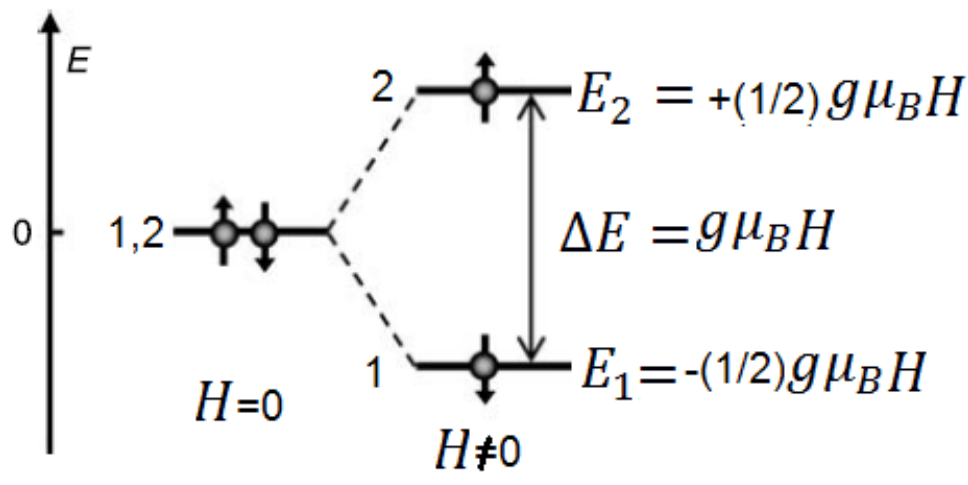

Figura 3.4: Antes da aplicação do campo magnético, os estados 1 e 2 estão superpostos num único estado (reparar na vertical de $H=0$ ). Na aplicação do campo magnético os estados se desdobram em dois, um com mais alta energia e outro com menor energia, com a metade do valor da diferença entre eles (reparar na vertical de $H \neq 0$ ). 
O momento magnético do elétron $\overrightarrow{m_{e}}$ associado com o momento angular de spin $\vec{S}$ do elétron é dado por [116],

$$
\overrightarrow{m_{e}}=g\left|\overrightarrow{\mu_{B}}\right| \vec{S}
$$

A separação de energia pelo campo é dada por,

$$
\Delta E=E_{2}-E_{1}=-\overrightarrow{m_{e}} \cdot \vec{H}=g\left|\overrightarrow{\mu_{B}}\right| \vec{S} \cdot \vec{H}=g \mu_{B} H
$$

Admite-se que o campo magnético $\vec{H}=H \hat{z}$ é aplicado no eixo $z$ e o spin assume $o$ valor $1 / 2$. Sendo $g \circ$ fator giromagnético e $\mu_{B}$ é o magnéton de Bohr, a unidade fundamental do momento magnético atômico. Um elétron de spin no estado 1, o estado de mais baixa energia, pode absorver um quanta de energia $h v$ da radiação eletromagnética, coincidente com a diferença entre os estados $2 \mathrm{e} 1$.

$$
\Delta E=E_{2}-E_{1}=h v
$$

Onde, $v$ é a frequência da radiação.

Portanto, para haver a absorção ressonante para amostra exposta à radiação de frequência $v$, a diferença de energia entre dois estados de spin deve satisfazer a condição de ressonância,

$$
\Delta E=E_{2}-E_{1}=h v=g \mu_{B} H .
$$

E a frequência de Larmor é dada por,

$$
v=\frac{g \mu_{B} H}{h}
$$

Esta é a equação fundamental da espectroscopia de Ressonância Ferromagnética RFM para uma partícula magnética esférica. O espectro RFM é um gráfico que ilustra a absorção da radiação de frequências, da região de micro-ondas da radiação eletromagnética, em função da intensidade do campo magnético aplicado. A derivação da absorção em relação à um campo magnético aplicado é que de fato é ilustrado no espectro RFM. A absorção de micro-ondas acontece ao redor de um valor central $H$ do campo magnético [116].

No espectro RFM, as medidas são: os valores do campo de ressonância $H$ no ponto onde os espectros corta a linha de base e o valor da largura de linha de ressonância $\Delta H$, dado pela distância à meia altura da linha de absorção ou a distância pico-à-pico $\Delta H_{p-p}$, conforme é exibido esquematicamente na figura abaixo, retirado do experimento deste trabalho. 


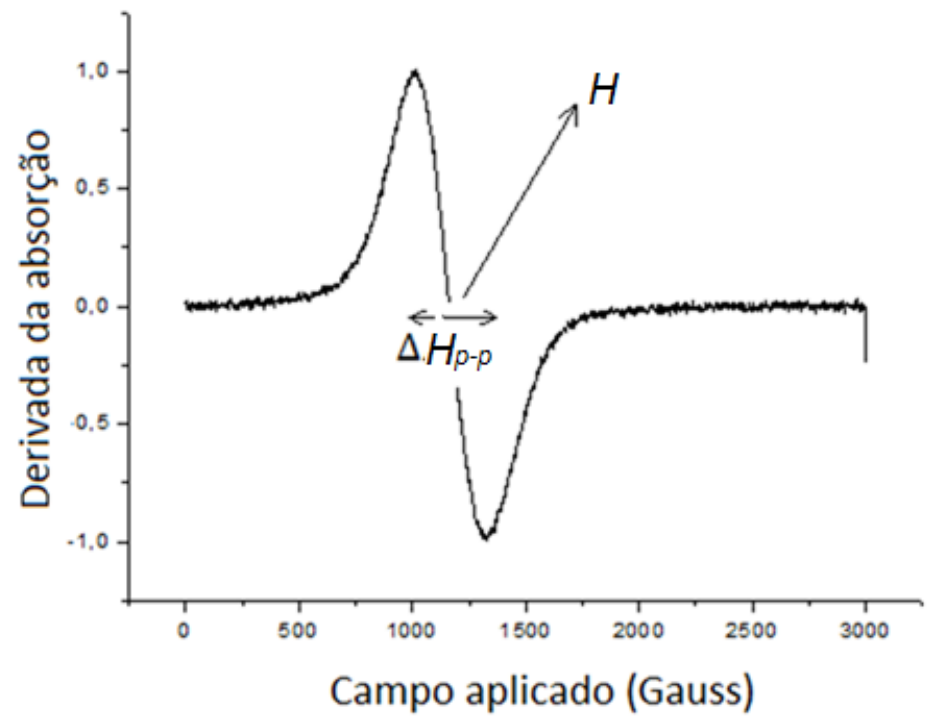

Figura 3.5: Espectro típico de RFM de partículas magnéticas. 


\section{CAPÍTULO 4}

\section{Procedimento experimental.}

Os procedimentos experimentais empregados na preparação dos nanomateriais são descritos neste capítulo. Os filmes finos híbridos formados por nanopartículas de óxidos de ferro embebidas na matriz polimérica foram obtidos por meio da técnica de spin-coating. A dispersão coloidal utilizada como fonte de partículas e a solução polimérica para a deposição dos filmes foram preparadas, separadamente, em uma primeira etapa.

\subsection{Materiais.}

Os materiais utilizados para a síntese das nanopartículas de óxido de ferro funcionalizadas com ácido oleico e dispersas em meio apolar e fabricação dos filmes, foram empregados conforme adquiridos. Os reagentes utilizados neste trabalho são: cloreto férrico $\left(\mathrm{FeCl}_{3} \cdot 6 \mathrm{H}_{2} \mathrm{O}\right)$, sulfato ferroso $\left(\mathrm{FeSO}_{4} \cdot 7 \mathrm{H}_{2} \mathrm{O}\right)$, ácido clorídrico $(\mathrm{HCl})$, hidróxido de sódio $(\mathrm{NaOH})$, ácido sulfúrico $\left(\mathrm{H}_{2} \mathrm{SO}_{4}\right)$, peróxido de hidrogênio $\left(\mathrm{H}_{2} \mathrm{O}_{2}\right)$, hidróxido de amônio $\left(\mathrm{NH}_{4} \mathrm{OH}\right)$, tolueno $\left(\mathrm{C}_{6} \mathrm{H}_{5} \mathrm{CH}_{3}\right)$, ácido 3-mercapto-1-propanosulfonato de sódio (3-MPS), ácido oleico $\left(\mathrm{C}_{18} \mathrm{H}_{34} \mathrm{O}_{2}\right)$, óxido de grafeno $\left(\mathrm{C}_{\mathrm{x}} \mathrm{O}_{\mathrm{y}} \mathrm{H}_{z}\right)$, poli(cloreto de dialildimetil amônio) (PDAC) e o polímero poliestireno-bloco-poli(etileno-ran-butileno)-bloco-poliestireno PS-PEB-PS ou SEBS (SEBS, $89000 \mathrm{~g} / \mathrm{mol}$ - Aldrich), com $70 \%$ de PEB e $30 \%$ de PS. Toda a água utilizada neste trabalho provém de um sistema de purificação Mili-Q (resistividade da água de 18 $\left.\mathrm{M} \Omega \mathrm{cm}^{-1}\right)$.

Substratos de vidro ótico BK7 $(1 \times 10 \times 20 \mathrm{~mm})$, e silício $(3 \times 3 \mathrm{~mm})$ utilizados para a deposição dos filmes, foram previamente limpos usando solução piranha $\left(\mathrm{H}_{2} \mathrm{SO}_{4} / \mathrm{H}_{2} \mathrm{O}_{2}, 3: 1\right.$ v/v) seguida da solução $\mathrm{RCA}\left(\mathrm{H}_{2} \mathrm{O} / \mathrm{H}_{2} \mathrm{O}_{2} / \mathrm{NH}_{4} \mathrm{OH}, 5: 1: 1\right.$, v/v). Após a limpeza, os substratos de vidro ótico e de silício exibem cargas negativas na superfície. A funcionalização da superfície dos substratos BK7 e microscopia com bicamadas de PDAC/GO por meio do método de automontagem [25] foi realizada para obtenção de superfície hidrofóbica. As lâminas de vidro recobertas com ouro, empregadas para as análises Raman, foram funcionalizadas com 3-MPS (0,18 g/L) em água deionizada por 12 horas [106]. Após este tempo, as lâminas foram enxaguadas em água ultrapura e colocadas no ultrassom de 2 à 3 minutos. O procedimento foi repetido e as lâminas secadas posteriormente.

A solução de SEBS $(\approx 10,0 \mathrm{~g} / \mathrm{L})$ foi preparada por meio de diluição deste copolímero na forma sólida em uma solução de tolueno.

\subsection{Preparação das partículas coloidais.}

A síntese das nanopartículas coloidais ocorreu no laboratório de polímeros do Instituto de Química da Universidade de Brasília e contou com a orientação do professor Leonardo Paterno. 
As nanopartículas foram sintetizadas pelo método de coprecipitação em meio alcalino e dispersas na forma coloidal em meio apolar seguindo procedimento disponível na literatura com pequenas alterações [119]. As etapas empregadas no processo de síntese das nanopartículas podem ser descritas resumidamente como: inicialmente foram preparadas as soluções aquosas de cloreto férrico $\left(\mathrm{FeCl}_{3} \cdot 6 \mathrm{H}_{2} \mathrm{O}-0,2 \mathrm{~mol} / \mathrm{L}\right)$ e sulfato ferroso $\left(\mathrm{FeSO}_{4} \cdot 7 \mathrm{H}_{2} \mathrm{O}-0,1 \mathrm{~mol} / \mathrm{L}\right)$, que posteriormente, foram adicionadas a uma solução de $\mathrm{NaOH}$ (1mol/L) sob agitação magnética ocorrendo a hidrólise e, posteriormente, os processos de nucleação e crescimento das nanopartículas de óxido de ferro. Em seguida, água deionizada foi adicionada para obter o volume de $200 \mathrm{~mL}$. A funcionalização das partículas sintetizadas foi obtida adicionando-se $1 \mathrm{~mL}$ de ácido oleico, e mantendo a dispersão por 30 minutos a $70^{\circ} \mathrm{C}$ sob agitação. A dispersão das nanopartículas em meio ácido foi obtida adicionando-se ao precipitado uma solução de ácido clorídrico $0,25 \mathrm{~mol} / \mathrm{L}$, até a obtenção do pH 5. Após a adição do ácido, deixou-se a solução sob decantação magnética para separar o precipitado magnético do sobrenadante. Em seguida foi realizada a lavagem com água ultrapura várias vezes. A solução foi deixada em agitação magnética por 30 minutos para a remoção do excesso de surfactante. Em seguida, adicionou-se acetona, ocorrendo a precipitação das partículas e, finalmente, adicionou-se hexano para a dispersão. A dispersão foi centrifugada a $8000 \mathrm{rpm}$ por 10 minutos, para remoção de agregados. $\mathrm{O}$ procedimento de síntese da partícula e sua cobertura está descrito na figura 4.1.

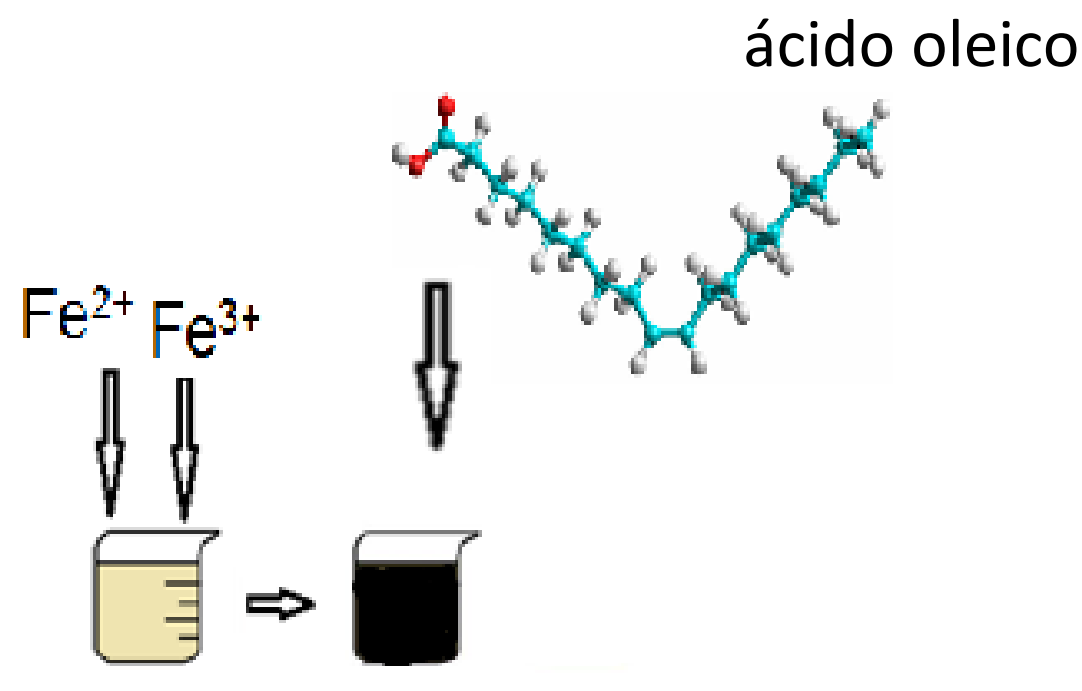

Figura 4.1. Processo de síntese das partículas de Magnetita com a cobertura de ácido oleico. 


\subsection{Caracterização das partículas coloidais}

Espectros UV-vis obtidos da dispersão coloidal mostraram a presença da partícula de óxido de ferro dispersa por meio do ombro em $480 \mathrm{~nm}[19,109]$ que pode indicar uma transição eletrônica entre o íon $\mathrm{Fe}^{2+}$ e $\mathrm{Fe}^{3+}$ ou de um desses dois íons com $\mathrm{O}^{2-}$.

As análises MET foram feitas a partir da deposição de fluido magnético sobre uma tela de microscópio coberta por uma membrana de carbono. O MET usado foi o modelo Jeol JEM 1011 com voltagem de $80 \mathrm{kV}$. Foi obtida uma imagem real das partículas após a detecção do sinal MET, onde se estimou o tamanho das mesmas. As imagens foram obtidas no Instituto de Física da Universidade Federal de Goiás.

A caracterização do raio hidrodinâmico do colóide de partículas magnéticas foi utilizada pelo EDL. O equipamento de medida foi o Zetasize da Malvern Instruments. As medidas foram realizadas no laboratório de Genética e Morfologia do Instituto de Biologia da Universidade de Brasília.

As medidas de espectroscopia Raman para identificação de uma das fases (magnetita ou maguemita) e da cobertura do óxido de ferro quando a partícula estiver dispersa no colóide foi realizada sem qualquer preparo, exceto pela secagem das partículas. O espectrômetro para as análises Raman foi do modelo da Jobin Yvon T64000, com CCD resfriada por nitrogênio líquido e com microscópio ótico de lente objetivas de 10, 20 e 50 vezes o aumento. Para a realização das análises, utilizou-se uma lente de 50x.

\subsection{Deposição do filme fino.}

Os filmes foram depositados no Laboratório de Amostra do professor José Antonio Huamaní Coaquira do Instituto de Física da UnB. Os filmes magnéticos foram preparados pela incorporação de nanopartículas de óxido de ferro na matriz copolimérica de SEBS. O fluido magnético usado como fonte de nanopartículas magnéticas e a solução de copolímero foram preparados separadamente.

Os filmes ultrafinos foram depositados em substratos funcionalizados por meio da técnica de spin coating e como controle, foram também depositados por "casting". Para a deposição dos filmes, as partículas coloidais foram dispersas em tolueno numa proporção de 1:2 (v/v), resultando em uma concentração de nanopartícula de aproximadamente 5,0 $\mathrm{g} / \mathrm{L}$. A solução de SEBS ( $\approx 10,0 \mathrm{~g} / \mathrm{L})$ foi preparada por meio de dissolução deste copolímero sólido em tolueno. O equipamento empregado na fabricação do filme fino de modelo WS650MZ-23NPP/UD30, que consiste de uma câmara cilíndrica, onde internamente acontece a rotação do disco para a formação do filme fino. Um sistema de controle à vácuo mantém o filme durante o processo de deposição. Um dispositivo de controle eletrônico controla os parâmetros como (ver figura 4.2): velocidade (rpm), tempo (segundos), aceleração (rpm/segundos). 
(a)

(b)
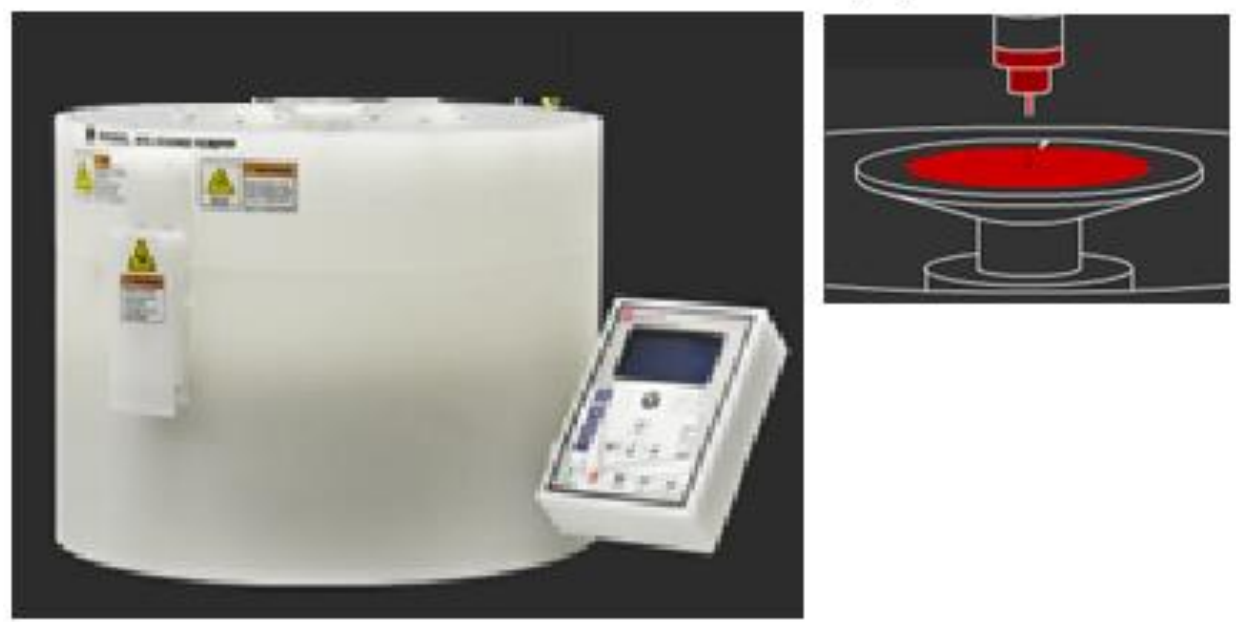

Figura 4.2. Câmara de spin coating. Em (a) a câmara cilíndrica e spin coating e o controle de programação. Em (b), o substrato onde se deposita a dispersão ou solução para a formação do filme.

Os filmes foram obtidos em função da concentração do colóide na solução de copolímero. As concentrações foram variadas segundo a relação 4.1, dada por,

$$
C_{1} V_{1}=C_{2} V_{2}
$$

Onde, $C_{1}$ representa a concentração inicial da solução de copolímero; $C_{2}$, a nova concentração, obtida pela diluição da primeira, de volume inicial $V_{1} \mathrm{e} ; V_{2}$, o volume final da concentração (colóide + copolímero). O volume final constitui a soma do volume inicial $V_{1}$ com outro volume inicial $V_{i}$, que também já vem presente uma determinada concentração de colóide $C_{i}$.

As amostras de filmes depositadas estão listadas na tabela 4.1. Foi dada uma nomenclatura para identificar cada filme fino conforme os parâmetros que os diferencia, levando em conta se a solução de copolímero contém ou não partícula, e se recozida ou não, e ainda, qual a diluição. A primeira linha e a última significam, respectivamente, o pó do copolímero sem o formato de NC e a representação do número que indica a diluição, sendo $x=2,3,4,5$ e $y=0$. O termo "solução de copolímero", em curso no texto, foi renomeado na tabela 4.1. para "copolímero". 
Tabela 4.1: Nomenclatura dos Filmes finos.

\begin{tabular}{ll}
\hline C & Pó do copolímero \\
\hline CD & Copolímero puro depois do recozimento \\
CA & Copolímero puro antes do recozimento \\
CPDXY & Copolímero com partícula depois do recozimento de diluição XY \\
& CPD20, CPD30, CPD40 e CPD50 \%. \\
\hline
\end{tabular}

As dispersões formadas pela solução de copolímero e partículas coloidais foram depositadas nos substratos de BK7, no disco, iniciando-se em seguida o movimento de rotação. Todas as amostras foram depositadas com velocidade de $500 \mathrm{rpm}$, tempo de deposição de $60 \mathrm{~s}$ e aceleração de $500 \mathrm{rpm} / \mathrm{s}$. As amostras foram recozidas à temperatura de $50^{\circ} \mathrm{C}$ durante 5 horas, para a evaporação do solvente.

O monitoramento da deposição dos filmes em função da concentração de partículas de magnetita foi realizado utilizando-se a técnica de espectroscopia UV-VIS, por meio da absorbância da magnetita, em $480 \mathrm{~nm}$. Os filmes foram produzidos em lâminas de vidro ótico - BK7.

Para avaliar a presença cobertura de ácido oleico na superfície das partículas, foram realizadas medidas de Termogravimetria (TG) no equipamento marca Shimadzu DTG 60 system. A massa da amostra analisada foi $10,24 \mathrm{mg}$ e a perda de massa foi estudada na faixa de temperatura de 100 à $700^{\circ} \mathrm{C}$, sob fluxo de nitrogênio de $50 \mathrm{~mL} / \mathrm{min}$ e variação de temperatura de $10^{\circ} \mathrm{C}$.

A análise por espectroscopia Raman foi realizada para identificar a fase da partícula dentro do filme e possíveis interações da partícula com a matriz copolimérica. Além da região entre 200 e $800 \mathrm{~cm}^{-1}$, a obtenção do espectro Raman também se estendeu á região entre 2500 à $3200 \mathrm{~cm}^{-1}$ para identificação dos modos da cobertura da partícula. A excitação dos modos da amostra de filme foi adquirida com um laser de Hélio-Neônio, de comprimento de onda de $632,8 \mathrm{~nm}$. Os filmes foram depositados em lâminas de vidro optico com ouro depositado.

As amostras de filme, depositadas em silício, separadas para medidas magnéticas, foram fixadas em um substrato diamagnético, e todas as medidas foram realizadas à temperatura ambiente. Dentre as medidas magnéticas, estudos referente a Ressonância Ferromagnética foram realizados em um espectrômetro Bruker, modelo EMX, na faixa de frequência de microondas da banda-X ( 9 a $10 \mathrm{GHz}$ ). A potência de microondas, o ganho, a amplitude de modulação e a temperatura foram mantidas constantes para todos os espectros, e seus valores são respectivamente, $100 \mathrm{~mW}, 100,5$ Oe e a temperatura ambiente. 


\section{CAPÍTULO 5}

\section{Resultados e discussões}

Neste capítulo serão apresentados os resultados obtidos no desenvolvimento do projeto. Inicialmente, os resultados da caracterização das partículas coloidais sintetizadas seguindo o protocolo apresentado na seção 4.2 serão apresentados e discutidos. A caracterização do coloide e do sólido nanoparticulado, foi realizada por meio de técnicas como o espalhamento de dinâmico de luz, microscopia eletrônica de transmissão, espectroscopia UV-vis e no infravermelho, termogravimetria e medidas magnéticas. Em seguida, o protocolo para deposição dos filmes, bem como, a caracterização dos mesmos, será discutida. Basicamente, foram empregadas as mesmas técnicas para a caracterização dos filmes, acrescentando-se a espectroscopia Raman e a perfilometria.

\subsection{Nanopartículas coloidais}

O protocolo de síntese das nanopartículas funcionalizadas com ácido oleico desenvolvido durante a realização deste trabalho foi apresentado no item 4.2.

O espectro de UV-VIS foi obtido na região de 250 a $900 \mathrm{~nm}$ (figura 5.1) para a amostra do coloide magnético composto por partículas de óxido de ferro funcionalizadas com ácido oleico obtidas a partir do fluido mãe, com diluição de 1:5 v/v (Figura 5.1.). A presença das nanopartículas de óxidos de ferro nos filmes depositados será monitorada por meio da banda $480 \mathrm{~nm}[19]$.

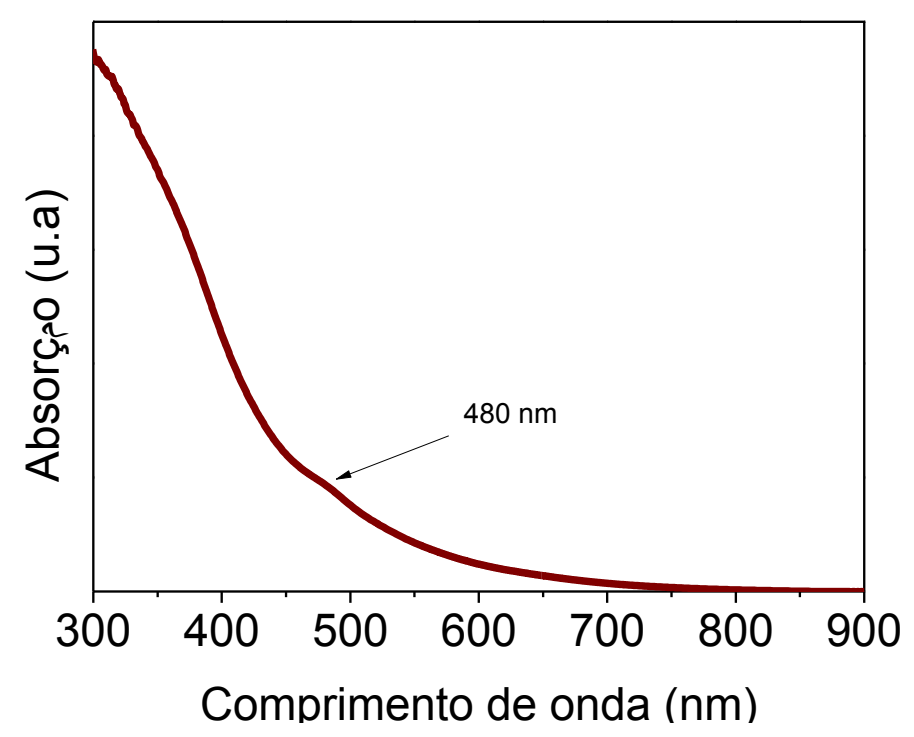

Figura 5. 2. Espectro UV-VIS do coloide magnético sintetizado. 
É possível monitorar os estágios da perda de massa da cobertura da amostra, conforme se observa na Figura 5.2 [112]. Para auxílio da perda da massa, um gráfico DTG (diferencial termogravimétrica), em azul, foi posto junto com o gráfico da análise termogravimétrica TG (em marrom). A região de máximo do gráfico DTG indica algum tipo de perda de massa.

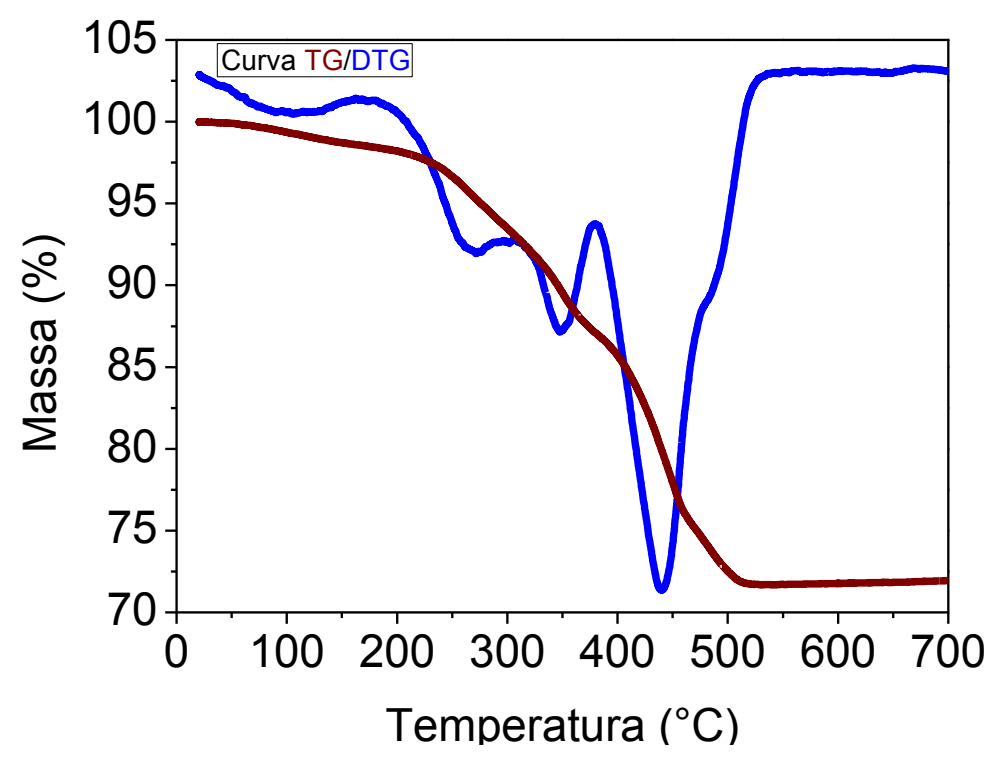

Figura 5.2. Análise TG e DTG da Nanopartícula/cobertura.

Observa-se que no primeiro estágio, na faixa de 100 a $240^{\circ} \mathrm{C}$, a primeira perda da massa, 2,2\%, refere-se à água. $O$ estágio seguinte, caracterizado pela inclinação na faixa de temperatura entre 305 à $344^{\circ} \mathrm{C}$ ocorre pode ser proveniente da decomposição de compostos orgânicos, e/ou desorção da molécula de ácido oleico ou parte dela. Pode acontecer da adsorção física não romper completamente durante o segundo estágio e, portanto, necessitar de um novo estágio, com temperaturas mais elevadas, para romper completamente as cadeias fisiosorvidas da estrutura. Na faixa de temperatura de 371 a 409 ${ }^{\circ} \mathrm{C}$ ocorre o terceiro estágio. Nesse estágio e no anterior, a perda de massa somou 13,6 \%, quase a metade para cada estágio. No quarto e último, na faixa de temperatura de 451 à $515^{\circ} \mathrm{C}$, a perda de massa foi de $11,1 \%$. Este último se refere à moléculas quimiosorvidas na superfície da partícula. $O$ grupo carboxilato era o responsável pela ligação química. Desprender as moléculas ou grupos funcionais quimiosorvido exige maior quantidade de energia, por isso, este estágio, normalmente ocorre em temperaturas mais altas. Após a perda da cobertura de ácido oleico, observa-se que a massa ficou constante [12].

A figura 5.3 mostra o espectro no infravermelho da partícula de óxido de ferro funcionalizada com ácido oleico na forma de pó. As bandas de absorção no Infravermelho 
em $451 \mathrm{~cm}^{-1}$ e superpostas em 583 e $636 \mathrm{~cm}^{-1}[12,118]$, são características dos óxidos de ferro [57].

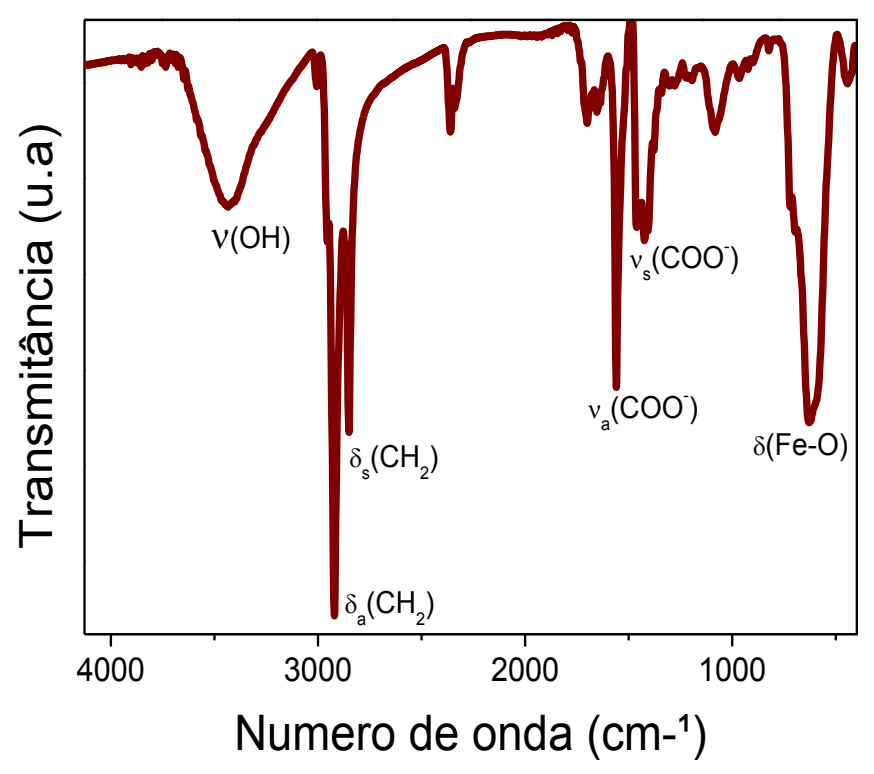

Figura 5.3. Espectro no infravermelho de sólido nanoparticulado funcionalizado com ácido oleico.

As bandas observadas na figura 5.3 foram identificadas considerando-se os dados da literatura. Enquanto as bandas de absorção em $2853 \mathrm{~cm}^{-1}$ e $2929 \mathrm{~cm}^{-1}$ correspondem aos modos de estiramento simétrico $\delta_{s}\left(\mathrm{CH}_{2}\right)$ e assimétrico do $\delta_{a}\left(\mathrm{CH}_{2}\right)$ e são atribuídas à presença da cobertura de ácido oleico [119], observou-se também, um modo vibracional em $3432 \mathrm{~cm}^{-1}$ correspondente à água. Em adição, os modos em torno de $3005 \mathrm{~cm}^{-1}$, relativos a fragmentos pertencentes ao modo do $v(\mathrm{CH})$ das cadeias insaturadas do ácido oleico só foi possível observado após a ampliação do espectro na região entre 3600 à $2400 \mathrm{~cm}^{-1}$ (ver figura 5.4), o que sugere que a maioria dessas cadeias se desprendeu da molécula do ácido oleico quando esta foi coordenada com a partícula e, portanto, não contribuiu com a intensidade dos modos característico 2853 e $2929 \mathrm{~cm}^{-1}$. No espectro de Infravermelho estão presentes ainda, os modos vibracionais da carbonila $(\mathrm{C}=\mathrm{O})$, com estiramento em torno de $1722 \mathrm{~cm}^{-1}$ e o aparecimento dos estiramentos relativos ao íon carboxilato (COO-), $1414 \mathrm{~cm}^{-1}$, assimétrico $v_{a}\left(\mathrm{COO}^{-}\right)$, e $1556 \mathrm{~cm}^{-1}$, simétrico $v_{s}\left(\mathrm{COO}^{-}\right)$, sugerindo, portanto, a complexação do íon de ferro (presente na nanoparticula de maguemita) com o ácido oleico. Observa-se que a banda relativa à carbonila (em $1722 \mathrm{~cm}^{-1}$ ) é pouco intensa, confirmando a ligação entre a molécula de ácido oleico e a superfície da partícula, pois caso contrário este pico seria expressivo. O Estiramento característico da partícula de óxido de ferro é $\delta(\mathrm{Fe}-\mathrm{O})$. Outros dois modos vibracionais, em 1414 e $1556 \mathrm{~cm}^{-1}$, conforme foi mencionado, se referem aos estiramentos assimétrico e simétrico do íon carboxilato, respectivamente. A diferença 
entre essas duas frequências, em torno de $142 \mathrm{~cm}^{-1}$, sugere uma coordenação bidentada em ponte do grupo $\mathrm{COO}^{\circ}$ ao ferro da superfície da nanopartícula [120].

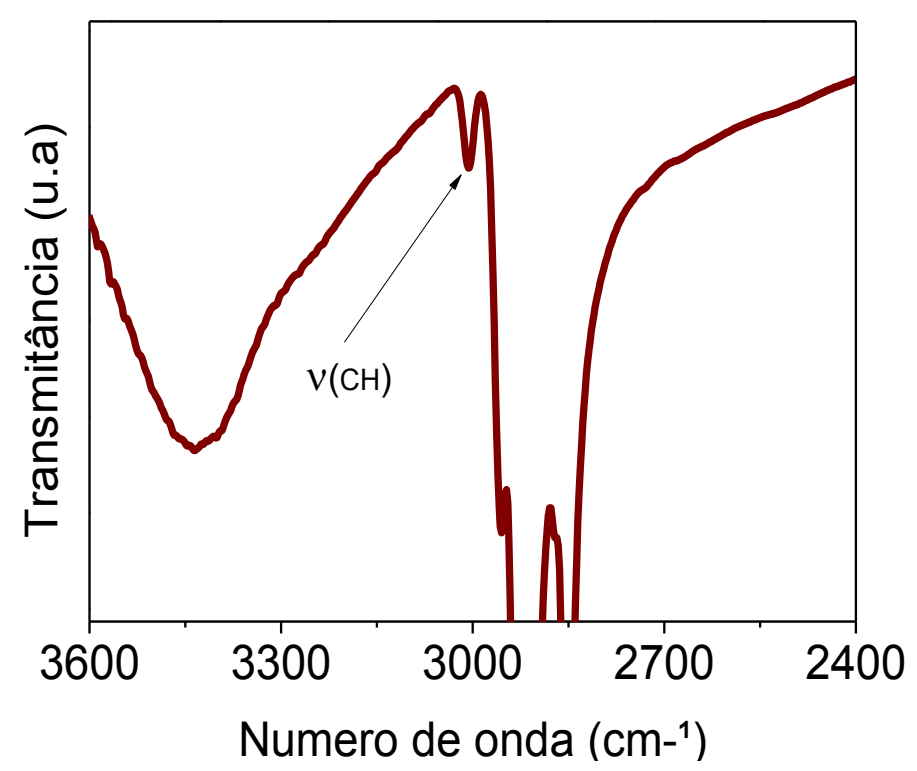

Figura 5.4. Espectro no infravermelho, restringido a região de 3600 à $2400 \mathrm{~cm}^{-1}$, de sólido nanoparticulado funcionalizado com ácido oleico.

A Figura 5.5 apresenta uma imagem MET típica das partículas coloidais sintetizadas. Observa-se partículas esféricas, com distribuição de tamanho esperado para os nanomateriais obtidos pelo método de coprecipitação química. A partir das imagens obtidas foi produzido o histograma mostrado na Figura 5.6, que foi ajustado por uma curva do tipo log-normal [72], a partir do qual, obteve-se o diâmetro médio de 5,81 nm e o desvio padrão de 0,22. Observa-se que o tamanho médio das partículas é menor do que o diâmetro crítico, indicando que as partículas sintetizadas estão no regime superparamagnético [12,76]. 


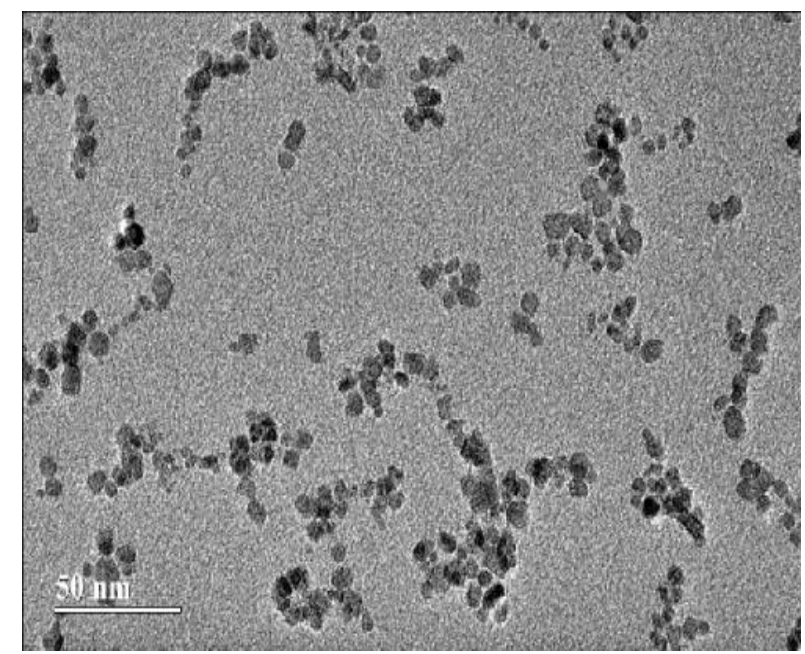

Figura 5.5: Imagem típica de MET (microscopia eletrônica de transmissão) de nanopartículas sintetizadas.

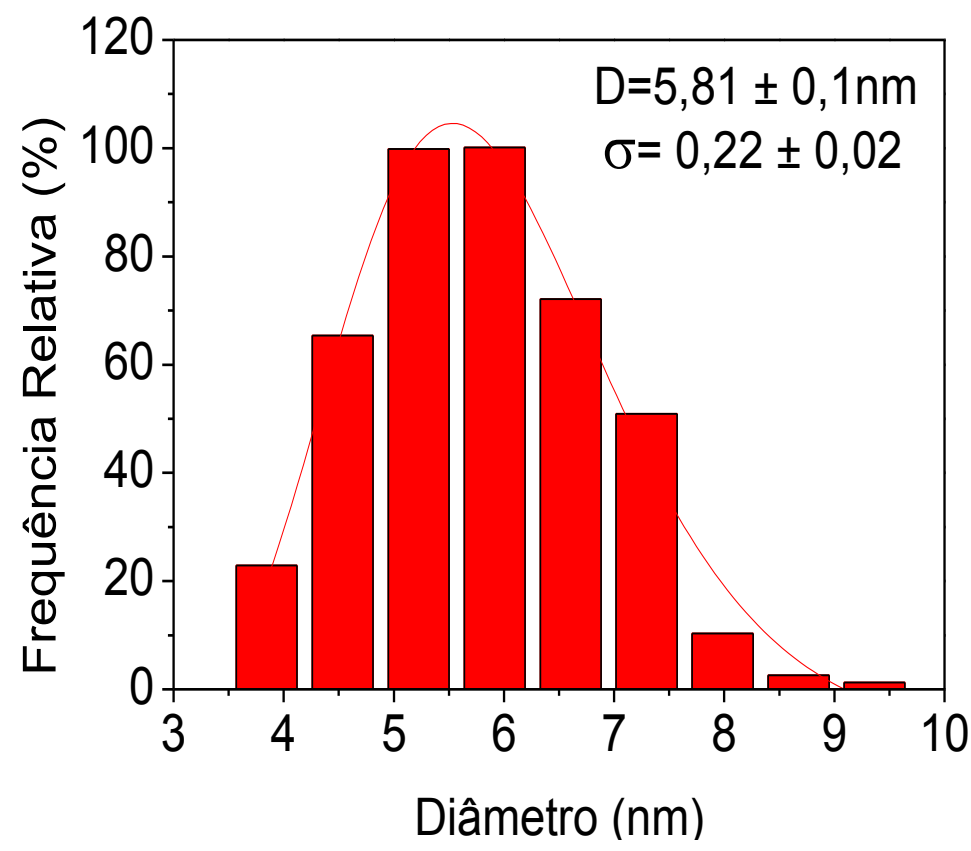

Figura 5.6. Histograma da distribuição de tamanho das partículas (barras verticais). A linha sólida representa o melhor ajuste usando uma função distribuição log-normal.

As partículas magnéticas dentro do colóide também tiveram medidas relacionadas ao tamanho das mesmas via EDL. A figura 5.7 mostra um padrão de distribuição das partículas no colóide, através do qual, exibe um diâmetro hidrodinâmico igual a $D_{h}=28,04 \mathrm{~nm}$. 


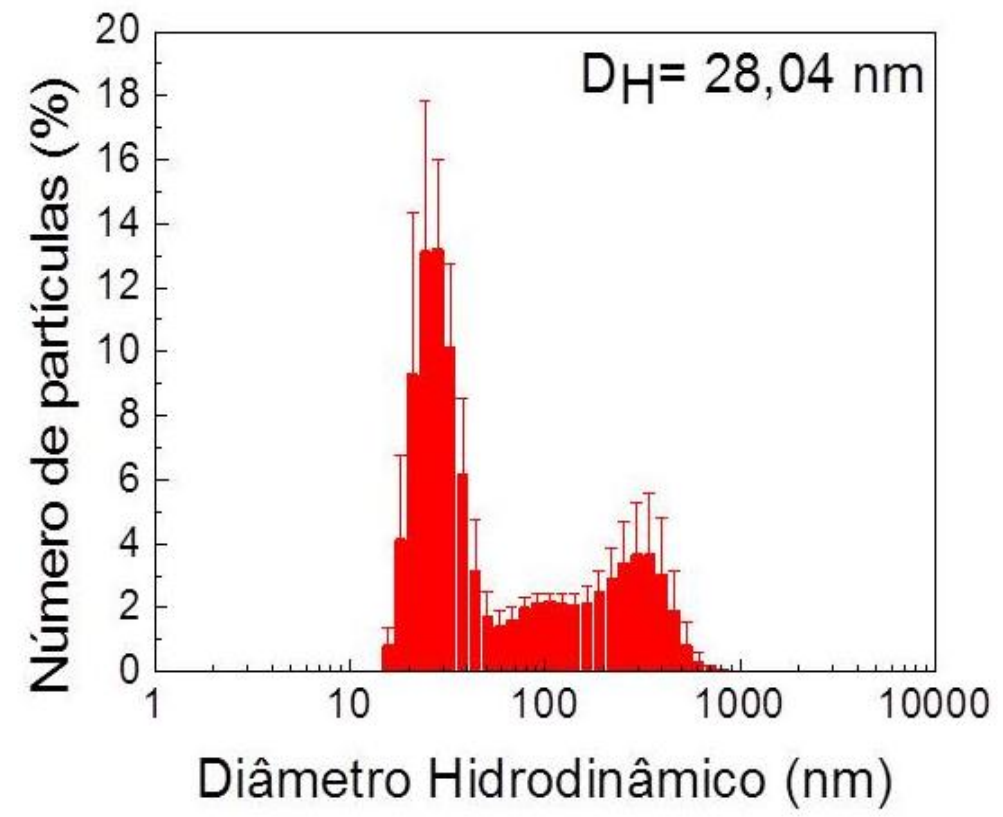

Figura 5.7. Gráfico de distribuição de partículas no colóide com diâmetro hidrodinâmico $D_{\text {hidr }}=28,04 \mathrm{~nm}$.

As partículas de óxido de ferro com cobertura de ácido oleico também foram caracterizadas por meio da técnica de espectroscopia Raman. O espectro mostrado na Figura 5.8 foi obtido sob a incidência de um laser $532 \mathrm{~nm}$ e intensidade do feixe que incide na amostra de $0.25 \mathrm{~mW}$ para evitar a degradação da mesma [131].

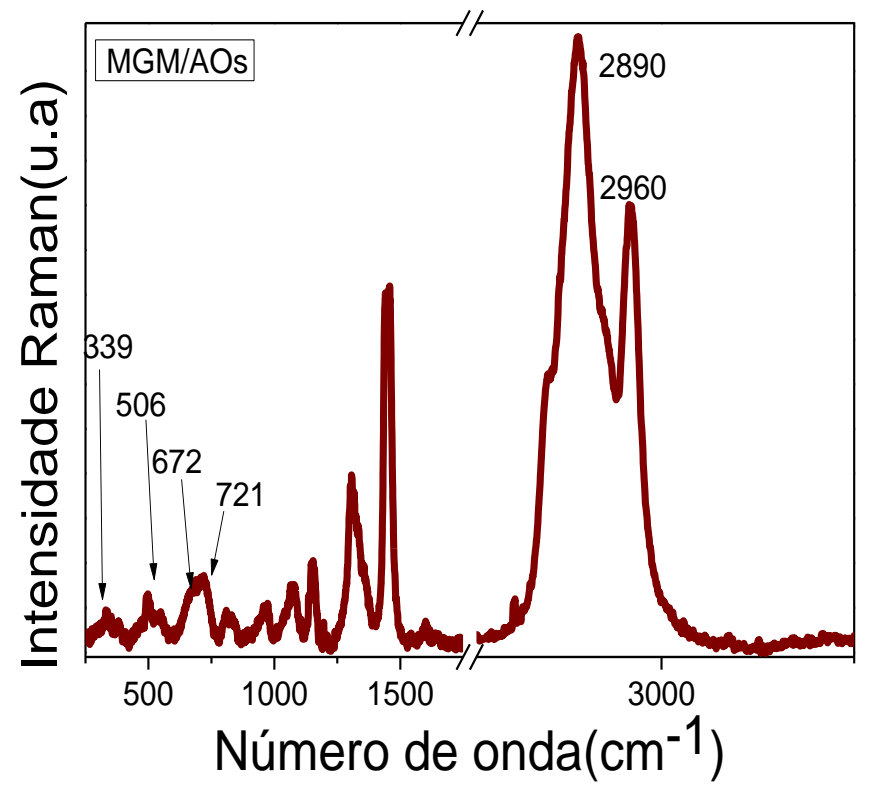

Figura 5.8. Espectro Raman da partícula de óxido de ferro coberta com Ácido Oleico. 
A cobertura de ácido oleico na partícula é representada na região entre 2800 e 3000 $\mathrm{cm}^{-1}$. O número de onda referente aos dois modos vibracionais característicos do ácido oleico é destacado em 2890 e $2960 \mathrm{~cm}^{-1}$. Esses modos correspondem ao $\mathrm{CH}_{2}$ de estiramento simétrico e assimétrico, respectivamente, característico do ácido oleico.

A presença da cobertura da partícula já havia sido observada através da espectroscopia no infravermelho. Os modos vibracionais, 2853 e $2929 \mathrm{~cm}^{-1}$, observados naquelas análises, diferem dos modos, 2890 e $2960 \mathrm{~cm}^{-1}$, apresentados das análises Raman. No efeito Raman a atividade está ligada ao momento de dipolo induzido na molécula pela incidência do campo elétrico da radiação na mesma. Enquanto que no Infravermelho é considerado o momento de dipolo intrínseco da molécula [95]. Sendo assim, é natural esperar pequenos desvios de energia entre as análises de um efeito e outro, evidenciado pelo deslocamento nos modos característico da cobertura, cujos desvios foram 37 e 31 cm-1 da técnica Raman em relação ao Infravermelho, respectivamente, do menor e maior modo relativo a cobertura.

\subsubsection{Caracterização das propriedades magnéticas}

A curva de magnetização em função do campo magnético aplicado obtida à temperatura ambiente, é apresentada na Figura 5.9. Observa-se que não há campo coercivo à temperatura ambiente, ou seja, as partículas se encontram no estado superparamagnético, indicando que o sistema é formado por partículas que não interagem entre si [12] por conta da cobertura de ácido oleico na superfície. O estado superparamagnético deve ser esperado para partículas de estrutura de monodomínio e tamanho abaixo do diâmetro crítico [76].

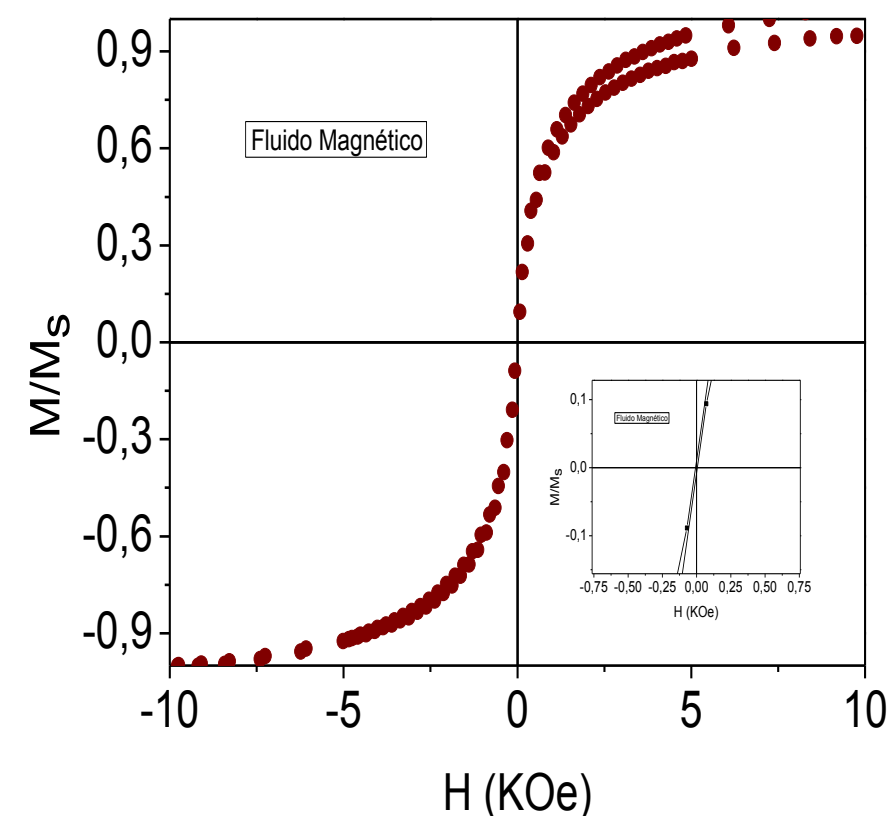

Figura 5. 9. Curva de histerese magnética do fluido magnético. 
Outra medida de caracterização magnética da partícula é a da ressonância ferromagnética. A figura 5.10 mostra um gráfico de ressonância ferromagnética da partícula dispersa no colóide.

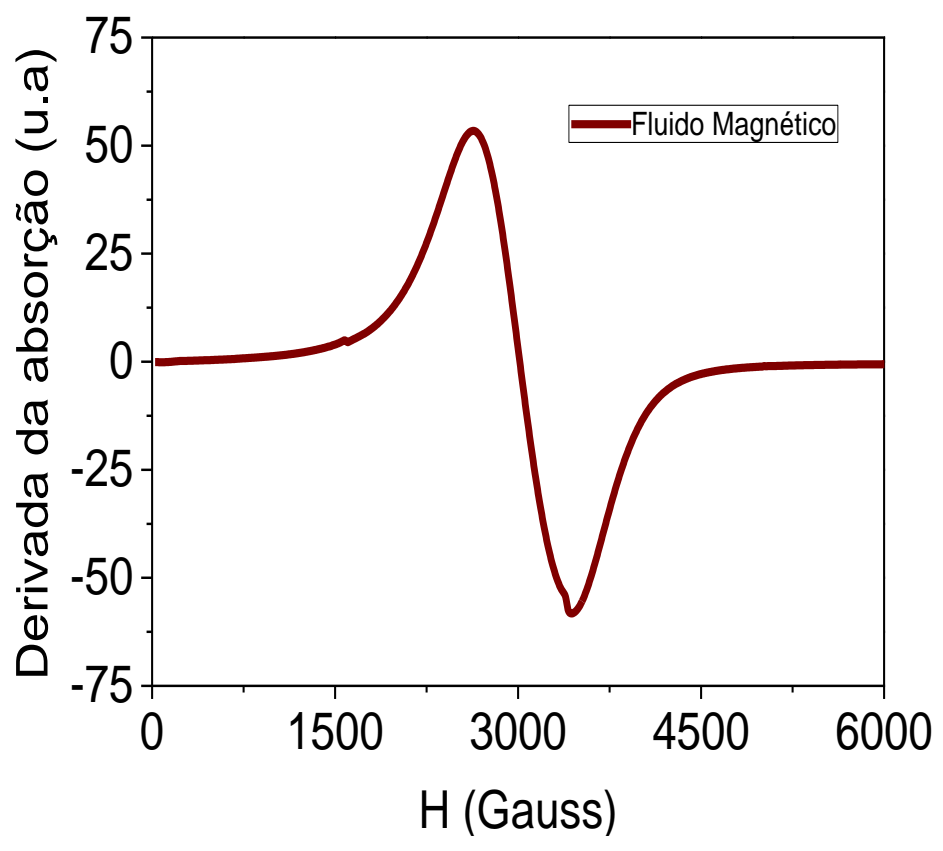

Figura 5.10. Espectro FMR do fluido magnético.

Ao comparar este gráfico, do fluido magnético, aos gráficos gerados mais adiante na seção de Ressonância Ferromagnética dos filmes, do colóide disperso na matriz de copolímero, o sinal de RFM do fluido aparece mais intenso que o do filme com partícula.

\subsection{Filme fino.}

Nesta seção serão apresentados os resultados obtidos das amostras produzidas em forma de Filme fino. Os Filmes produzidos sofreram tratamento térmico à temperatura de $50^{\circ} \mathrm{C}$ durante 5 horas. As amostras produzidas foram rotuladas para identificar cada filme, conforme os parâmetros que os diferencia, levando em conta se a solução de copolímero contém ou não partícula, e se com tratamento térmico ou não, e ainda, qual a diluição do coloide, conforme a tabela 4.1 .

\subsubsection{Caracterização das propriedades estruturais}

A espessura dos filmes produzidos com diferentes diluições foi obtida em um perfilômetro. Todos os nanocompósitos sofreram tratamento térmico à temperatura de $50^{\circ} \mathrm{C}$ durante 5 horas antes das medidas. A tabela 5.2. exibe as espessuras obtidas. 
Tabela 5.2. Espessura das amostras produzidas obtidas por perfilometria.

\begin{tabular}{cc}
\hline Nanocompósito & Espessura (nm) \\
\hline CD & 45 \\
CPD20 & 85 \\
CPD30 & 90 \\
CPD40 & 94 \\
CPD50 & 104 \\
\hline
\end{tabular}

Observa-se na Tabela 5.2 que, com o aumento da concentração do fluido magnético na solução de copolímero a espessura do filme aumenta linearmente, conforme se observa na Figura 5.11.

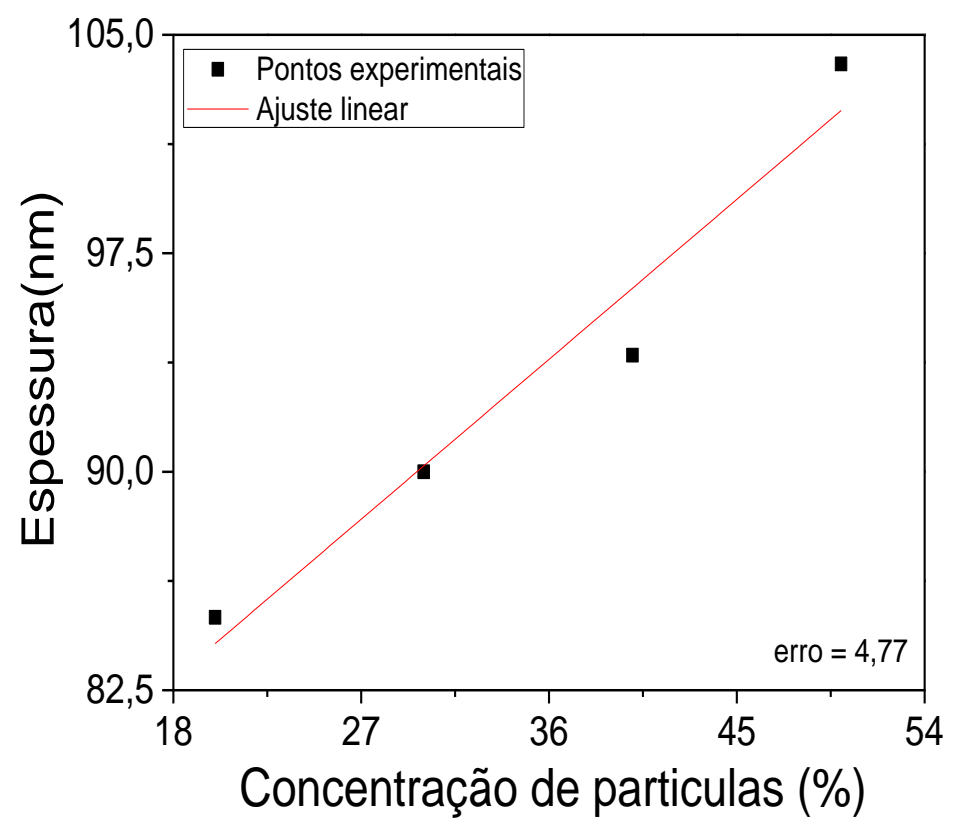

Figura 5.11: Ajuste linear da espessura.

O monitoramento da deposição dos filmes foi obtido por meio de da curvas de absorção para diferentes concentrações de partículas na matriz copolimérica (amostras CD, CPD20, CPD30, CPD40 e CPD50), conforme se observa na figura 5.12. 


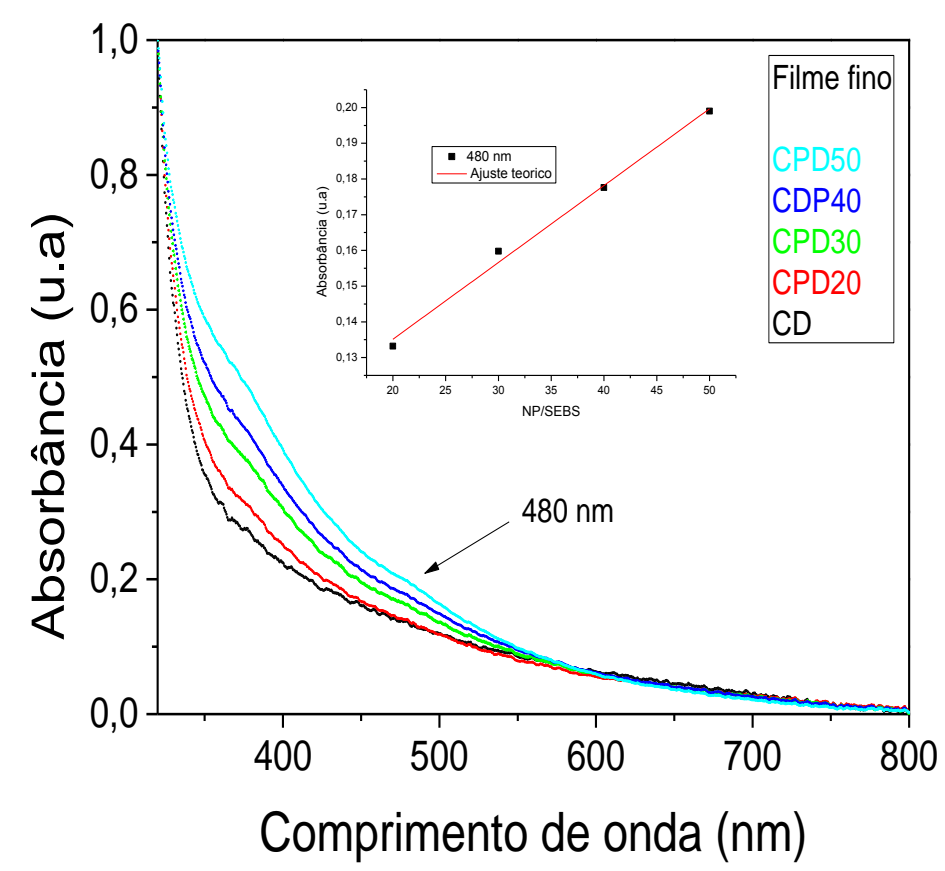

Figura 5.12: Espectros UV-vis obtidos do controle (CD) e do filmes preparados com diferentes concentrações de partículas magnéticas (amostras CD, CPD20, CPD30, CPD40 e CPD50). No interior da figura observa-se o gráfico da absorbância obtida em $480 \mathrm{~nm}$ para as diferentes amostras.

A nanopartícula de óxido de ferro possui duas bandas características, 360 e $480 \mathrm{~nm}$ [19,109]. Para cada diluição, monitorou-se a absorbância da banda em 480 nm, verificandose o aumento linear da absorbância com o aumento do volume do fluido magnético na solução do copolímero SEBS. Como se esperaria, o sinal de transição eletrônica da partícula na banda 480 é proporcional à concentração de nanopartículas na matriz do SEBS.

Para caracterizar as propriedades estruturais dos filmes, foi utilizada a espectroscopia Raman. Um laser de Hélio-Neônio $633 \mathrm{~nm}$ na região de número de onda de 150 á $3200 \mathrm{~cm}^{-1}$ foi usado para excitar os modos vibracionais dos filmes. Esses filmes também foram recozidos à $50^{\circ} \mathrm{C}$ durante 5 horas. 


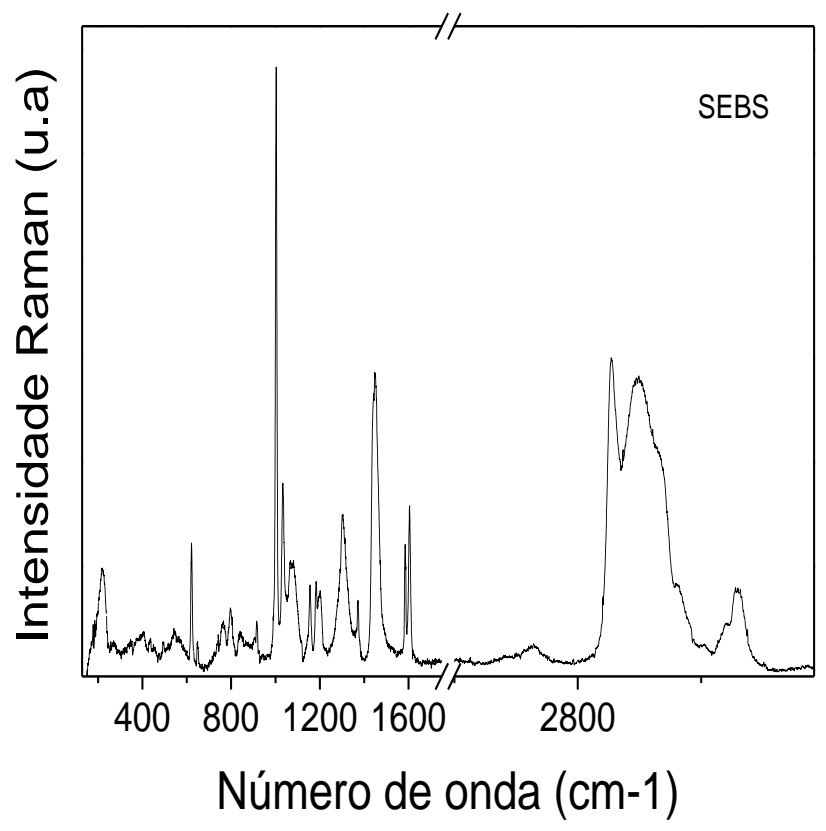

Figura 5.13. Espectro Raman típico do copolímero SEBS na forma de pó (C).

A Figura 5.13 mostra o espectro Raman típico do copolímero SEBS, obtido na forma como foi adquirido, em pó, que pode ser comparado com o espectro disponibilizado pela Sigma Aldrich, (Figura 5.14).

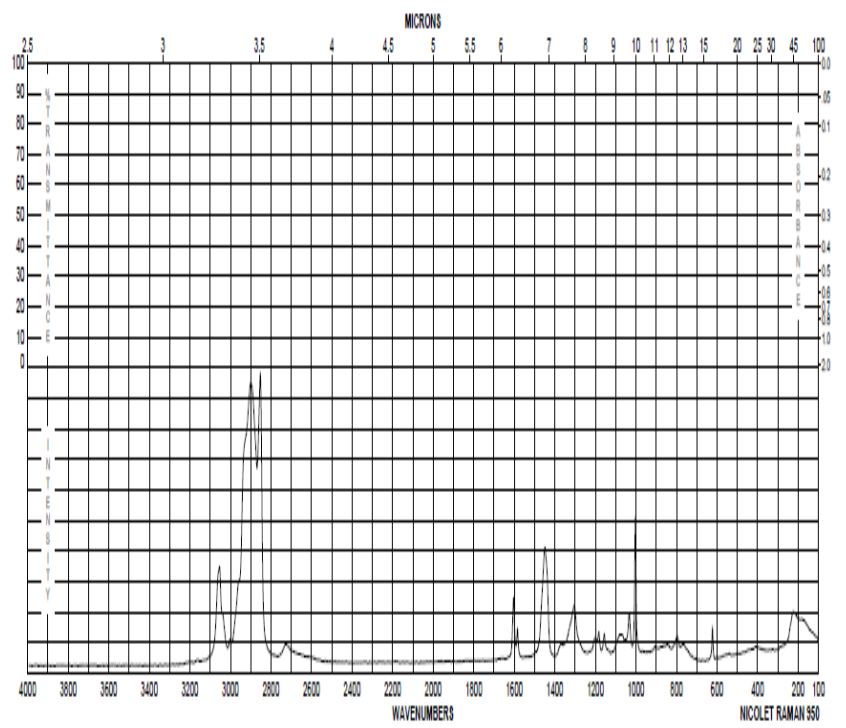

Figura 5.14: Espectro Raman disponibilizado pelo fornecedor do SEBS, Sigma.

Para efeito de atribuição dos modos Raman obtidos experimentalmentes, foram listados na Tabela 5.3, os números de onda referentes aos modos Raman, do pó do 
copolímero obtido neste trabalho, do poliestireno [121] e do copolímero disponibilizado pela Sigma Aldrich. É possível indicar quais modos se referem ao bloco de polímero de cadeia aleatória do poli(etileno-butileno), um dos blocos do copolímero SEBS, enquanto o outro bloco do SEBS é o poliestireno. Portando, todos os modos listados na tabela, que não se relacionam ao poliestireno, e estão presentes na amostra de SEBS, são provenientes dos modos do poli(etileno-ran-butileno). 
Tabela 5.2: Números de onda atribuídos aos modos Raman obtidos do espectro do SEBS (pó), da Sigma Aldrich e do poliestireno [121].

\begin{tabular}{|c|c|c|}
\hline Poliestireno & Sigma Aldrich & SEBS deste trabalho \\
\hline \multicolumn{3}{|l|}{152} \\
\hline & 225 & 224 \\
\hline & 405 & 392 \\
\hline & 540 & 548 \\
\hline 628 & 630 & 627 \\
\hline \multicolumn{3}{|l|}{657} \\
\hline & 765 & 764 \\
\hline & 801 & 802 \\
\hline & 840 & 842 \\
\hline 908 & 908 & 914 \\
\hline \multicolumn{3}{|l|}{952} \\
\hline 1011 & 1001 & 1001 \\
\hline \multirow[t]{2}{*}{1034} & 1042 & 1031 \\
\hline & 1070 & 1075 \\
\hline 1165 & 1153 & 1152 \\
\hline 1190 & 1180 & 1196 \\
\hline 1206 & 1205 & 1208 \\
\hline \multicolumn{3}{|l|}{1275} \\
\hline \multirow[t]{3}{*}{1298} & 1305 & 1304 \\
\hline & 1370 & 1373 \\
\hline & 1450 & 1448 \\
\hline 1592 & 1590 & 1585 \\
\hline 1613 & 1602 & 1603 \\
\hline \multicolumn{3}{|l|}{2464} \\
\hline \multicolumn{3}{|l|}{2507} \\
\hline & 2735 & 2729 \\
\hline 2886 & 2854 & 2853 \\
\hline \multirow[t]{4}{*}{2935} & 2900 & 2896 \\
\hline & 2960 & 2965 \\
\hline & 3000 & 3006 \\
\hline & 3038 & 3038 \\
\hline 3057 & 3058 & 3061 \\
\hline 3138 & & \\
\hline
\end{tabular}


Observa-se nos dados apresentados na Tabela 5.3 pelo menos 13 modos (em vermelho) que ocorrem nas amostras de SEBS, este trabalho e da Sigma Aldrich, que não são atribuídos ao poliestireno. Por outro lado, é perceptível pela mesma tabela, identificar os modos do poliestireno que não aparecem após a formação do copolímero de tri-bloco do SEBS. Esses modos, provavelmente, interagiram de alguma forma com a cadeia de poli(etileno-ran-butileno). Os modos que são comuns apenas ao SEBS mostram um forte indício de que estes sejam relativos á cadeia de poli(etileno-ran-butileno). Alguns desses modos também podem estar relacionados á interação entre as duas cadeias de polímero, mas essas interações não foram avaliadas por este trabalho. É possível notar na tabela que, os modos vibracionais obtidos neste trabalho são relativamente parecidos com os apresentados pela Sigma Aldrich, ou seja, todos os modos vibracionais deste trabalho concordaram com os apresentados pela Sigma.

A Figura 5.15. apresenta os espectros obtidos das amostras C (SEBS na forma de pó), CA (filme de SEBS obtido por spin coating sem tratamento térmico) e CD (filme de SEBS obtido por spin coating após o tratamento térmico), visando compará-los. Observa-se que os modos vibracionais identificados na amostra $C$ conferem com aqueles listados na Tabela 5.2 disponibilizado pela Sigma Aldrich. Considera-se que este resultado confere a confiabilidade dos espectros obtidos neste trabalho.

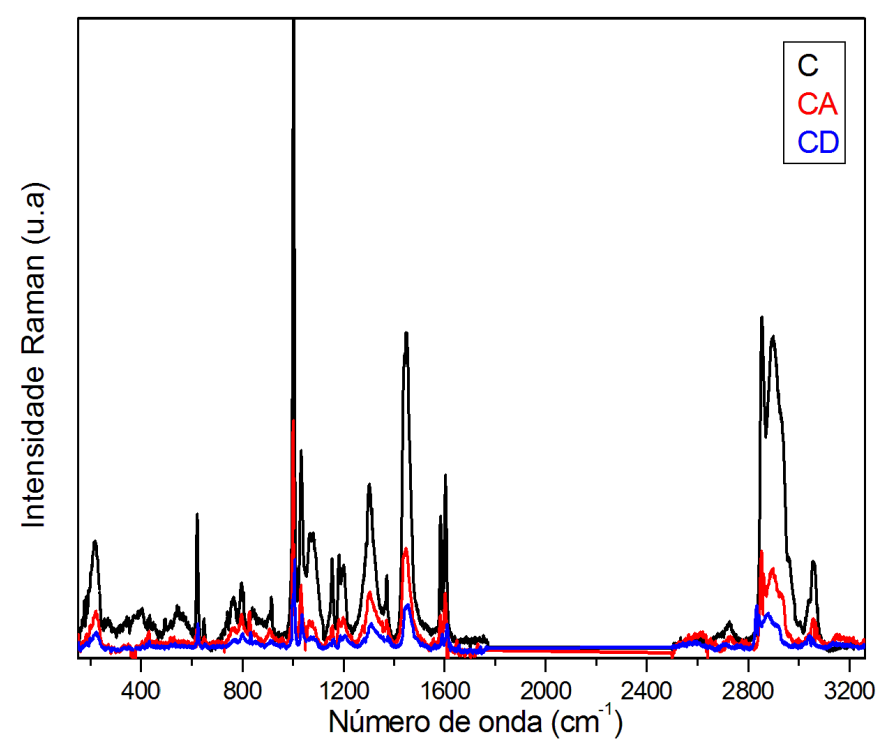

Figura 5.15. Espectros Raman das amostras: C (SEBS na forma de pó, em preto), e do polímero depositado na forma de filme antes do tratamento térmico (CA) em vermelho e após o tratamento térmico (CD), em azul. 
Considerando-se apenas a região na faixa de 170 a $960 \mathrm{~cm}^{-1}$ do espectro da Figura 5.15 é possível visualizar melhor a comparação do espectro obtido do copolímero $\mathrm{C}$ com os dos filmes CA e CD.

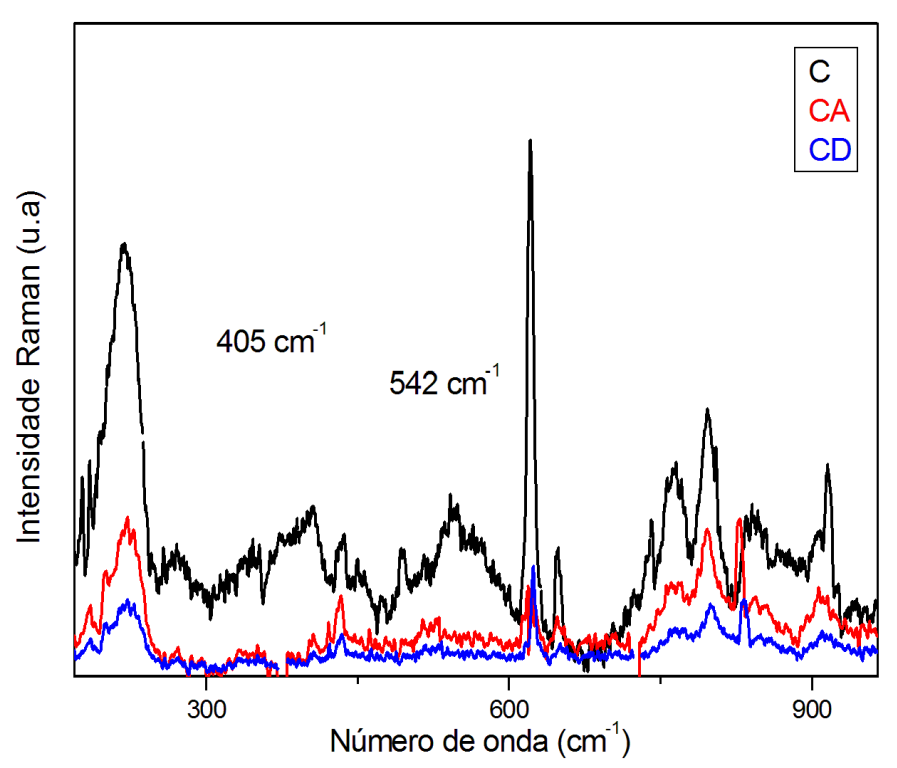

Figura 5.16: Espectros Raman na região entre 170 e $964 \mathrm{~cm}^{-1}$ obtidos das amostras: C (SEBS na forma de pó), em preto, e do polímero depositado na forma de filme antes do tratamento térmico (CA), em vermelho, e após (CD), em azul.

O modo vibracional $548 \mathrm{~cm}^{-1}$ presente no espectro obtido da amostra C ( Figura 5.16) não está presente nos filmes CA e CD. Por outro lado, o modo $405 \mathrm{~cm}^{-1}$ está presente nos dois filmes fino $C A$ e $C D$, porém, muito menos intenso. A molécula do copolímero SEBS é formada por seguimentos em bloco, dois de poliestireno e entre estes, uma macromolécula de polímero composta de etileno e butileno. A massa relativa do bloco de poli(etileno-ranbutileno) é de $70 \%$. A do poliestireno é de aproximados $30 \%$. É provável que, alguns desses atributos do bloco do poli(etileno-ran-butileno), incluindo massa relativa e distribuição aleatória de etileno e butileno, tenha contribuído pela ausência do modo vibracional $548 \mathrm{~cm}^{-1}$ indicados na Figura 5.15. após a formação do filme, caracterizando, portanto, uma interação entre o grupo ligado ao poli(etileno-ran-butileno).

Os blocos de copolímero são hidrofóbicos e a superfície do substrato que o filme fino está depositado também é hidrofóbica. Isto significa que, após a formação dos filmes, estes ficam ligados por interações de Van der Waals. Esta interação poderia ser identificada por meio dos modos vibracionais relativos ao espectro da amostra $\mathrm{C}$, com intensidade aumentada ou diminuída. Entretanto, observa-se na Figura 5.17, em outra região (673 à $1413 \mathrm{~cm}^{-1}$ ) do espectro da Figura 5.15, que, com a formação do filme CA e CD, anterior e 
posterior ao tratamento térmico, novos picos começam a aparecer, primeiro em 1144 e 1147 $\mathrm{cm}^{-1}$ e em maiores números de onda, em 1277 e $1281 \mathrm{~cm}^{-1}$, respectivamente ao CA e CD para as duas regiões. É interessante notar ainda que, o copolímero na forma de pó apresenta uma banda larga na base, cujos picos são 1155 e $1302 \mathrm{~cm}^{-1}$, e a largura da primeira região dos picos citados vai de 1127 à $1169 \mathrm{~cm}^{-1}$ e da segunda, de 1253 à 1352 $\mathrm{cm}^{-1}$. Nessas duas regiões de banda larga é que aparecem os picos da primeira região em 1144 e $1147 \mathrm{~cm}^{-1}$, e os da segunda região em 1277 e $1281 \mathrm{~cm}^{-1}$ quando o SEBS está no formato de filme. Apesar da ausência de partículas na matriz copolimérica, é possível que a própria estrutura do copolímero tri-bloco, constituída de novelos [121], seja ordenada após a influência de fatores externos que dêem mobilidade á estrutura interna do copolímero como, o movimento de rotação no momento da formação do filme durante a deposição, bem como o tratamento térmico [28].

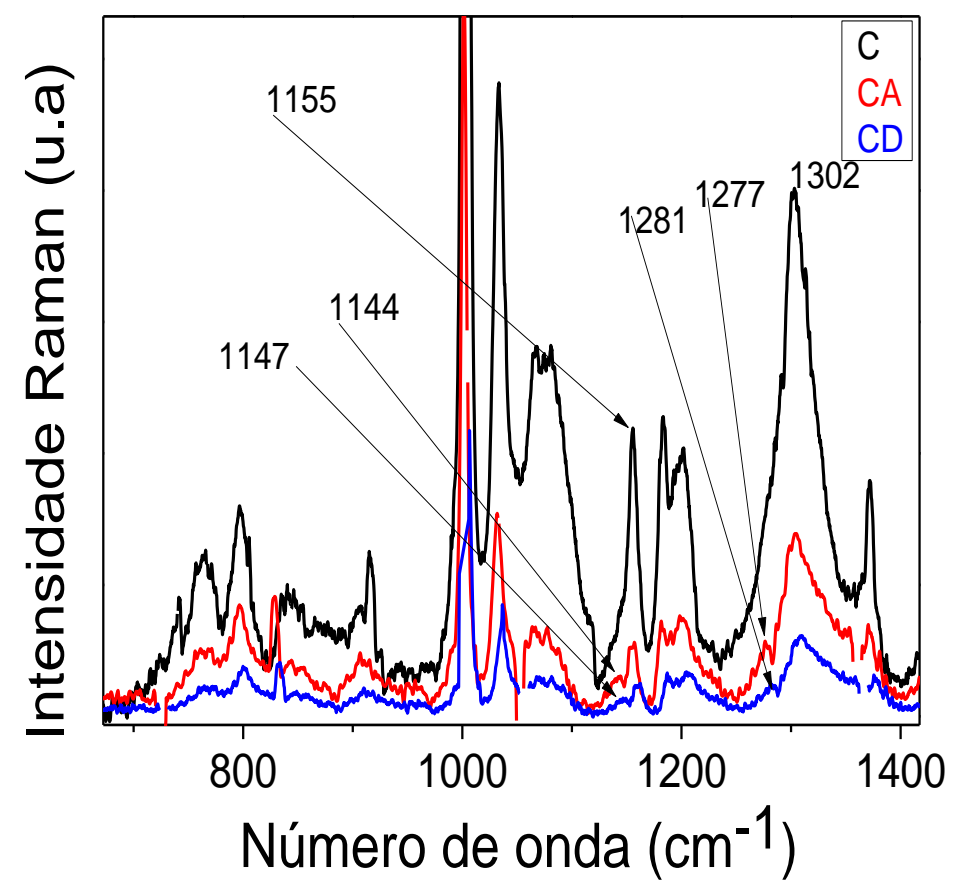

Figura 5.17: Espectros Raman na região entre 673 e $1413 \mathrm{~cm}^{-1}$ obtidos das amostras: C (SEBS - na forma de pó, em preto), e do polímero depositado na forma de filme (CA) antes do tratamento térmico, em vermelho, e após, em azul (CD).

Este ordenamento da estrutura de novelo pode ser entendido como o aparecimento dos picos citados nas amostras de filme em CA e CD. Após o filme recozido, percebe-se pelo gráfico da figura 5.17, na região de 1200 à $1750 \mathrm{~cm}^{-1}$ que os picos em 1584 e $1589 \mathrm{~cm}^{-}$ 
1 deslocaram-se para 1602 e $1609 \mathrm{~cm}^{-1}$. Este deslocamento pode também indicar algum movimento da estrutura de novela no filme após sua formação e o recozimento [34].

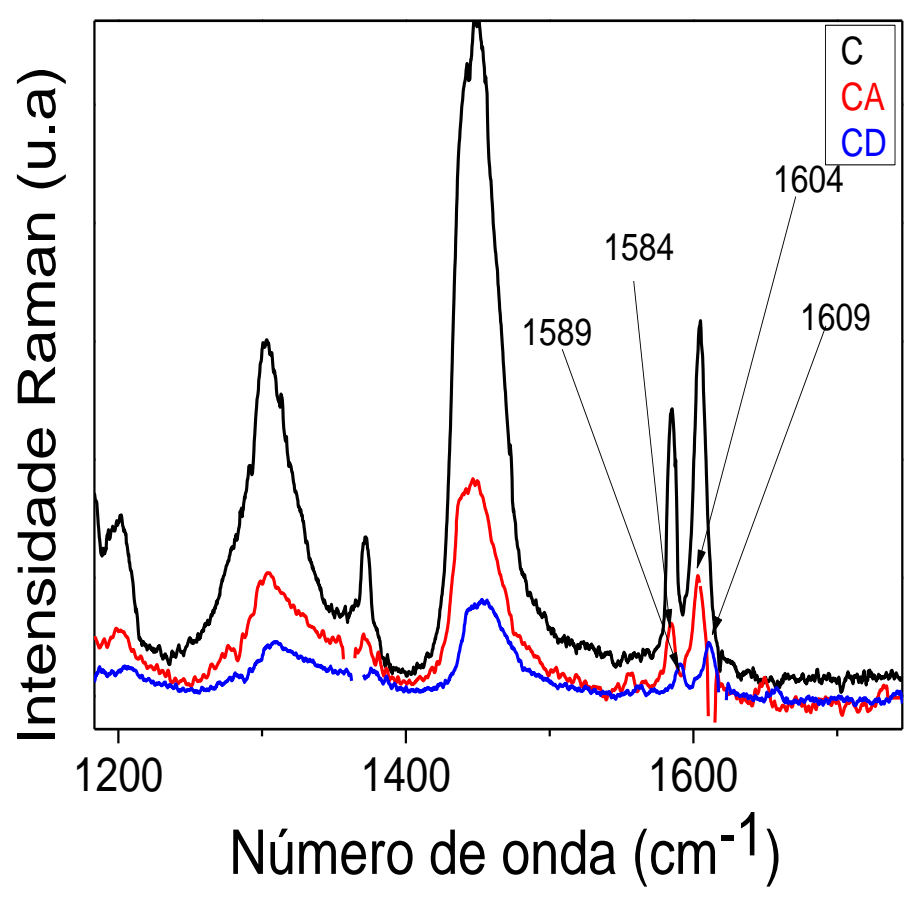

Figura 5.18: Espectros Raman na região entre 1200 à $1750 \mathrm{~cm}^{-1}$ obtidos das amostras: C (SEBS - na forma de pó, em preto), e do polímero depositado na forma de filme (CA) antes do tratamento térmico, em vermelho, e após, em azul (CD).

No caso dos espectros Raman na faixa de 200 a $3200 \mathrm{~nm}$ (figura 5.19) obtidos dos filmes depositados a partir de dispersões contendo o SEBS e nanopartículas, por exemplo, para a o caso da amostra CPD50, observa-se uma nova tendência dos modos vibracionais do espectro Raman, quando comparado ao do filme controle CD. A presença das partículas de magnetita no filme é confirmada pela introdução dos modos vibracionais característicos da mesma: 340, 505 e $673 \mathrm{~cm}^{-1}$ [12]. Segundo os dados da literatura, espera-se que a presença das mesmas influencie no ordenamento, bem como, no processo de ordenamento dos novelos $[45,46,47,48]$. 


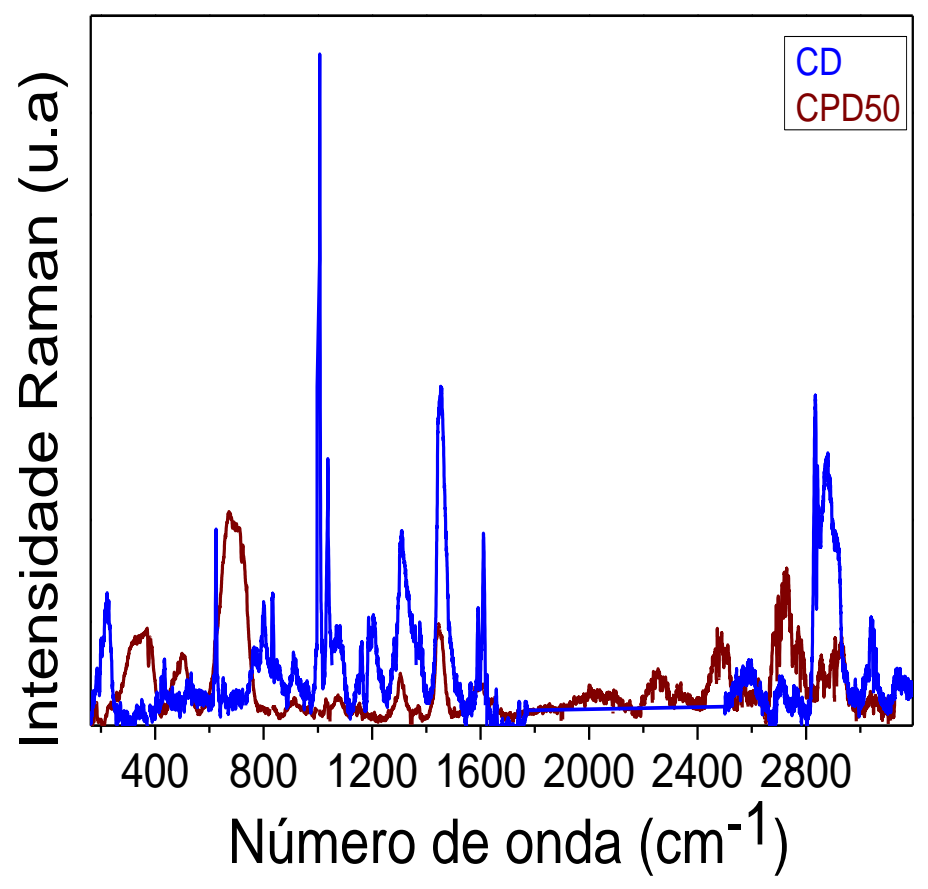

Figura 5.19: Espectros Raman obtidos dos filmes CD e CPD50.

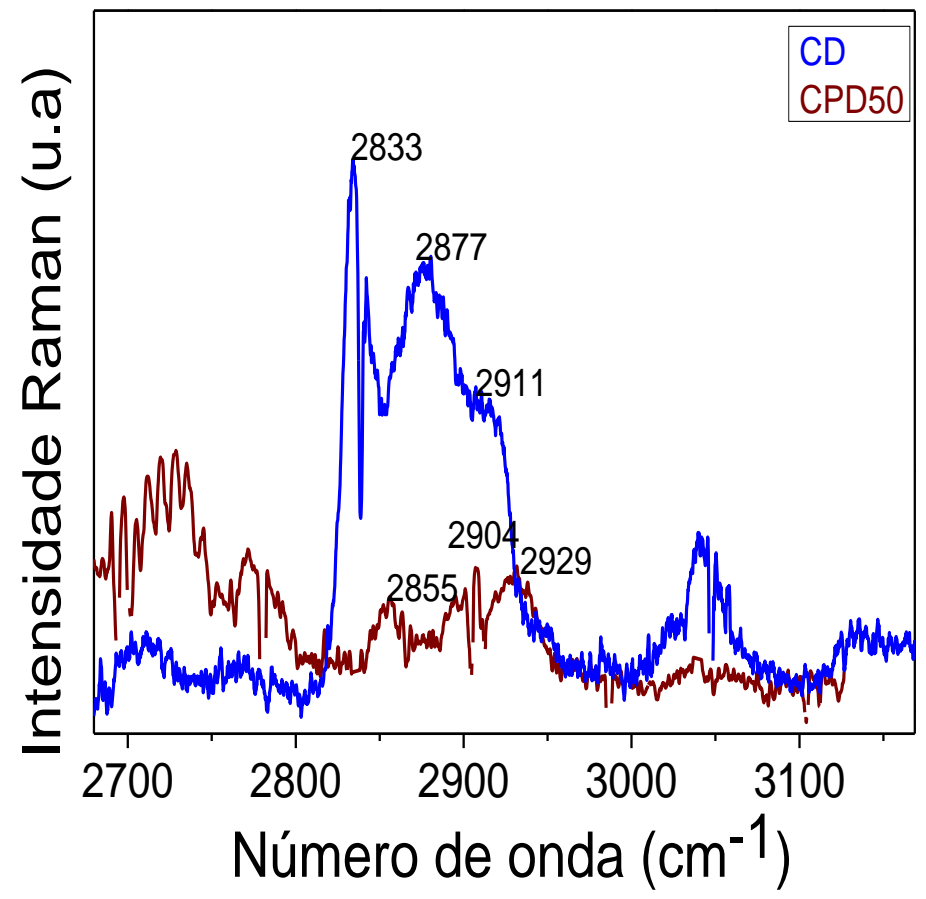

Figura 5.20: Espectros Raman obtidos dos filmes CD e CPD50 para a região entre 2681 e $3165 \mathrm{~cm}^{-1}$.

A Figura 5.20 apresenta em detalhe os espectros Raman obtidos dos filmes CD e CPD50 para a região entre 2681 e $3165 \mathrm{~cm}-1$, cujos modos podem ser relacionados com o 
grupo $-\mathrm{CH}_{2^{-}}$, com o objetivo de estudar a interação da cobertura de ácido oleico com o copolímero. Alguns trabalhos mostram que após o tratamento térmico, além da estrutura de novelo se reordenar dentro do copolímero, partículas magnéticas imersas também se reordenam e migram para dentro dos novelos [34]. Esta nova configuração das partículas dentro do copolímero é devido às estruturas serem quimicamente semelhantes, além do agente de mobilidade como o recozimento do filme. Os modos relativos ao grupo $\mathrm{CH}_{2}$ para o filme sem partícula CD têm os picos 2833, 2877 e $2911 \mathrm{~cm}^{-1}$, deslocados no filme com partícula CPD50 para 2855, 2904 e $2929 \mathrm{~cm}^{-1}$. Estes deslocamentos de 22, 27 e $18 \mathrm{~cm}^{-1}$, sugerem o ordenamento dos novelos, inicialmente por rotação da solução copolímero/partícula, antes do filme se tornar rígido e também, devido ao tratamento térmico, dando consistência ao filme $[28,34,48]$ e reordenando a estrutura.

\subsubsection{Propriedades magnéticas}

As propriedades magnéticas do filme híbrido (CPD50) foram estudadas por meio da técnica VSM à temperatura ambiente. A curva de magnetização em função do campo magnético aplicado pode ser observada na figura 5.21 e 5.22. Nesse estudo, é avaliada a resposta magnética a partir das distintas técnicas de produção do filme fino híbrido e a interação partícula e matriz copolimérica.

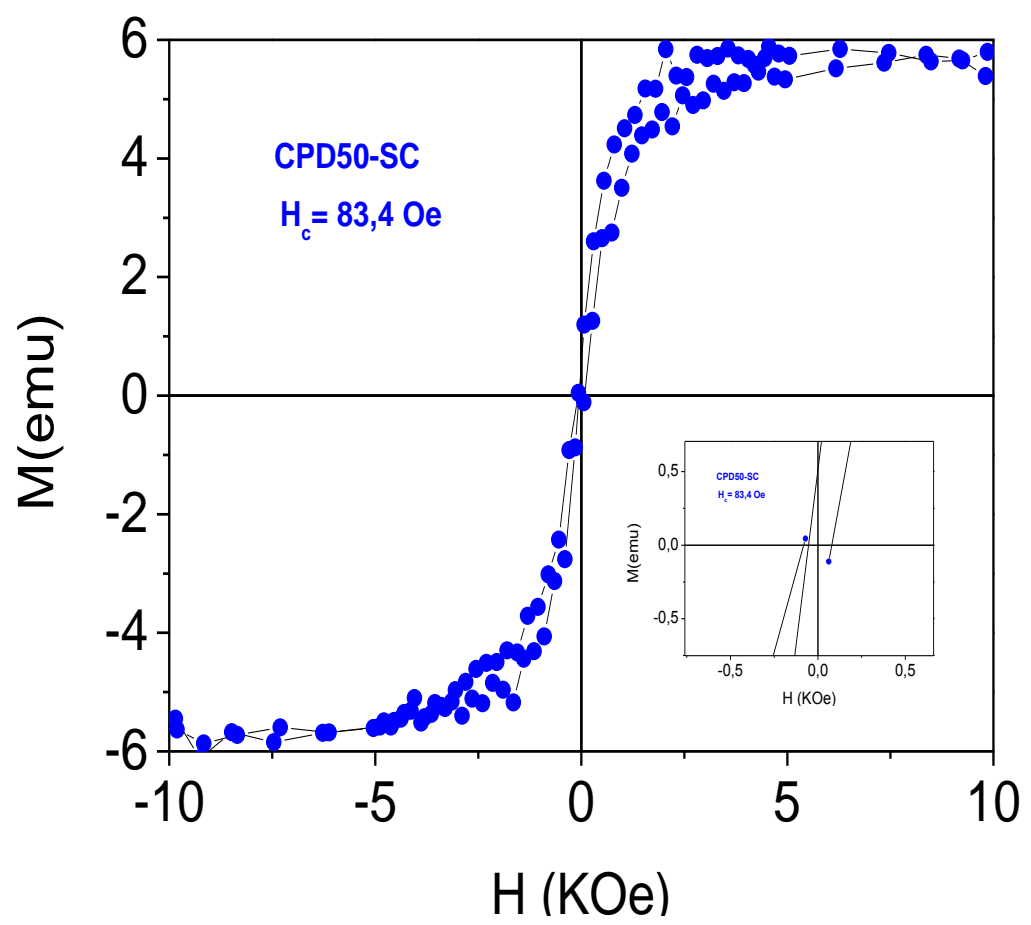

Figura 5.21. Curva de magnetização em função do campo magnético aplicado do filme CPD50, depositado por meio da técnica spin coating. 


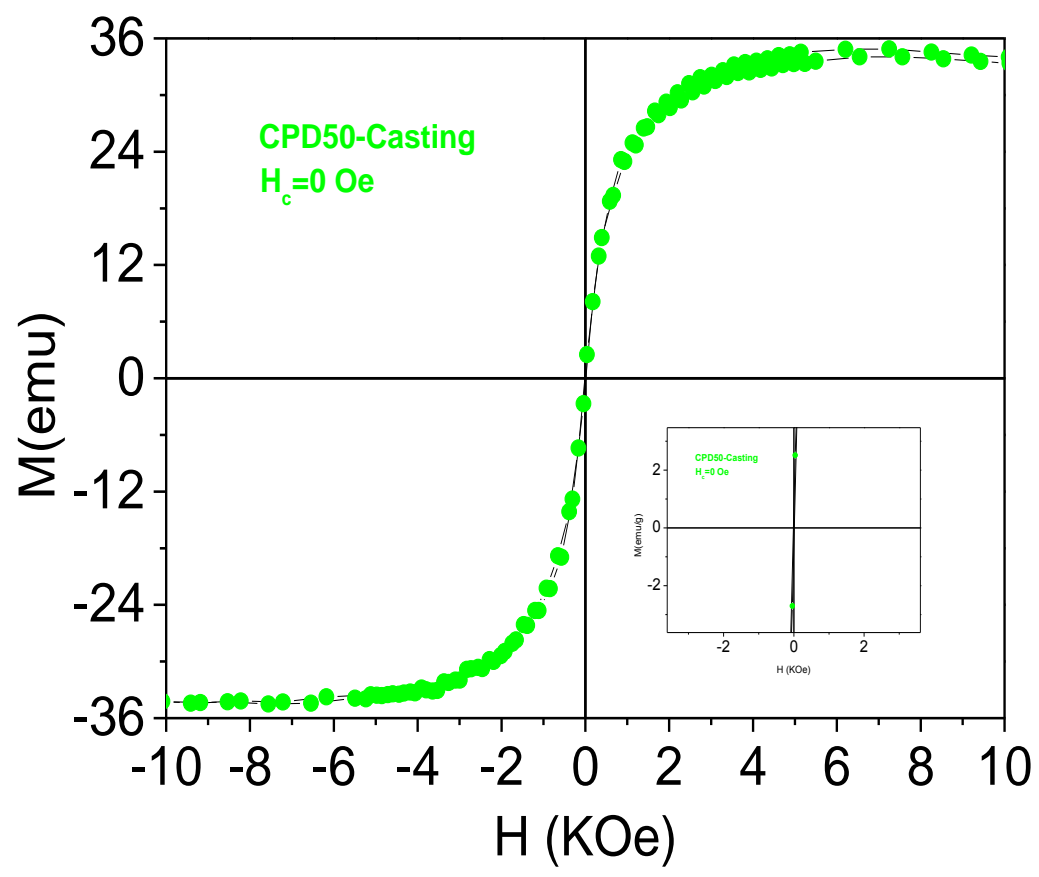

Figura 5.22. Curva de magnetização em função do campo magnético aplicado do filme CPD50, depositado por casting.

O valor da magnetização de saturação é dada por $M_{s} \approx 36$ emu e $M_{s} \approx 6$ emu para o filme fino produzido a partir do método Casting e Spin-coating, respectivamente. A magnetização de saturação do filme produzido por Casting está de acordo com a literatura [23]. Observa-se nas curvas apresentadas nas Figuras 5.21 e 5.22 a presença das partículas de óxido de ferro no filme fino, e que as mesmas apresentam comportamento superparamagnético, assim como antes de serem arranjadas na matriz copolimérica não magnética. Observa-se também que, em ambas as amostras, produzidas pelas duas técnicas, que a magnetização de saturação é produzida por spin-coating é quase seis vezes menor do que aquela apresentada pela amostra produzida pelo método Casting. Isto acontece porque, no processo de formação do filme fino pelo método de spin coating, grande parte da dispersão deixa o substrato, o que deixa-o composto minoritariamente por partículas em relação ao método Casting todo o material sólido é depositado enquanto o solvente é evaporado lentamente. No sinal observado na curva de magnetização em função do campo magnético externo aplicado, o campo coercivo e a magnetização remanescente são nulos. Além disso, o tamanho das partículas magnéticas, mostrada na seção do MET, ficou abaixo do tamanho crítico, indicando que o arranjo das partículas no filme fino híbrido manteve o comportamento superparamagnético, indicando que às partícula não interagem entre si por conta da cobertura da molécula de ácido oleico na superfície. 
A matriz copolimérica que compõem o filme fino é constituída de blocos de polímeros e nenhum desses blocos são polímeros condutores ou sequer são protonados, o que ajudaria no transporte de cargas. Este fato poderia induzir propriedades magnéticas na matriz copolimérica.

\subsubsection{Medidas de Ressonância Ferromagnética}

As figuras 5.23 e 5.24 mostram os espectros de ressonância obtidos para as amostra CPD40, e CPD50, respectivamente. Os espectros foram obtidos para diferentes ângulos entre a direção perpendicular à superfície do filme e a direção do campo magnético aplicado.

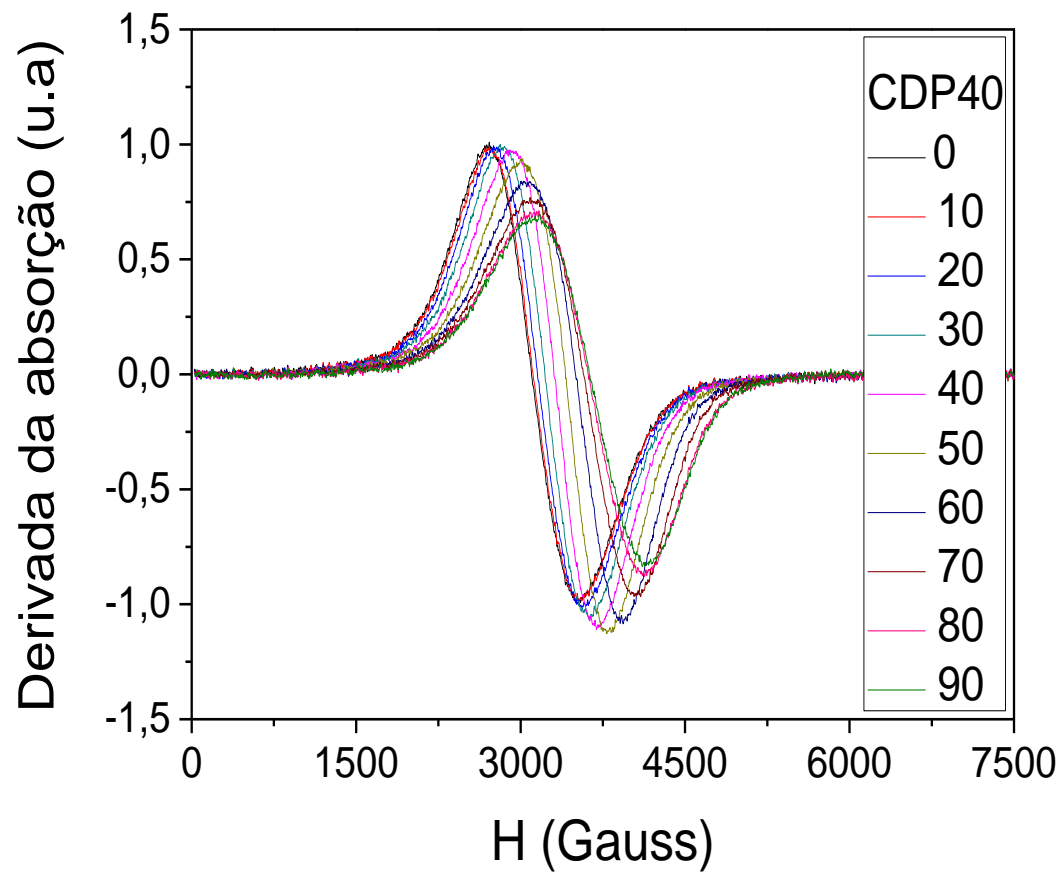

Figura 5.23. Espectros de ressonância ferromagnética. Medidas da intensidade em função do ângulo para a amostra CPD40. 


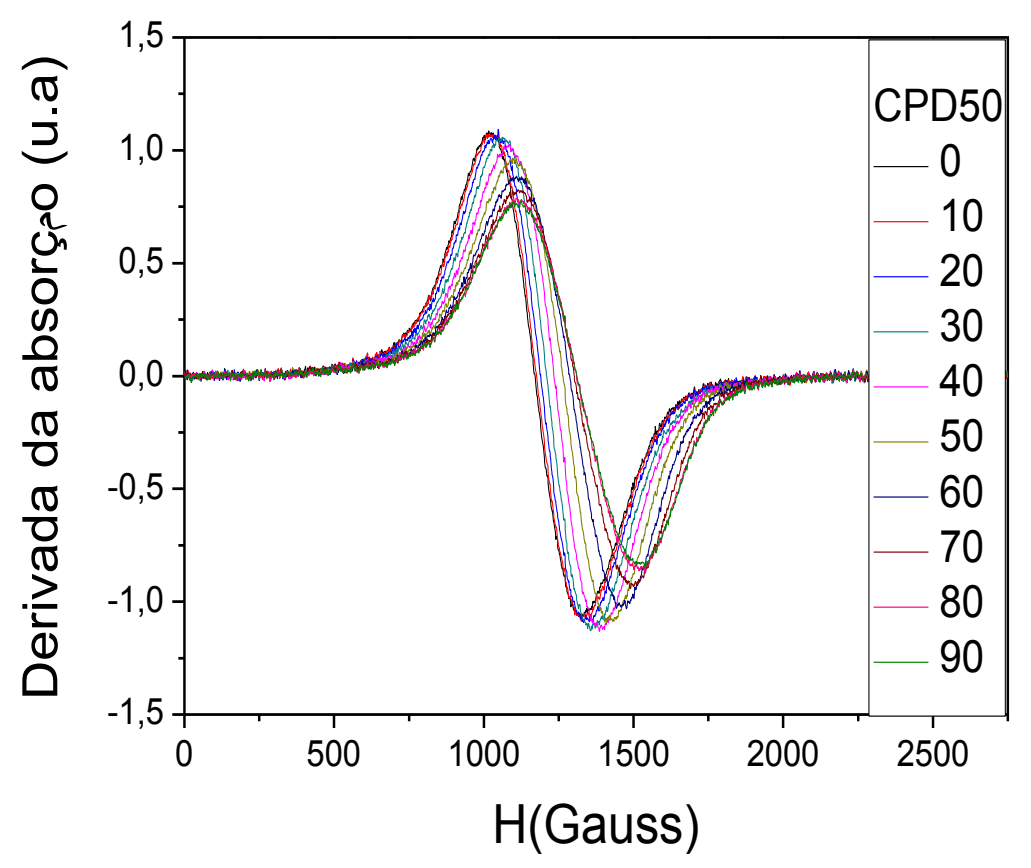

Figura 5.24. Espectros de ressonância ferromagnética. Intensidade em função do ângulo para a amostra CPD50.

Observa-se nas Figuras 5.23 e 5.24 um deslocamento do campo de ressonância com a variação angular, para as duas amostras. Estes deslocamentos foram de 480 e $99 \mathrm{G}$, respectivamente, para as amostras de filmes CPD40 e CPD50. Comparando-se as intensidades dos sinais de ressonância ferromagnética dos filmes CPD40 e CPD50, verificase que a amostra com maior concentração de nanopartículas de maguemita (CPD50) é mais intensa, resultado esperado pois, esta amostra possui maior número de centros magnéticos.

As próximas figuras 5.25 e 5.26, são relativas as medidas do sinal de ressonância ferromagnética dos filmes CPD40 (em vermelho) e CPD50 (em preto). Essas medidas foram feitas em função de duas variáveis. Além da concentração de partículas no filme, as medidas também foram realizadas em função da incidência do campo aplicado, paralelo e perpendicular a superfície. 


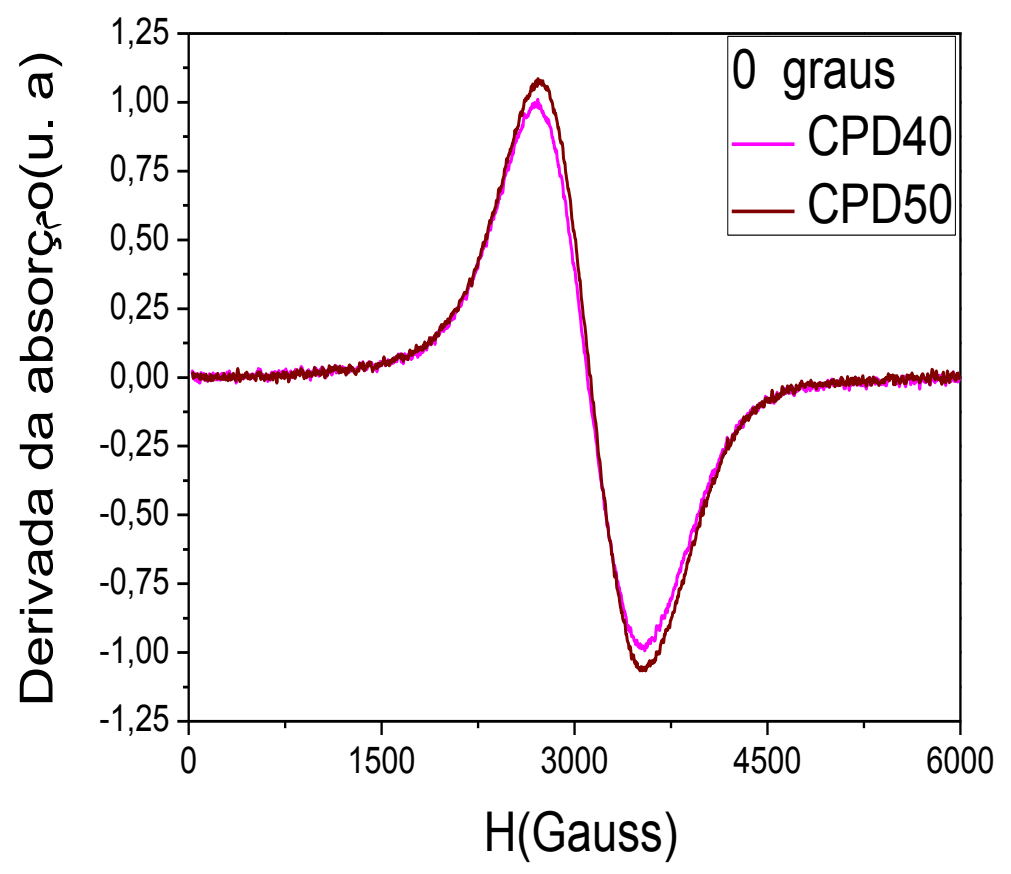

Figura 5.25. Espectro de FMR do filme de CPD40 e 50. Comparação com a direção paralela do campo magnético aplicado.

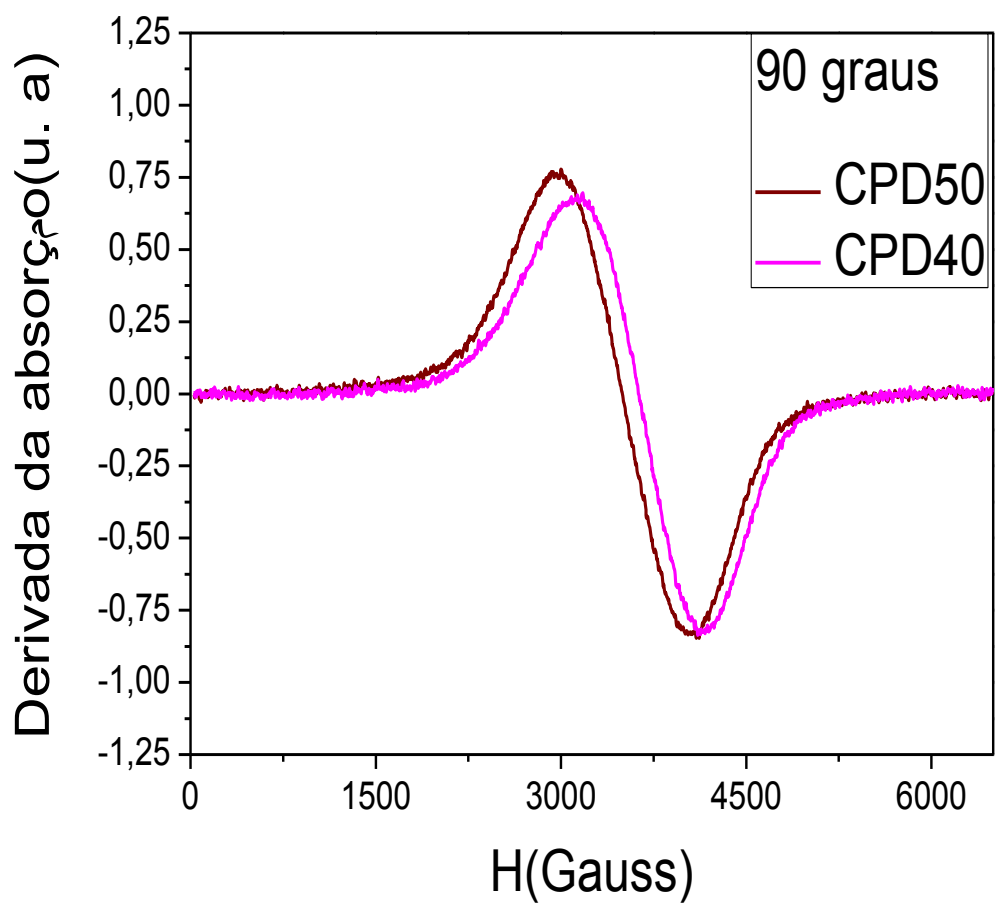

Figura 5.26. Espectro de FMR do filme de CPD40 e CPD50. Comparação com a direção perpendicular ao campo magnético aplicado.

Comparando se pode observar, o sinal de ressonância ferromagnética privilegia a presença da maior quantidade de partícula no filme, isto é, a absorção foi maior para o CPD50 em ambas as medidas, paralela e perpendicular a superfície do filme. 


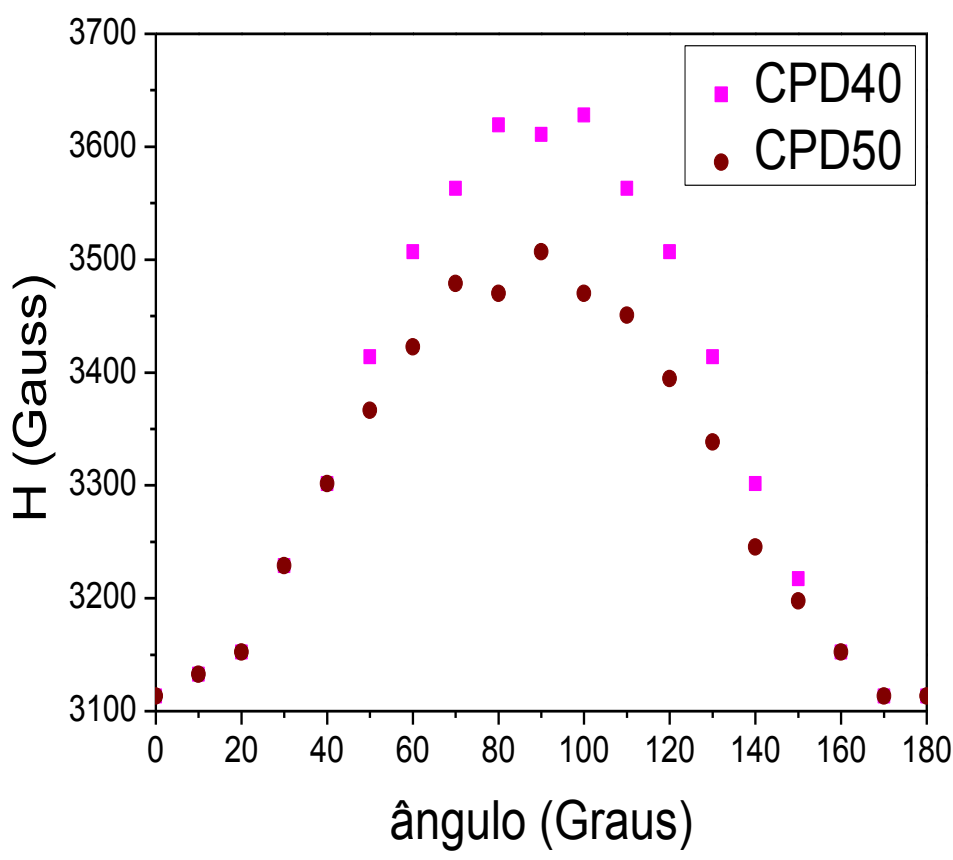

Figura 5.27. Comportamento do campo ressonante em função de vários ângulos para as amostras CPD40 e CPD50.

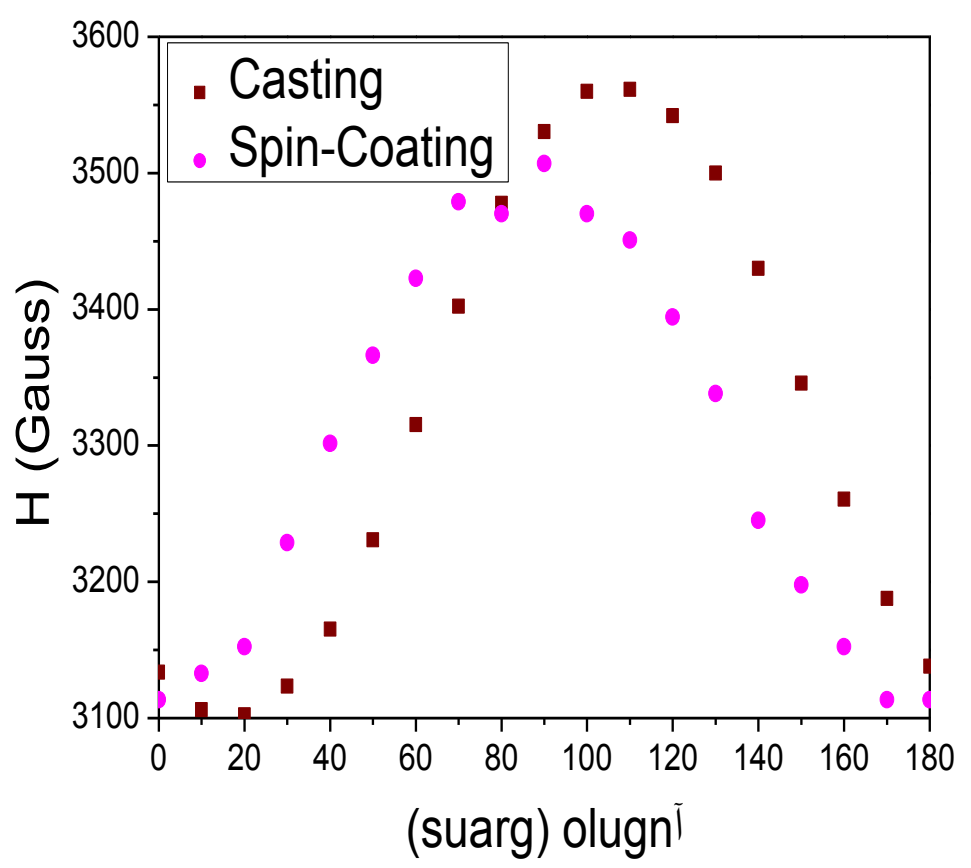

Figura 5.28. Comportamento do campo ressonante em função de vários ângulos para as amostras CPD50 depositadas por spin-coating e casting.

O gráfico da figura 5.27 e 5.28 representa o campo magnético aplicado em função do ângulo. Para o primeiro, a comparação é entre dois filmes, depositados pela mesma técnica, com diferentes concentrações de partículas em relação ao copolímero. A técnica de 
deposição foi a Spin coating. No segundo, a comparação foi entre técnicas, spin coating e casting. A concentração de partículas é a mesma nos dois filmes, CPD50.

Observa-se que em ambos os gráficos que, o campo magnético aplicado na direção perpendicular à amostra de filme é máximo, enquanto que para configuração paralela é mínima. Neste caso, a direção de fácil magnetização dos filmes produzidos é a direção perpendicular à de aplicação do campo magnético.

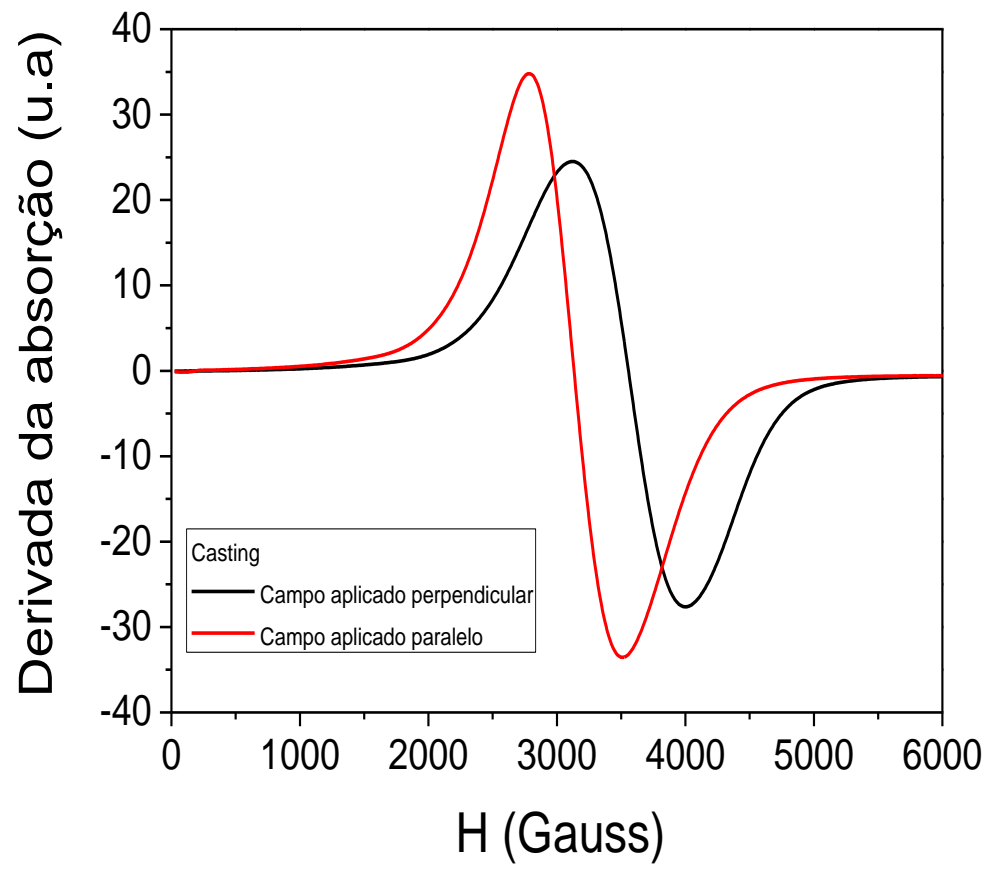

Figura 5.29. Espectro FMR da amostra CPD50-casting com campo magnético aplicado paralelamente e perpendicularmente à superfície do filme.

Na Figura 5.29 um dos sinais da curva de FMR representa, em linha preta, o campo incidente perpendicular à superfície do filme, enquanto em vermelho, representa a medida FMR do campo incidente, paralelamente à superfície do filme. A intensidade da derivada da absorção diminuiu quando o campo incidente é de $90^{\circ}$.

Nestas medidas de FMR de filme depositados por Casting, pode-se observar que, o eixo de fácil magnetização corresponde àquele cujo campo magnético aplicado seja $90^{\circ}$ ou próximo deste ângulo. A anisotropia magnética está associada ao eixo de fácil magnetização. O maior deslocamento do campo ressonante ocorreu na direção perpendicular à superfície do filme. A absorção ressonante pode ser entendida por conta da existência de aglomerados de partículas dentro da matriz copolimérica. Um aumento dessa absorção pode indicar um maior número partículas. O campo aplicado na direção paralela mostrou a intensidade do sinal do RFM maior que o sinal RFM do campo aplicado na perpendicular. 


\section{CAPÍTULO 6}

\section{Conclusões e perspectivas}

O coloide magnético preparado a partir da síntese das partículas magnéticas foi empregado como fonte de nanopartículas de óxidos de ferro, para a produção de filmes finos híbridos com a matriz copolimérica de poliestireno-bloco-poli(etileno-ran-butileno)bloco-poliestireno. O coloide, o sólido nanoparticulado, bem como os filmes foram caracterizados por meio das técnicas de espectroscopia Raman, UV-vis e no infravermelho, microscopia eletrônica de transmissão, análise termogravimétrica TG, perfilometria e medidas magnéticas. Os resultados mostraram que as partículas sintetizadas apresentaram diâmetro de 5,81 \pm 0,08nm e desvio de 0,22 $\pm 0,02$. O diâmetro da partícula é menor que o tamanho crítico, o que indica o comportamento superparamagnético, que foi observado nas curvas de magnetização em função do campo magnético aplicado, bem como coercividade nula. A presença da cobertura de ácido oleico foi evidenciada por meio das técnicas de espectroscopia Raman e no infravermelho, bem como de termogravimetria, indicando que as moléculas de ácido oleico coordenam por meio de grupos carboxilato ao íon de ferro da partícula via ligação bidentada em ponte.

A presença das partículas dispersas na matriz copolimérica foi confirmada por meio das técnicas de espectroscopia de UV-vis e Raman, bem como das medidas magnéticas. Uma banda característica dos óxidos de ferro em $480 \mathrm{~nm}$ presente nos espectros UV-vis, teve sua absorbância aumentada linearmente com o aumento da concentração de nanopartículas de óxidos de ferro da dispersão empregada para deposição dos filmes. As espessuras, na faixa de 45 a $104 \mathrm{~nm}$, aumentam linearmente com a concentração de nanopartículas no filme. Os espectros Raman dos filmes, quando comparados com os espectros de cada uma das diferentes amostras que formam o filme, mostraram a presença das nanopartículas embebidas na matriz, bem como que a estrutura interna de novelos do polímero sofreu um reordenamento. As medidas magnéticas mostraram que os filmes apresentam comportamento superparamagnético.

Com relação às perspectivas para a continuidade do trabalho, sugere-se a análise da morfologia da superfície por meio das técnicas de microscopia de força atômica e de varredura, bem como de microscopia de força magnética. 


\section{Referências bibliográficas}

[1]SIEGRIST, T.; VANDERAH, T.A.; Combining Magnets and Dielectries: Crystal Chemistry in the $\mathrm{BaO}-\mathrm{Fe}_{2} \mathrm{O}_{3}-\mathrm{TiO}_{2}$ system. Eur. J. Inorg. Chem. v. 2003, p. 1483-1501, 2003.

[2]KAZANTSEVA, N. E.; et al.; J. Commun. Technol. Electron. v. 48, p. 173, 2003.

[3]BUERKLE, A.; SARABANDI, K.; A Wide-Band, Circularly Polarized, Magnetodielectric Resonator Antenna. IEEE Trans. Antennas Propag. v. 53, p. 3436, 2005.

[4]ALCÂNTARA, G. B., et al.; Dielectric properties of cobalt ferrite nanoparticles in ultrathin nanocomposite films. Phys.Chem. Chem. Phys., v. 15, p. 19853-19861, 2013.

[5]ALCÂNTARA, G. B., et al.; Layer-by-Layer assembled Cobalt Ferrite Nanoparticles for Chemical Sensing. Journal Of Nanofluids., v. 2, p. 175-183, 2013.

[6]DAI, Q., et al. Self-assembly Ferrimagnet-polymer composites for magnetic recording media. Nano lett. v.10, p. 3216-3221, 2010.

[7]SALES, F. V., et al.; Investigation of optical and structural properties of InGaAs/GaAS quantum wells grown on vicinal GaAs (001) substrates. Physica. B, Condensed Matter. , v.311, p.285 - 291, 2002.

[8]SALES, F. V., et al.; Carrier kinetics in quantum dots through CW photoluminescence modeling: a systematic study on a sample with surface dot density gradient. Journal of Applied Physics. , v. 94, p.1787 - 1794, 2003.

[9]TRIPATHI, A. K., et al.; Structural, optical and photoconductivity Structural OF Sn and Mn doped TiO2 nanoparticles. Journal of Alloys and Compounds, v. 622, p. 37-47, 2015.

[10]MELO, T.; et al.; Investigation of surface passivation process on magnetic nanoparticles by Raman spectroscopy. Surface Science. v. 600, p.3642 - 3645, 2006.

[11]NUNES, E. S., et al.; Evidence of iron (III) reduction in $\mathrm{y}-\mathrm{Fe}_{2} \mathrm{O}_{3}$ nanoparticles due to meso-2,3-dimercaptosuccinic acid functionalization. Materials Research Express, v.1, p.01610, 2014. 
[12]VIALLI, W. R., et al Investigation of the Molecular Surface Coating on the Stability of Insulating Magnetic Oils. J. Phys. Chem. C, v. 114, p. 179-188, 2010.

[13]MORAIS, P.C., et al., Tailoring Magnetic Nanoparticle for Transformers Application. Journal of Nanoscience and Nanotechnology. v.10, p. 1-4, 2010.

[14]YOO, D. et al. Theranostic magnetic nanoparticles, Acc. Chem. Res., v. 44, p. 863-874, 2011.

[15]SOLER, M. A. G., Paterno, L. G., Cap. 6. Nanomateriais magnéticos. Nanoestruturas: Princípios e aplicações. Coleção nanociência e nanotecnologia. v.1. p.175-221, 2015.

[16]SUNDAR, S.; et al.; Synthesis and characterization of amine modified magnetite nanoparticles as carriers of curcumin-anticancer drug. Powder Technology, v. 266, p. 321328, 2014.

[17]SOLER, M.A.G., et al., Interaction of Erythrocytes with magnetic nanoparticles. Journal of Nanoscience and Nanotechnology. v.7, p.1069-1071, 2007.

[18]PEDROZA, R., et al.; Raman study of nanoparticle-template interaction in a CoFeO/SiObased nanocomposite prepared by sol gel method. Journal of Magnetism and Magnetic Materials. , v. 289, p.139 - 141, 2005.

[19]PATERNO, L. G., et al.; Magnetic Nanocomposites fabricated via layer by layer approach. J. Nanosci. Nanotech. 10, 2679-2685, 2010.

[20]ALCANTARA, G. B., et al.; Morphology of cobalt ferrite nanoparticle-polyelectrolyte multilayered nanocomposites. J. Magn. Magn. Mater. 323 (2011) 1372-1377, 2011.

[21]PATERNO, L. G., et al.; Tuning of magnetic dipolar interactions of maghemite nanoparticles embedded in polyelectrolyte layer-by-layer films. J. Nanosci. Nanotech., v. 12, p. 6672-6678, 2012.

[22]SOLER, M. A. G, et al.; Assembly of $\gamma-\mathrm{Fe}_{2} \mathrm{O}_{3} /$ polyaniline nanofilms with tuned dipolar interaction. J. Nanopart. Res. 1414:653-10, 2012. 
[23]YANG, T., et al.; Magneto-dielectric properties of polymer- $\mathrm{Fe}_{3} \mathrm{O}_{4}$ nanocomposites. Journal of Magnetism and Magnetic Materials. v. 320, p. 2714-2720, 2008.

[24]HUR, J and Bae, J. Solvent induced conversion of microdomain structure in block copolymer electrolyte thin films Journal of Industrial and Engineering Chemistry, v. 21, p. 851-855, 2015.

[25]PATERNO, L. G., et al.; Layer-by-layer assembly of bi-functional nanofilms: Surfacefunctionalized maghemite hosted in polyaniline. J. Phys. Chem. C v. 113, p. 5087- 5095, 2009

[26]NEUMANN, R. F., et al., Morphology and magnetism of multifunctional nanostructured $\mathrm{Y}^{-}$ $\mathrm{Fe}_{2} \mathrm{O}_{3}$ films: Simulation and experiments. J. Magn. Magn. Mater. v. 347, p. 26-32, 2013.

[27]KITTEL, C., Theory of the Structure of Ferromagnetic domains in films and small particles. Phys. Rev. v. 70, p. 965, 1946.

[28]LIN, Y., et al., Nanoparticle-Driven Assembly of Block Copolymers: A Simple Route to Ordered Hybrid Materials. J. Am. Chem. Soc. v. 133, p. 6513-6516, 2011.

[29]HAMMOND, M. R., et al., Mutual Alignment of Block Copolymer-Magnetic Nanoparticle Composites in a Magnetic Field. Macromolecules, v. 43, p. 8340-8343, 2010.

[30]NGO, A. T., PILENI, M. P.; Cigar-shaped ferrite nanocrystals: Orientation of the easy magnetic axes. J. Appl. Phys. v. 92, p. 4649-4652, 2002.

[31]YAO, Y., et al., Self-Assembly of Diblock Copolymer-Maghemite Nanoparticle Hybrid Thin Films. ACS Appl. Mater. Interfaces. v. 6, p. 18152-18162, 2014.

[32]HORECHYY, A., et al., Nanoparticle directed domain orientation in thin films of asymmetric block copolymers. Colloid Polym Sci, v. 292 : p. 2249-2260, 2014.

[33]CHEN, H. RUCKENSTEIN, E. Journal of Colloid and Interface Science v. 363, p. 573$578,2011$. 
[34]MOTTAKIN M. ABUL KASHEM., et al., Array of Magnetic Nanoparticles via Particle Cooperated Self-Assembly in Block Copolymer Thin Film. Macromolecules, v. 42, p. $6202-$ 6208, 2009.

[35]PATTERSON, G., A prehistory of polymer Science. Springer, 2012.

[36]KUMAR, N., et al., Adv.Drug Deliv.Rev., 53, 23, 2001.

[37]YOKOYAMA, M., Crit. Rev. Drug Carr. Sys., 9 213, 1992.

[39]SAKURAI, s. Progress in control of microdomain orientation in block copolymers Efficiencies of various external fields. Polymer, v.49, p. 2781 - 2796, 2008.

[40]LIN, Y. Et al.,Self-directed self-assembly of nanoparticles/copolymer mixtures. NATURE. v .434, 3 MARCH, 2005.

[41]BALAZS, A. C. Interactions of nanoscopic particles with phase-separating polymeric mixtures. Curr. Opin. Colloid Interf. Sci. v. 4, p. 443-448, 2000.

[42]LEE, J. Y., SHOU, Z. \& BALAZS, A. C. Modeling the self-assembly of copolymernanoparticle mixtures confined between solid surfaces. Phys. Rev. Lett. v. 91, 136103, 2003.

[43]LEE, J. Y., SHOU, Z. \& BALAZS, A. C. Predicting the morphologies of confined copolymer/nanoparticle mixtures. Macromolecules. v. 36, p. 7730-7739, 2003.

[44]HAMDOUN, B., et al., Copolymer nanoparticles composites: Lamellar period. J.Phys. II v. 6, p. 503-510, 1996.

[45]BOCKSTALLER, M. R. AND THOMAS, E. L. Proximity effects in self-organized binary particle-block copolymer blends. Phys. Rev. Lett. v. 93, p. 166106, 2004.

[46]CHEN, H. AND RUCKENSTEIN, E. Nanoparticle aggregation in the presence of a block copolymerJ. Chem. Phys. v. 131, p. 244904, 2009.

[47]CHIU, J. J.; et al.; Control of Nanoparticle Location in Block Copolymers. J. J. Am. Chem. Soc. v. 127, 5036, 2005. 
[48]CHIU, J. J.; et al.; Distribution of Nanoparticles in Lamellar Domains of Block Copolymers. Macromolecules. v. 40, p. 3361-3365, 2007.

[49]ZOU, S.; et al.; Ordered CdSe Nanoparticles within Self-Assembled Block Copolymer Domains on Surfaces. Langmuir. v. 23, p. 1612-1614, 2007.

[50]HUH, J.; GINZBURG, V. V.; BALAZS, A. C. Thermodynamic Behavior of Particle/Diblock Copolymer Mixtures: Simulation and Theory. Macromolecules. v. 33, p. 8085-8096, 2000.

[51]BOCKSTALLER, M. R.; et al.; Size-Selective Organization of Enthalpic Compatibilized Nanocrystals in Ternary Block Copolymer/Particle Mixtures. J. Am. Chem. Soc. v. 125, p. 5276-5277, 2003.

[52]MACKAY, M. E.; et al.; General Strategies for Nanoparticle Dispersion. Science. v. 311, 1740, 2006.

[53]SCHULTZ, A. J., Hall, C. K., and Genzer, J. Macromolecules. v. 38, p. 3007, 2005.

[54]LETTI, J. C., Dissertação de mestrado. Estudo de Nanocompósitos Formados por Partículas de óxidos de ferro e Polímeros por Meio da Espectroscopia Raman. Instituo de Física - PPGF-UnB, 2013.

[55]CASTILHO,A. P. O., Nanofilmes com Óxidos de Ferro Nanoestruturados e Biopolímeros Depositados por Automontagem. Instituto de Biologia - Cnano/PPGB-UnB, 2014.

[56]CARVALHO, A. J. F, et al..Self-organization of triblock copolymer patterns obtained by drying and dewetting. Eur. Phys. J. E. v. 20, p. 309-315, 2006.

[57]CORNELL, R. M., Schwertmann, U., The Iron Oxides: Structure, properties, Reactions, Occurences and Uses. Willey V-CH, 2003.

[58]CHAPLINE, M.G.; WANG, S.X. Spin filter based tunnel junctions. J. Appl. Phys., v.100, p.123909, 2006.

[59]LI, G.X.; et al.; Spin valve sensors for ultrasensitive detection of superparamagnetic nanoparticles for biological applications. Sens. Actuators A Phys., v.126, n.1, p.98-106, 2006. 
[60]GLEICH, B.; WEIZENECKER, R. Tomographic imaging using the nonlinear response of magnetic particles. Nature, v.435, n.7046, p.1214-1217, 2005.

[61]DUGUET, E.; VASSEUR, S; MORNET, S.; DEVOISSELLE, J.M. Magnetic nanoparticles and their applications in medicine. Nanomedicine, v.1, n.2, p.157-168, 2006.

[62]SARTORATTO, P.P.C.; NETO, A.V.S; LIMA, E.C.D.; RODRIGUES DE S'A, A.L.C.; MORAIS, P.C. Preparation and electrical properties of oil-based magnetic fluids. J.Appl.Phys., v.97, n.10, p.10Q917, 2005.

[63]SCHUTH, F. et al. Magnetic Nanoparticles: Synthesis, Protection, Functionalization and Application. Angew. Chem. Int. Ed. v. 46, 1222-1244, 2007.

[64]BATLLE, X. Labarta, A., Finite-size effects in fine particles, magnetic and transport properties. J Phys D: Appl Phys v. 35 p. R15-R42, 2002.

[65]E. J. W. Verwey, Nature (London) 144, 327 (1939)

[66]DE FARIA, D. L. A. Venâncio Silva, S. De Oliveira, M. T. Raman Microspectroscopy of Some Iron Oxides and Oxyhydroxides. JOURNAL OF RAMAN SPECTROSCOPY, v. 28, p. 873-878, 1997.

[67]GOTO, Y. Jpn . J . Appl . Phys . v. 3, 741, 1964.

[68]DEBOER, F.E. and Selwood, P. W . J . Am. Chem. Soc . v. 76, 3366, 1954.

[69]MATHEW, D. S.; JUANG, R.-S. An overview of the structure and magnetism of spinel ferrite nanoparticles and their synthesis in microemulsions. Chem. Eng. J., v.129, n. 1-3, p. 51-65 mai. 2007.

[70]SPALDIN, N. A. Magnetic materials: Fundamentals and applications. 2nd ed. New York: Cambridge University Press, 2003.

[71]FERGUSON, G.A.; HASS, M. Magnetic structure and vacancy distribution in $\mathrm{Y}-\mathrm{Fe}_{2} \mathrm{O}_{3}$ by neutron diffraction. Phys. Review, v.112, n.4, p.1130-1131, 1958. 
[72]ALCÂNTARA, G. B., Dissertação de mestrado. Nanopartícula de Maguemita complexada com Ácido Oleico. Instituo de Física - PPGF-UnB, 2013.

[73]NAKAGOMI, F., Efeito da distribuição da população de Cobalto e Magnésio nas propriedades estruturais e magnéticas de partículas $\mathrm{Co}_{x} \mathrm{Fe}_{3-\mathrm{x}} \mathrm{O}_{4}$ e $\mathrm{Mg}_{x} \mathrm{Fe}_{3-\mathrm{x}} \mathrm{O}_{4}$.

[74]DIONNE, G. F. Magnetic Oxides. Springer, 2009.

[75]O' HANDLEY, R. C. Modern Magnetic Materials: Principles and Applications. New York: John Wiley and Sons, 2000.

[76]GUIMARÃES, A. P.; Nanoscience and Nanotechnology: Principles of nanomagnetism. Springer, 2009.

[77]REITZ, J. R. et al. Fundmaentos da teoria eletromagnética. Editora campos, Rio de

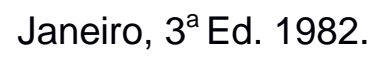

[78]GRIFFITHS, D. J., Eletrodinâmica, Pearson, São Paulo, 3ª Ed. 2011.

[79]ASCROFT, N. W. and Mermin, N. D. Solid State Physics. Cornell University, 1976.

[80]O'HANDLEY, R. C., Modern magnetic Materials: Principles and Applications. John Wiley and Sons, Inc. 2000.

[81]COEY, J. M. D., et al., Introduction to Magnetic Oxides. Wiley-VCH, 2013.

[82]AHARONI, A., Introduction to the Theory of Ferromagnetism. International Series of Monographs on Physic-109. Oxford Science publications, $2^{\mathrm{a}}$ Ed, 1996.

[83]ANDERSON, P.W. and HASEGAWA, H. Considerations on double exchange. Phys. Rev., 100, 675, 1955.

[84]NOLTING, W. AND RAMAKANTH, A. Quantum Theory of Magnetism, Springer-Verlag, Berlin, 2009.

[85]ANDERSON, P.W. Antiferromagnetism. Theory of superexchange interaction. Phys. Rev., 79, 350, 1950. 
[86]NUNES, W. C. et al. Temperature dependence of the Coercitive Field in Single-domain particles Systems, Phys. Rev. B, v.70, p. 014419, 2004.

[87]ROSENSWEIG, R.E. Ferrohydrodynamics. Cambridge University Press., ISBN-13: 9780-486-67834-4 e ISBN-10: 0-486-67834-2, Crambridge, 1985.

[88]HUNTER, R. J. Foundations of colloid science, second edition, Oxford University press, ISBN 019850502 7, Oxford, 1986.

[89]MASSART, R. Preparation of aqueous magnetic liquids in alkaline and acidic media. IEEE, v.17, n.2, p.1247-1248, 1981.

[90]SHAW, D. J. Introdução a química dos colóides e de superfícies. São Paulo:Blucher, 1975.

[91]BROWN, W. F., Thermal fluctuations of single-domain particle, J. Appl. Phys.,v.34, p. 1319-1320, 1963.

[92]ATKINS, P., De Paula, J. Physical-Chemistry. Molecular Symmetry, $9^{a}$ ed., p. 417-444, 2010.

[93]TUNG, WU. KI., Group Theory in Physics: An introduction to symmetry in principles, group representation and special functions in classical and quantum physics. World scientific publishing, 2003.

[94]SHEBANOVA, O.N.; LAZOR, P. Raman spectroscopic study of magnetite (FeFe2O4): a new assignment for the vibrational spectrum. J. Sol. Sat. Chem., v.174, n.2, p.424-430, set.2003.

[95]SALAS, O., Fundamentos de espectroscopia Raman e Infravermelho, EdUSP, ISBN: 957189-111-4, 1996.

[96]WHITE, W. B. AND DE ANGELIS, B. A. Interpretation of the vibrational spectra of spinels. spectrochim. acta 23a, 985-995, 1967.

[97]KRUPICKA, S.; NOVAK, P. Oxide Spinels. In: WOHLFARTH, E. P. (Org.).Ferromagnetic Materials: a handbook on the properties of magnetically ordered substances. 3.ed. Amsterdam: North-Holland Publishing Company, 1982. 
[98]SOLER, M. A. G.; FANYAO, Q. Raman Spectroscopy of Iron Oxide Nanopartices. In: Raman Spectroscopy for Nanomaterials Characterization. Berlin: Springer, p. 379-416, 2012.

[99]EISBERG, R and Resnick, R. Física quântica: Átomos, Moléculas, Sólidos, Núcleos e Partículas. Elsiever, Editora Campus. Universidade da Californaia, Santa Barbara.

[100]KUBICKI, J.D., et al. Attenuated total reflectance Fourier-transform infrared spectroscopy of carboxylic acids adsorbed onto mineral surfaces. Geochimica et Cosmochimica Acta, v. 63, n.18, p.2709-2725, set.1999.

[101]WARTEWIG, S. IR and Raman Spectroscopy. Spectroscopic Techniques:An Interactive Course. Fundamental Processing, ISBN 3-527-30245-X, 2003.

[102]CANÇADO, L. G. O. L., Raman Spectrocopy Nanographites. Tese de doutorado, Universidade Federal de Minas Gerais, UFMG, Setembro de 2006.

[103]MOREIRA, L. M., Raman spectroscopy of graphene: probing phonons, electrons and electron-phonon interactions. Tese de doutorado, Universidade Federal de Minas Gerais UFMG, setembro de 2009.

[104]OTERO, V. et al. Characterization of metal Carboxylates by Raman and Infrared Spectroscopy in works of art. Journal Raman Spectroscopy. v. 45, p. 1197-1206, 2014.

[105]WANG, N. G., Z.Q. et al. High-pressure x-ray diffraction and Raman spectroscopic studies of the tetragonal spinel CoFe2O4. Phys. Rev. B, v. 68, n. 9, p. 094101,sep. 2003.

[106]ALCÂNTARA, G. B., Filmes Poliméricos dopados com nanopartículas de Ferrita de Cobalto. Tese de doutorado, Programa de Pós-Graduação em Física, Instituto de Física, Universidade de Brasília. p. 49, Jul. 2011.

[107]MORAIS, P.C, da Silva S.W, Soler, M.A.G., Raman investigation of uncoated and coated magnetic fluids. J Phys Chem A. v.104, p. 2894-2896, 2000.

[108]DONALD, L. Paiva., Gary M. Lampman., George S. Kriz., James R. Vyvyan. Introdução à Espectroscopia. $4^{\circ}$ Ed, 2010. 
[109]SANTOS, et al., Iron Oxide Nanostructured Electrodes for Detection of Copper(II) Ions. J. Nanosci. Nanotechnol. v. 14, 1-10, 2014.

[110]PATTERNO, L. G. et al., Magnetic Nanocomposites Fabricated via the Layer-by-Layer Approach. J. Nanosci. Nanotechnol. v.10, p. 2679-2685, 2010

[111]DEDAVID, B. A; Gomes, C; Machado, G. Microscopia Eletrônica de Varredura: Aplicações e preparação de amostra. Materiais poliméricos, metálicos e semicondutores, 2007.

[112]COATS, A.W., REDFERN, J. P. Thermogravimetric Analysis. A review. Analyst, v. 88, n¹052, p. 906-924, 1963.

[113]GORDON, S., "Encyclopedia of Science and Technology," McGraw-Hill Book Co. Inc., New York, Toronto and London, p. 556, 1960.

[114]RIVERA, L. M. R., Síntese de complexo nanoestruturado formado com óxido de ferro e sulfato de condroitina. Dissertação de mestrado, Programa de Pós-graduação em Nanociência e Nanobiotecnologia, Instituto de Ciências Biológicas, Universidade de Brasília, 2013.

[115]McCREERY, R. L., Raman Spectroscopy for Chemical Analysis. A John Wiley \& Sons, Inc., Publication, v.157, 2000.

[116]CORVAJA, C. Introduction to Electron Paramagnetic Resonance. Electron Paramagnetic Resonance: A Practitioner's Toolkit. Published by John Wiley \& Sons, Inc., Hoboken, New Jersey, p. 3-35, 2009.

[117]FONER, S. Versatile and Sensitive Vibrating-Sample Magnetometer. The Review of Scientific Instruments. v. 30, n 7, Jul, 1959.

[118]COLTHUP, N. B.; DALY, L. H.; WIBERLEY, S. E.; Introduction to Infrared and Raman Spectroscopy. Academic Press, Inc. Third Edition, ISBN 0-12-182554-x, 1990.

[119]AYYAPPAN, S. et al. Effect of Surfactant Monolayer on Reduction of Fe3O4 Nanoparticles under Vacuum. J. Phys. Chem. C, v. 112, p. 18376-18383, 2008. 
[120]NAKAMOTO, K; Infrared and Raman spectra of inorganic and coordination compounds. 6ํㅡ. Ed. John Wiley \& Sons. Hoboken, 2009.

[121]PALM, A., Raman spectrum of Polystyrene. Department of Chemistry, The Polytechnic Institute of Brooklyn, Brooklyn, New York, 1950

[122]OLIVEIRA, I. S.; Introdução à Física do Estado Sólido. Editora livraria da Física, 2 ed. ISBN 978-85-7861-061-6, 2011.

[123]HEISENBERG, W. Zur Theorie des Ferromagnetismus, Z. Phys. v. 49, p. 619, 1928.

[124]CURIE, P.; Annales de Chimie et de Physique. v. 5, p.289, 1895.

[125]JUN, Y.W.; SEO, J.W.; CHEON, J. Nanoscalling laws of magnetic nanoparticles and their applicabilities in biomedical sciences. Acc. Chem. Res., v. 41, n. 2 , p. $179-189$, feb. 2008.

[126]SOUZA, F.F. et al., Curcumin Associeted magnetic nanoparticles inhibit in vitro melanoma cell growth, J. Nanosci. Nanotechnology, v. 11, p. 7603-7610, 2011.

[127]SAWYER, L. C., GRUBB, D. T., MEYERS, G. F. Polymer Microscopy. Springer Third edition, ISBN: 978-0-387-72627-4, USA, 2008.

[128]YOKOYAMA, M., Block Copolymers as Drug Crriers. Crit. Rev. Drug Carr. Sys., v.9 p. 213-248.

[129]KUMAR, N., Ravikumar, M. N. J., Domb, A. J., biodegradable block copolymers. Adv.Drug Deliv.Rev. v. 53, p. 23-44, 2001.

[130]STRAWHECKER KE, KUMAR SK, DOUGLAS JF, KARIM A. The critical role of solvent evaporation on the roughness of spin-cast polymer films. Macromolecules; v. 34, 4669-72, 2001.

[131]SILVA, S. W., MELO, T., SOLER M. A. G., Da Silva, M.F., Lima, E.C.D, MORAIS, P. C. Stability of citrate-coated magnetite and cobalt-ferrite nanoparticles under laser irradiation: a Raman spectroscopy investigation. IEEE Transactions on Magnetics. , v.39, p.2645 - 2647, 2003. 
[132]PECORE, R. Dynamic Light Scattering. Aplications of fótons correlation spectroscopy. Stanford University. ISBN-13: 978-1-4612-9459-7 e ISBN-13: 978-1-4613-2389-1, New York and London, 1985.

[133]GASPAROV, L.V. et al. Infrared and Raman studies of the Verwey transition in magnetite. Phys. Rev. B, v.62, n.12, p.7939-7944, 2000.

[134]CHOURPA, I. et al. Molecular composition of iron oxide nanoparticles, precursors for magnetic drug targeting, as characterized by confocal Raman microspectroscopy. Analyst, v.130, n.10, p.1395-1403, out. 2005.

[135]HANESCH, M. Raman spectroscopy of iron oxides and (oxy)hydroxides at low laser power and possible applications in environmental magnetic studies. Geophys. J. Int., v. 177, n. 3, p. 941-948, 2009.

[136]SOLER, M. A. G. et al. Study of molecular surface coating on the stability of maghemite nanoparticles. Surf. Sci., v. 601, n. 18 , p. 3921-3925, set. 2007. 